\title{
Systematics and molecular pathogenesis of oomycetes with emphasis on flagellar genes
}

\author{
by \\ Gregg P. Robideau
}

A thesis submitted to the Faculty of Graduate and Postdoctoral Affairs in partial fulfillment of the requirements for the degree of

Doctor of Philosophy

in

Biology

Carleton University

Ottawa, Ontario

(C) 2012, Gregg P. Robideau 
Library and Archives

Canada

Published Heritage

Branch

395 Wellington Street

Ottawa ON K1A ON4

Canada
Bibliothèque et

Archives Canada

Direction du

Patrimoine de l'édition

395 , rue Wellington

Ottawa ON K1A ON4

Canada
Your file Votre référence

ISBN: 978-0-494-94228-4

Our file Notre référence

ISBN: $978-0-494-94228-4$
NOTICE:

The author has granted a nonexclusive license allowing Library and Archives Canada to reproduce, publish, archive, preserve, conserve, communicate to the public by telecommunication or on the Internet, loan, distrbute and sell theses worldwide, for commercial or noncommercial purposes, in microform, paper, electronic and/or any other formats.

The author retains copyright ownership and moral rights in this thesis. Neither the thesis nor substantial extracts from it may be printed or otherwise reproduced without the author's permission.
AVIS:

L'auteur a accordé une licence non exclusive permettant à la Bibliothèque et Archives Canada de reproduire, publier, archiver, sauvegarder, conserver, transmettre au public par télécommunication ou par l'Internet, prêter, distribuer et vendre des thèses partout dans le monde, à des fins commerciales ou autres, sur support microforme, papier, électronique et/ou autres formats.

L'auteur conserve la propriété du droit d'auteur et des droits moraux qui protege cette thèse. $\mathrm{Ni}$ la thèse ni des extraits substantiels de celle-ci ne doivent être imprimés ou autrement reproduits sans son autorisation.
In compliance with the Canadian Privacy Act some supporting forms may have been removed from this thesis.

While these forms may be included in the document page count, their removal does not represent any loss of content from the thesis.
Conformément à la loi canadienne sur la protection de la vie privée, quelques formulaires secondaires ont été enlevés de cette thèse.

Bien que ces formulaires aient inclus dans la pagination, il n'y aura aucun contenu manquant. 


\begin{abstract}
Oomycetes are ubiquitous fungus-like protists which include serious pathogens of agricultural, horticultural, and aquatic commodities. Proper identification to the species level is a critical first step in any investigation of oomycetes, and the use of DNA for oomycete species identification is well established, but DNA barcoding with cytochrome c oxidase (COI) is a relatively new and potentially useful approach that had yet to be assessed over a significant sample of oomycete genera. DNA sequencing of COI from 1205 isolates representing 23 genera and a comparison to internal transcribed spacer (ITS) sequences from the same isolates showed that COI-based identification and the dataset generated are a valuable addition to the currently available oomycete taxonomy resources. Due to the fact that studies of oomycete evolution and taxonomy have traditionally been heavily reliant on ribosomal RNA and mitochondrial cytochrome oxidase sequencing to infer species boundaries and higher level phylogenetic relationships, a new approach to oomycete molecular systematics was undertaken using two single-copy protein-coding flagellar genes, PF16 and OCM1, showing their utility in species delimitation and in phylogenetic reconstruction of oomycete evolution. This approach also demonstrates a recently proposed codon substitution-based phylogenetic method. Using the codon model, the phylogenetic relationships inferred by flagellar genes are largely in agreement with the current views of oomycete evolution, whereas nucleotide and amino acid models failed to reconstruct monophyly in several clades. Interesting parallels exist between the molecular evolution of flagellar genes and zoospore ontology, supporting the tree obtained using the codon model. Sequencing of
\end{abstract}


OCM1 in particular revealed high variability among oomycetes and indicated a potential role of this protein in host-interaction of zoospores. A hypothesized role of OCM1 in host recognition, possibly through interaction with host C-type lectin was tested, and although the role of OCMI was not confirmed, plant C-type lectin was shown to contribute to susceptibility of Arabidopsis seedlings to Pythium zoospores. This is a novel and important finding which helps to understand the unknown function of C-type lectin in plants. As a whole, this thesis contributes new resources and knowledge to the study of oomycetes, molecular evolution, and plant pathology. 


\section{DEDICATED TO}

My mother, Karen Emily Robideau 


\section{ACKNOWLEDGEMENTS}

This is an important list of people without whom this thesis would have been impossible or certainly much more difficult.

I will start by thanking my father Gerry and my mother Karen (R.I.P.) for their neverending love and support throughout my life. They constantly went out of their way to help me and they always encouraged me to do the things I loved. They also drilled the idea of higher education into my head at an early age, so I decided to leave no room for disappointment. Thank you mom and dad. My wife Allison is certainly owed a debt of gratitude. Being married to a guy who works long hours for less than minimum wage is not everyone's idea of marital bliss. If she wasn't so loving and understanding I'd be hanging my $\mathrm{Ph} . \mathrm{D}$. degree in a bachelor apartment. I also need to thank my daughter Hunter for making me smile so much every day and giving me another good reason to get a solid career started. I know... a solid career in science? Oh well, too late now. My sister Kathy and her husband Hamed are two of my favourite people in the world so I'd like to acknowledge them here for being so awesome. My friends also helped me stay sane throughout this process by always being good company and encouraging me to study the effect of alcohol intake on thesis completion time.

On the business end, I really owe a huge thank you to my supervisor André Lévesque. He took me into his lab and gave me a chance before I even knew how to do a DNA extraction. His technician Nicole Désaulniers (ret.) taught me molecular biology technique and how to work in a lab in general. André as well has always been a great teacher and has offered great opportunities that I'm very grateful for. He has always been supportive of my research ideas even when they went off on tangents, which was fairly often. Since joining his lab for my undergrad thesis project, I've learned practically everything I know, thanks in no small part to the amazing communal atmosphere at ECORC (Agriculture Canada). When everything in the building is considered property of the Queen of England, nobody really hesitates to share. It's the perfect learning environment. There is an entire chapter of this thesis that could not have been done without the help and guidance of our ECORC colleague Gopal Subramaniam. Big thanks to Gopal. I would also like to acknowledge valuable technical support from the following people: Rafik Assabgui, Julie Chapados, Kasia Dadej, and Wayne McCormick for DNA sequencing service at Agriculture and Agri-Food Canada; Kelly Babcock, Modra Kaufert, and Caitlin O'Reilly for providing cultures from CCFC; Dave Chitty, Quinn Eggertson, Zeinab Robleh-Djama, and Tara Rintoul for providing an extra set of hands for lab work, Satpal Bilkhu and Chris Lewis for bioinformatics support.

Grad school has been a great experience for me. It's so much better than undergrad. But I'm still glad that it's over. 


\section{PREFACE}

The DNA barcoding primers for COI were designed by André Lévesque. Culturing, DNA extraction, PCR, and sequence editing of the majority of the isolates used in Chapter 3 were performed by Gregg Robideau, with assistance from David Chitty and Quinn Eggertson. Additional DNA sequence data and sequence editing were provided by the co-authors of the cited publication. Gregg Robideau performed all the data management and analyses in Chapter 3 except the distance matrix analyses and statistics which were performed by André Lévesque. The publication from Chapter 3 was written by Gregg Robideau. The contribution of Gregg Robideau to the Pythium ultimum genome project described in Chapter 4 involved DNA extraction, comparative genomics of flagellar genes, manual annotation of flagellar genes, writing a portion of the manuscript, and manuscript review. Gregg Robideau was one of ten equal contributors from the total 48 authors of the genome publication. Sequencing, assembly, automated annotation of the genome, and transcriptome sequencing were performed by co-authors of the cited publication. The idea of using flagellar genes for a study of oomycete systematics and molecular evolution was devised by Gregg Robideau, inspired by the work of Donald Barr and Nicole Désaulniers. The codon model of substitution described in Chapter 4 was developed and implemented by Nicolas Rodrigue. Analyses which produced the codon model phylogram and the distribution of scaled selection coefficients were performed by Nicolas Rodrigue. All other lab work and analyses described in Chapter 4 were performed by Gregg Robideau, with DNA sequencing assistance from Tara Rintoul. The manuscript cited in Chapter 4 was written by Gregg Robideau. The work described in Chapter 5 was devised and carried out by Gregg Robideau, with technical guidance from 
Gopal Subramaniam and André Lévesque. Statistics for Chapter 5 were performed by André Lévesque. Tara Rintoul lent assistance for the plant pathogenicity trials.

Readers are encouraged to cite the published work and forthcoming publications from this thesis using the references provided at the start of Chapters 3 and 4 . The results of Arabidopsis pathogenicity trials in Chapter 5 are being used to prepare a manuscript for submission in early 2013. The DNA barcoding publication cited in Chapter 3 was reproduced with the permission of the Minister of Agriculture and Agri-Food, Canada, 2012. The Pythium ultimum genome publication cited in Chapter 4 is an open access article distributed under the terms of the Creative Commons Attribution License, which permits unrestricted use, distribution, and reproduction in any medium, provided the original work is properly cited. 


\section{Table of Contents}

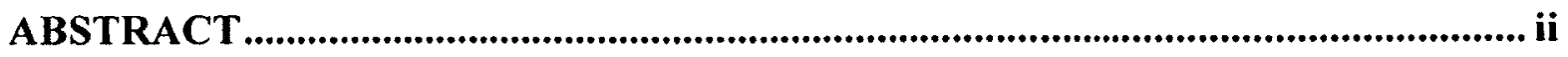

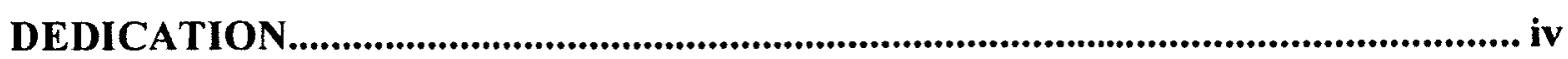

ACKNOWLEDGEMENTS ............................................................................................... v

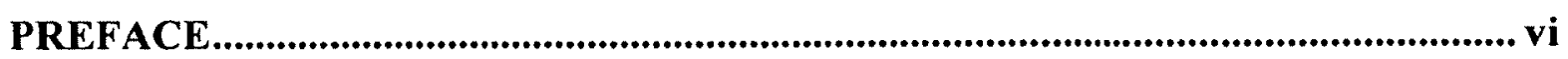

List of Tables ......................................................................................................................... $\mathrm{x}$

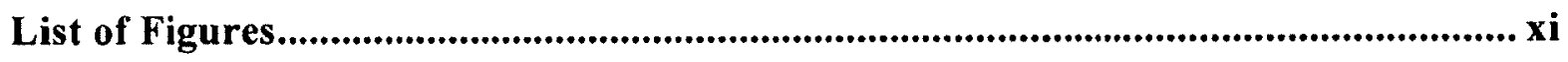

List of Appendices............................................................................................................ xii

List of Abbreviations ....................................................................................................... xiii

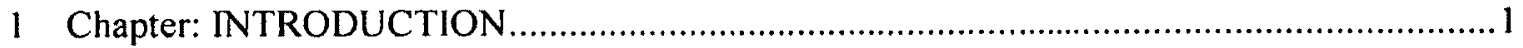

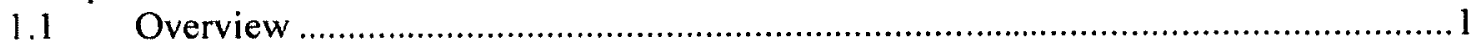

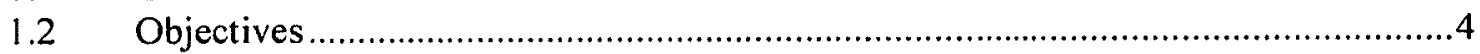

2 Chapter: METHODS SUMMARY ............................................................................

$2.1 \quad$ Molecular biology methods ...............................................................................

$2.2 \quad$ Phylogenetic methods .........................................................................................

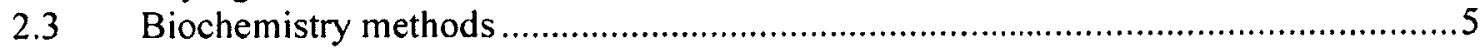

$2.4 \quad$ Plant pathology trials .......................................................................................

3 Chapter: DNA BARCODING OF OOMYCETES .......................................................6

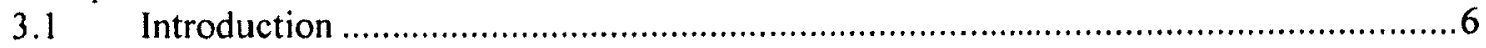

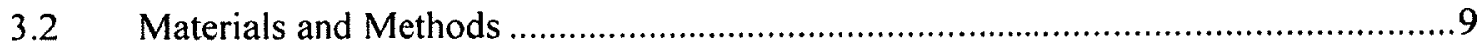

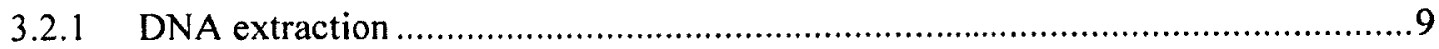

3.2.2 COI primer design....................................................................................10

3.2.3 DNA amplification ................................................................................10

3.2.4 Cloning PCR products................................................................................11

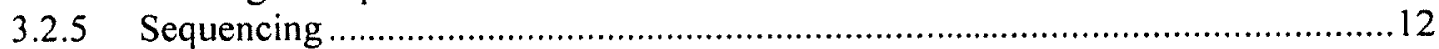

3.2.6 Sequence editing, alignment, and cluster analysis ...........................................13

3.2.7 Distance matrix statistical analysis .............................................................14

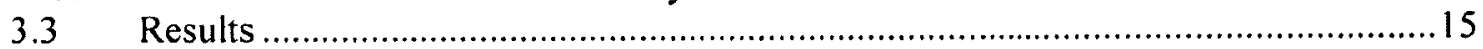

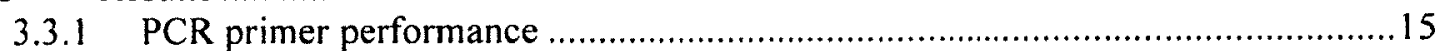

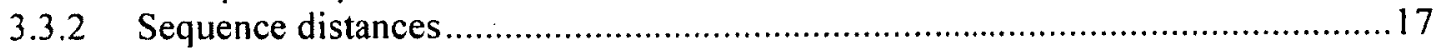

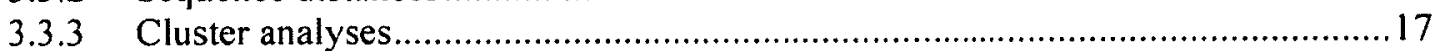

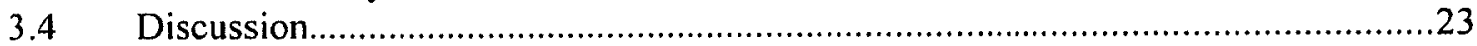

4 Chapter: COMPARATIVE GENOMICS AND PHYLOGENETIC STUDY OF

OOMYCETE FLAGELLAR GENE EVOLUTION …………..............................................29

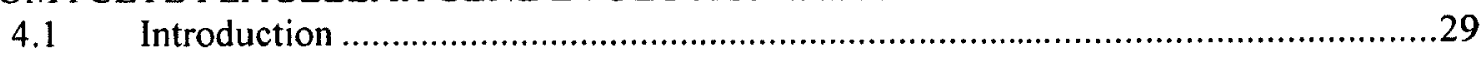

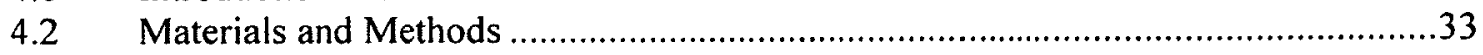

4.2.1 Comparative genomics and genome annotation....................................................33

4.2.2 Pythium ultimum genome assembly and mRNA transcription profiling ..............34

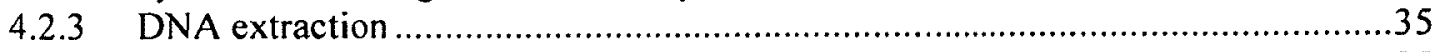

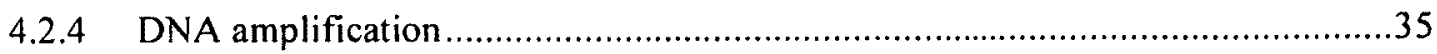

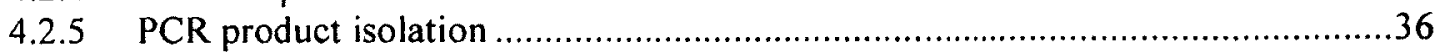

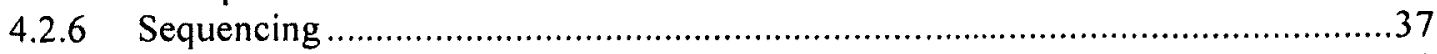

4.2.7 Sequence assembly and alignment .................................................................38

4.2.8 Sequence distances.......................................................................................39

4.2.9 Phylogenetic inference and distribution of selection coefficients .........................40

4.2.10 Evolutionary rate of codon positions ..........................................................4 


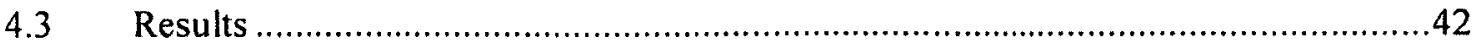

4.3.1 Comparative genomics and P. ultimum flagellar gene expression...................42

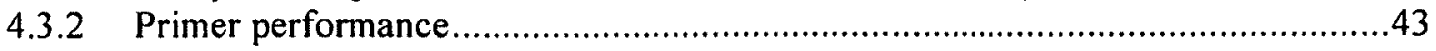

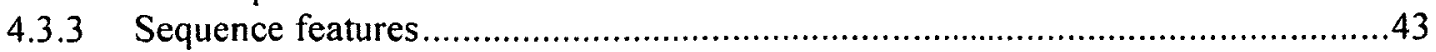

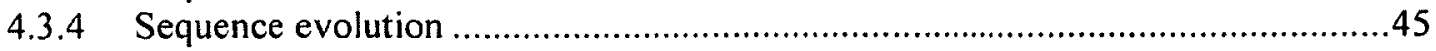

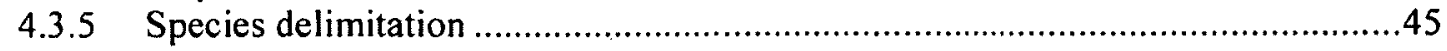

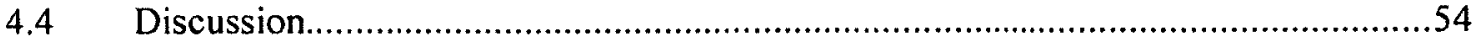

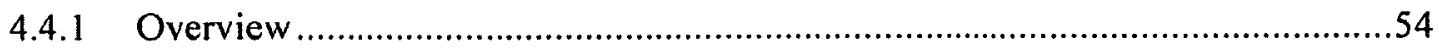

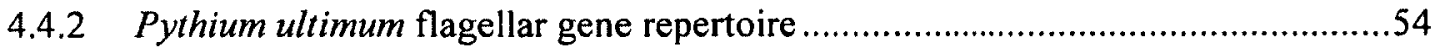

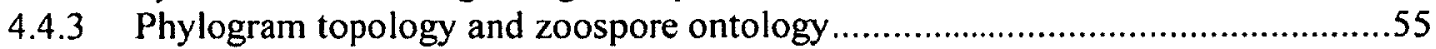

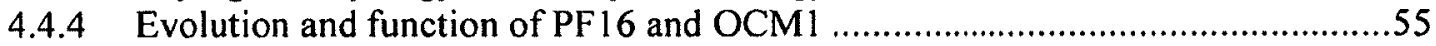

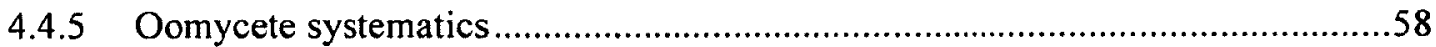

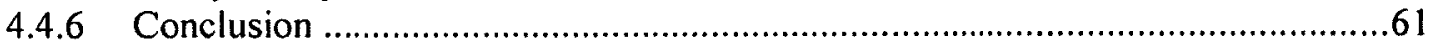

5 Chapter: INVESTIGATION OF THE POSSIBLE ROLE OF OOMYCETE FLAGELLAR

PROTEIN AND PLANT C-TYPE LECTIN IN HOST-PATHOGEN INTERACTION .........62

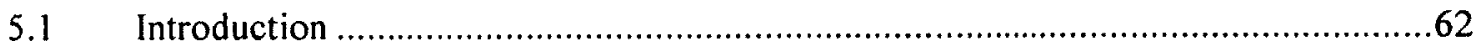

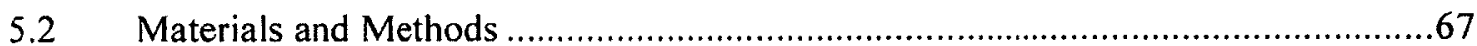

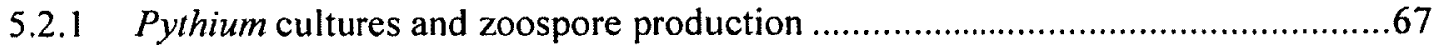

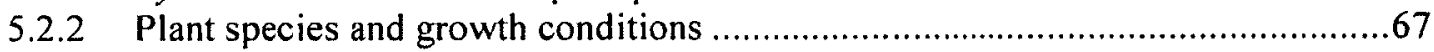

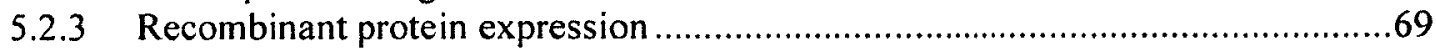

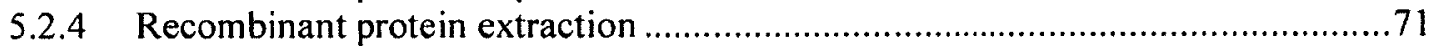

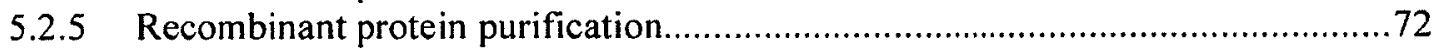

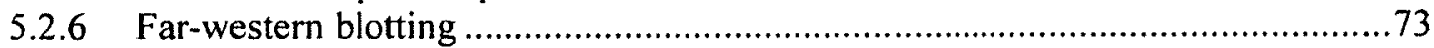

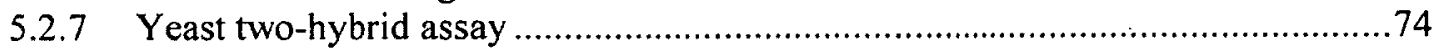

5.2.8 Zoospore interaction with refolded agarose-bound C-type lectin ......................75

5.2.9 Cucumber pathogenicity trial - host defense response to flagellar protein...........75

5.2.10 Arabidopsis pathogenicity trial - C-type lectin knockout ...............................76

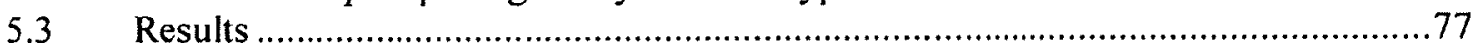

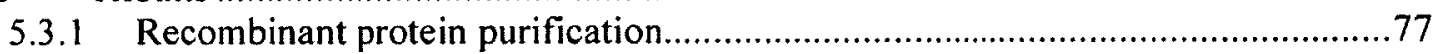

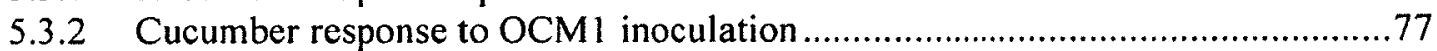

5.3.3 Interaction between $\mathrm{OCM}]$ and C-type lectin.............................................81

5.3.4 Zoospore recognition of refolded CsCL and TaCL ...........................................81

5.3.5 Pythium susceptibility of C-type lectin knockout Arabidopsis .............................85

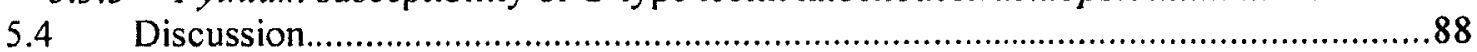

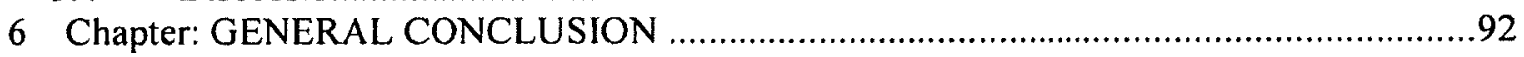

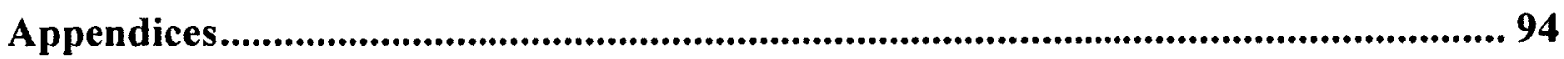

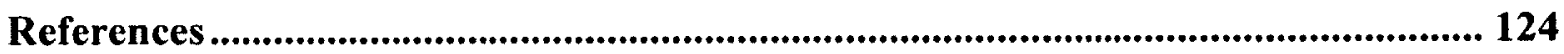




\section{List of Tables}

Table 5.1. Disease rating of cucumber seedling treatments............................... 80 


\section{List of Figures}

Figure 3.1. Diagram of COI gene region and COI PCR primer locations...................... 16

Figure 3.2. Phylograms and distance histograms for COI, ITS, and LSU....................... 20

Figure 3.3. Direct comparison of ITS and COI phylograms by clade ............................. 23

Figure 4.1. Illustration of PF16 and OCM1 genes displaying PCR primers .................. 46

Figure 4.2. Distribution of scaled selection coefficients (S) from PF 16 and OCM1 ....... 47

Figure 4.3. Mean evolutionary rate of each codon position in PF16 and OCM1 ........... 48

Figure 4.4. Intraspecific/interspecific amino acid distances of PF16 and OCM1 ........... 49

Figure 4.5. Illustrated Bayesian codon model phylogram from PF16 and OCM1 ......... 51

Figure 4.6. Phylogram reconstructed from LSU sequences............................................ 52

Figure 4.7. Comparison between codon, nucleotide, and amino acid models................ 53

Figure 5.1. Schematic illustration of Arabidopsis thaliana C-type lectin gene ................ 66

Figure 5.2. SDS-PAGE of purified PF 16 and OCM1, and CsCL and TaCL................... 78

Figure 5.3. Root hairs of treated cucumber seedlings.................................................... 79

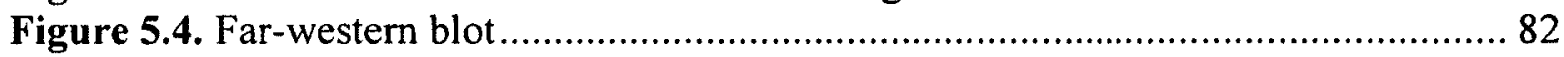

Figure 5.5. Yeast two-hybrid assay ......................................................................... 83

Figure 5.6. Refolded CsCL bound to Ni-NTA agarose beads with zoospores ................ 84

Figure 5.7. Survival of knockout (KO) and wild-type (WT) Arabidopsis ....................... 86

Figure 5.8. Dry weight and leaf count of $\mathrm{KO}$ and WT Arabidopsis ............................... 87 


\section{List of Appendices}

Appendix A. List of isolates used and DNA sequence accession numbers ............ 94

Appendix B. Species resolved by COI that are indistinguishable by ITS $\ldots \ldots \ldots \ldots \ldots 110$

Appendix C. Species that are indistinguishable with either COI or ITS $\ldots \ldots \ldots \ldots \ldots \ldots 110$

Appendix D. Apparent species complexes based on COI and ITS ..................111

Appendix E. Flagellar apparatus-related genes in Pythium and Phytophthora ...........112

Appendix F. Isolates used and sequence accessions................................116

Appendix G. Sequence alignments of PF16 and OCM1 ...............................119

Appendix H. Recombinant flagellar protein and C-type lectin sequences...............121 


\title{
List of Abbreviations
}

\author{
3AT - 3-Amino-1,2,4-triazole \\ BLAST - Basic local alignment search tool \\ BOLD - Barcode of Life Data systems \\ BSA - Bovine serum albumin \\ CBS - Centraalbureau voor Schimmelcultures \\ CCFC - Canadian Collection of Fungal Cultures \\ CHAPS - 3-[(3-Cholamidopropyl)dimethylammonio]-1-propanesulfonate \\ CMA - Corn meal agar \\ COI - cytochrome $c$ oxidase subunit I \\ CsCL - Cucumis sativus C-type lectin \\ DAOM - Canadian National Mycological Herbarium \\ DNA - Deoxyribonucleic acid \\ dNTP - Deoxyribonucleotide triphosphate \\ dpi - Days post-inoculation \\ DTT - Dithiothreitol \\ EDTA - Ethylenediaminetetraacetic acid \\ EtOH - Ethanol \\ HPLC - High performance liquid chromatography \\ HRP - Horseradish peroxidase \\ IMAC - Immobilized metal affinity chromatography \\ IPTG - Isopropyl $\beta$-D-1-thiogalactopyranoside \\ ISR - Induced systemic resistance \\ ITS - internal transcribed spacer of ribosomal RNA \\ LB - Lysogeny broth \\ LSU - large subunit $28 \mathrm{~S}$ ribosomal RNA \\ MAFFT - Multiple alignment program for amino acid or nucleotide sequences \\ MSS - Mineral salt solution \\ MUSCLE - Multiple sequence comparison by log-expectation \\ $\mathrm{NaOCl}$ - Bleach (Sodium hypochlorite) \\ OCM1 - tubular mastigoneme protein \\ PAMP - Pathogen-associated molecular pattern \\ PAUP - Phylogenetic analysis using parsimony (and other methods) \\ PCR - Polymerase chain reaction \\ PF16 - axoneme central apparatus protein \\ PMSF - Phenylmethanesulfonyl fluoride \\ RNA - Ribonucleic acid \\ RPKM - Reads per kilobase per million mapped reads \\ SDS - Sodium dodecyl sulfate \\ SDS-PAGE - Sodium dodecyl sulfate - polyacrylamide gel electrophoresis
}


TaCL - Triticum aestivum C-type lectin

TBE - Tris/Borate/EDTA buffer

TBS - Tris-buffered saline

TE - Tris, EDTA

TES - Tris, EDTA, SDS

Tris - Trisaminomethane

UPGMA - Unweighted pair group method with arithmetic mean

YEB - Yeast extract broth

YPD - Yeast peptone dextrose 


\section{Chapter: INTRODUCTION}

\subsection{Overview}

Oomycetes are microbes which resemble filamentous fungi, but which are actually more closely related to brown algae. In the environment, oomycetes are capable of surviving as saprophytes, living off of dead organic material, but they are often pathogenic, causing diseases of many different plants and animals. They are commonly referred to as water moulds since they typically thrive in water bodies or in wet conditions on land. Common names of oomycete diseases include late blight, downy mildew, cotton wool disease, swamp cancer, sudden oak death, damping off, and root rot. Oomycetes are found all over the world, and they consistently cause serious damage to agricultural, horticultural, and aquatic commodities.

The scientific study of oomycetes has a rich history which laid the foundation for modern plant pathology. Since Anton de Bary's seminal work on the potato late blight organism Phytophthora infestans (de Bary, 1861), oomycete research has grown to encompass a wide range of disciplines such as agronomy, pathology, molecular biology, cell biology, biochemistry, genetics, genomics, taxonomy, systematics, phylogenetics, biological control, ecology, and biogeography. In contribution to the scientific knowledge of oomycetes, this thesis describes new research in the areas of taxonomy, systematics, phylogenetics, genomics, biochemistry, and pathology.

Taxonomy is the process of arranging organisms into biological groups based on shared characteristics. With respect to oomycetes, taxonomy entails identification and characterization of environmental isolates, enabling an assessment of the risk or benefit that the isolates pose to human interests. In modern taxonomy, the state of the art relies 
heavily on DNA sequence data to augment the traditional taxonomic characters of morphology (Tautz, et al., 2002, Kang, et al., 2010). One approach to the use of DNA sequencing for taxonomy is DNA barcoding (Hebert, et al., 2003). DNA barcoding has become a global initiative which aims to discover a unique and easily detectable DNA reference sequence, a "DNA barcode", from the genome of every living organism on earth. The idea is that with a database of carefully catalogued DNA barcodes, any organism on earth will be easily identifiable by simply obtaining a small amount of its DNA. In Chapter 3, I summarize the creation and validation of a DNA barcode database for oomycetes, which will enhance the ability to identify currently known species, as well as describe previously undiscovered species.

The taxonomic arrangement of organisms into biological groups naturally leads to the question of how different groups are related to each other. The desire to understand the evolutionary relationships between biological groups is what drives the study of systematics and phylogenetics, with the ultimate goal of creating a "tree of life" in which the intricate relationships between different organisms are defined. Phylogenetic trees create a framework for our modern understanding of biology, where individual organisms in the tree can be better understood by knowledge of the organisms that they are closely related to. Like taxonomy, systematics and phylogenetics have been modernized by the accessibility of DNA sequence data, especially whole genome sequences, giving rise to the disciplines of comparative genomics (Hardison, 2003) and phylogenomics (Eisen \& Fraser, 2003). Comparing organisms at the genome level can provide an incredible amount of information, including a list of shared genes whose molecular evolution can be analyzed to better define the evolutionary relationships between the organisms. In 
Chapter 4, I describe my contribution to the Pythium ultimum genome sequencing project, where I focused on annotation of flagellar genes for comparison to the flagellar gene repertoire of other oomycetes. The comparison of oomycete flagellar genes led to the use of two particular genes, PF16 and OCM1, for a phylogenetic study of oomycetes, where oomycete systematics as well as the molecular evolution of flagellar genes are examined.

In light of the fact that OCM1 is an extracellular flagellar protein (Bouck, 1971) with a highly-variable amino acid sequence (Chapter 4), the potential role of this protein in pathogenicity was investigated. Extracellular proteins that are involved in the infection process of pathogenic microbes often undergo rapid molecular evolution, generating amino acid sequence diversity to evade recognition by host organisms (Deitsch, et al., 1997, Persson, et al., 2006). The diversity of OCM1 sequences among oomycetes and the presence of conserved protein-binding domains within OCM1 indicate that this protein may somehow interact with oomycete hosts. The similarity of OCM1 to animal tenascin protein also gave an indication of the possible host protein that OCM1 may interact with. Tenascins are a family of extracellular glycoproteins that are known to be involved in protein-protein interactions, namely with a family of C-type lectin proteins (Aspberg, et al., 1995, Lundell, et al., 2004). Animals have a wide variety of C-type lectins that are often involved in immune response (Cambi, et al., 2005), whereas plants typically have only one or two C-type lectins (Jiang, et al., 2010) whose function is unknown (Bouwmeester \& Govers, 2009). Using plant-oomycete host-pathogen models, I studied the possibility that oomycete zoospores recognize host plants by interacting with their C- 
type lectin. The studies conducted on the potential role of OCM1 and C-type lectin in plant-oomycete interaction are presented in Chapter 5.

\subsection{Objectives}

i. Sequence COI from a vast array of oomycete strains, encompassing as many genera and as many isolates from closely related species as possible in order to assess the utility of $\mathrm{COI}$ in oomycete identification to the species level.

ii. Use comparative genomics to identify putative flagellar genes in the genome of Pythium ultimum. Compare the flagellar gene repertoire of $P$. ultimum to that of other oomycetes and identify candidate genes for further studies in systematics.

iii. Use advanced phylogenetic methods to reconstruct an oomycete phylogeny based on PF 1.6 and OCM1 sequences. Study the molecular evolution of these genes to gain insight into their biological function.

iv. Purify heterologously-expressed Pythium aphanidermatum OCM1 protein for cucumber inoculation to test potential host response or acquired resistance to subsequent $P$. aphanidermatum infection.

v. Purify heterologously-expressed plant C-type lectin from cucumber and wheat to test potential recognition of the protein by Pythium zoospores.

vi. Test potential protein-protein interaction between P. aphanidermatum OCM1 and plant C-type lectin.

vii. Test pathogenicity of Pythium aphanidermatum zoospores towards transgenic Arabidopsis thaliana plants with C-type lectin gene knockout. 


\section{Chapter: METHODS SUMMARY}

\subsection{Molecular biology methods}

Common molecular biology methods were used. Of particular note is the use of small volume $(10 \mu 1)$ PCR mixtures with minimal primer concentration, an approach which was optimized by N. Désaulniers, R. Assabgui, and C.A. Lévesque to offset the cost and PCR product purification processing time associated with high-throughput DNA sequencing.

\subsection{Phylogenetic methods}

Multiple phylogenetic methods were used, depending on the best-suited method for each task with respect to computational intensity and suitability to the scientific question. A recently proposed phylogenetic method developed and implemented by N. Rodrigue is presented in Chapter 4, which employs a codon model of substitution for phylogenetic reconstruction from protein-coding DNA sequences.

\subsection{Biochemistry methods}

Common biochemistry methods were used for recombinant protein purification and protein-protein interaction assays.

\subsection{Plant pathology trials}

Pathology trials were carried out in light- and temperature-controlled growth chambers with plants grown in standard potting mix. 


\section{Chapter: DNA BARCODING OF OOMYCETES}

\section{Adapted from:}

Robideau, GP, de Cock, AWAM, Coffey, MD, Voglmayr, H, Brouwer, H, Bala, K, Chitty, DW, Desaulniers, N, Eggertson, QA, Gachon, CM, Hu, CH, Kupper, FC, Rintoul, TL, Sarhan, E, Verstappen, EC, Zhang, Y, Bonants, PJ, Ristaino, JB, Lévesque, CA (2011). DNA barcoding of oomycetes with cytochrome $c$ oxidase subunit I and internal transcribed spacer. Moleclar Ecology Resources 11: 1002-1011. Reproduced with the permission of the Minister of Agriculture and Agri-Food, Canada, 2012.

\subsection{Introduction}

Oomycetes are fungal-like organisms that are found in a wide range of environments and ecological niches. They are classified among the stramenopiles (=Straminipila), a lineage including brown algae and diatoms that is very distant phylogenetically from the kingdom Eumycota, the true Fungi. Many oomycete species are pathogens of plants and animals. The devastating speed with which they are able to spread makes rapid detection and identification crucial to implementation of control strategies. Biocontrol of oomycetes is an active area of study, and there are examples of oomycete species that are used as biological control against other oomycetes (Jones \& Deacon, 1995, Picard, et al., 2000), exemplifying the range of ecological functions between species.

Due to their wide variety of ecological roles, broad distribution and economic impact, proper identification is of great importance in oomycete studies. Identification of species can be a laborious and difficult task requiring time and expertise to cultivate the distinguishing morphological characters and compare them by microscopy. Also the decreasing number of experts able to identify oomycetes by morphological features is an important factor. Although matrix-based Lucid keys are being developed that will improve the speed of identification by morphology (Abad \& Coffey, 2008, Ristaino, et al., 2008), DNA-based identification can be done quickly and easily by a non-specialist, 
achieving accurate results in a fraction of the time if there is an adequate database of reference strains. DNA-based identification is particularly important for identifying groups where species boundaries are not well delineated. Many oomycetes are selffertile, making reproductive isolation an inappropriate criterion for species delineation. Species must instead be considered as a monophyletic assemblage of strains where gene flow between the strains is evident.

Currently the most common region of DNA being used for identification of oomycetes to the species level is the internal transcribed spacer (ITS) region of rDNA. The ITS region in oomycetes is easy to amplify for DNA sequencing in most species with the use of universal eukaryotic PCR primers (White, et al., 1990, Ristaino, et al., 1998). Cooke et al. (Cooke, et al., 2000) were the first to publish a database of ITS sequences that covered all the known and available species of an oomycete genus. ITS then became the de facto DNA barcode for identification of Phytophthora species and similar comprehensive databases for Pythium (Lévesque $\&$ de Cock, 2004) and downy mildews (Voglmayr, 2003) followed. However, due to the apparent lack of functional constraint on this untranslated region of rDNA, alignment of ITS sequences is hampered by large amounts of insertions and deletions (indels), which can be an issue for accurate comparisons. ITS is part of the ribosomal RNA cistron, which occurs in tandem repeats of approximately 200 copies. Indels in the ITS can even be observed within a single strain due to differences in alleles or differences among the multiple copies of the ITS, making direct sequencing of PCR products impossible (Kageyama, et al., 2007). In some species of downy mildews, excessive length due to long insertions can raise difficulties when sequencing the complete ITS region. There are also certain cases where the ITS 
sequences of formally described species are extremely similar, particularly when they are evolutionarily closely related such as Phytophthora infestans, $P$. phaseoli, P. ipomoeae, Phytophthora sp. "andina", and P. mirabilis (Gomez-Alpizar, et al., 2008) which are 99.9\% similar in ITS sequence (Kroon, et al., 2004). Due to these limitations of the ITS region for identification, the use of another region for this purpose may lend more clarity to the molecular depictions of oomycete taxonomy.

Cytochrome c oxidase subunit I (COI, COX1) is a mitochondrially-encoded gene which is recognized as an extremely useful DNA barcode capable of accurate species identification in a very broad range of eukaryotic life forms (Hebert, et al., 2004, Ward, et al., 2005, Hajibabaei, et al., 2006, Seifert, et al., 2007). COI is the default DNA barcode approved by GenBank and the Consortium for the Barcode of Life (CBOL) and it must be proven ineffective as a DNA barcode to be rejected as such. COI has proven useful in phylogenetic studies of the oomycete genus Phytophthora (Martin \& Tooley, 2003, Kroon, et al., 2004), and the success of COI barcoding in red algae (Saunders, 2005) made it a very intriguing prospect for barcoding of all oomycetes due to their algal ancestry. Because $\mathrm{COI}$ is a protein-coding region, alignment of $\mathrm{COI}$ sequences is simple and devoid of gaps if introns are absent. With the use of primers that amplify the 5 ' end of COI, accurate species delimitation has been achieved with sequences of only 650 base pairs (bp) or less (Meusnier, et al., 2008). With the advent of massively parallel sequencing from environmental samples, it is important to compare COI and ITS since the marine and animal science communities appear to have a strong interest in COI, whereas ITS is the established species-level marker in the mycology community (Schoch, et al., 2012), although not implemented by GenBank as a DNA barcode yet. Reported 
here is the utility of $\mathrm{COI}$ sequence data for accurate species delimitation in oomycetes, and a comparison of $\mathrm{COI}$ identification to the benchmark of ITS identification is made with 1205 isolates representing 23 genera including the recently described genus Phytopythium (formerly Pythium Clade K) (Bala, et al., 2010). Nearly all the currently described species of the two largest genera that can be maintained in culture (Pythium and Phytophthora) have been included in this study. In addition to COI and ITS, the D1D3 region of nuclear large subunit (LSU) rDNA, a commonly used marker for phylogeny and identification of oomycetes and Fungi, was sequenced from a subset of 388 isolates from 20 genera and is analyzed in comparison to COI and ITS. The complete list of isolates used for this study is shown in Appendix A.

\subsection{Materials and Methods}

\subsubsection{DNA extraction}

Extraction methods varied depending on the source of the cultures. For cultures grown from the Centraalbureau voor Schimmelcultures (CBS), mycelia from 5 - 14 day old liquid cultures grown in pea broth (de Cock, et al., 1992) were harvested by vacuum filtration, freeze dried, and DNA was extracted following the protocol of Möller et al. (1992). For cultures grown from the Canadian Collection of Fungal Cultures (CCFC), mycelia from $5-14$ day old liquid cultures grown in potato dextrose broth (Difco) at room temperature were removed from broth and DNA was extracted following the protocol of Möller et al. (1992) with a modification to the tissue lysis step. Instead of grinding mycelia in liquid nitrogen, mycelia were placed in $2 \mathrm{ml}$ screw cap tubes containing $300 \mathrm{mg}$ of zirconium oxide spheres and one $1 / 4$ " zirconium oxide sphere (Fox 
Industries), along with TES buffer (100 mM Tris $\mathrm{pH} 8.0,10 \mathrm{mM}$ EDTA, 2\% SDS) and proteinase K. Lysis was achieved by placing tubes in a FastPrep® machine (BIO 101) for 45 seconds at speed 4.0 . Tubes were incubated at $65^{\circ} \mathrm{C}$ for $1 \mathrm{~h}$ and subsequent steps were performed following the original protocol. At the final step, DNA pellet was resuspended in $0.1 \times$ TE buffer containing $20 \mu \mathrm{g} / \mathrm{ml}$ RNase A and tubes were incubated at $65^{\circ} \mathrm{C}$ for 10 $\min$.

\subsubsection{COI primer design}

In order to design COI barcode primers for a broader range of oomycete genera, the $5^{\prime}$ and middle region of COI, overlapping the commonly used barcode primers, was amplified and sequenced using eight different genera of oomycetes with a combination of FM79, FM80, FM82, FM83 and FM85 originally designed for Phytophthora (Martin \& Tooley, 2003). OomCoxI-Levup was designed to overlap LCO1490 (Folmer, et al., 1994) and GazF1 (Saunders, 2005) primers whereas Fm85mod was a modified version of Fm85 from Martin and Tooley (2003). OomCoxI-Levlo was designed to overlap HCO2198 (Folmer, et al., 1994) and GazR1 (Saunders, 2005).

\subsubsection{DNA amplification}

Sequencing templates were amplified from DNA extracts using the universal eukaryotic primers UN-up18S42 (5'-CGTAACAAGGTTTCCGTAGGTGAAC-3') (Bakkeren, et al., 2000) and the new UN-lo28S1220 (5'-

GTTGTTACACACTCCTTAGCGGAT-3') (Bala, et al., 2010) for the combined ITS and LSU regions (Lévesque \& de Cock, 2004). In some cases the ITS region alone was 
amplified using UN-up18S42 and UN-lo28S22 (5'-

GTTTCTTTTCCTCCGCTTATTGATATG-3') (Lévesque \& de Cock, 2004). The oomycete-specific primers OomCoxI-Levup (5'-TCAWCWMGATGGCTTTTTTCAAC3') and Fm85mod (5'-RRHWACKTGACTDATRATACCAAA-3'), modified from Martin and Tooley (2003), were designed to amplify $727 \mathrm{bp}$ from the 5' end of COI mitochondrial DNA. In some cases, an alternative reverse primer, OomCoxI-Levlo (5'CYTCHGGRTGWCCRAAAAACCAAA-3'), was used with OomCoxI-Levup, amplifying a slightly smaller $680 \mathrm{bp}$ fragment of COI, perfectly overlapping the standard DNA barcode used in other groups. PCR volume was $10 \mu \mathrm{L}$ containing final concentrations of $1 X$ Titanium Taq buffer (with $3.5 \mathrm{mM} \mathrm{MgCl} 2$ ), $0.1 \mathrm{mM}$ dNTPs, 0.08 $\mu \mathrm{M}$ each of forward and reverse primer, $0.5 \mathrm{X}$ Titanium Taq polymerase, and approximately $1-10 \mathrm{ng} / \mu \mathrm{L}$ of DNA. Reaction volume was brought up to $10 \mu \mathrm{L}$ with sterile HPLC water. Thermocycler program for amplification of the ITS/LSU region was: $95^{\circ} \mathrm{C}$ for $3 \mathrm{~min}$ followed by 40 cycles of $95^{\circ} \mathrm{C}$ for $30 \mathrm{~s}, 68^{\circ} \mathrm{C}$ for $45 \mathrm{~s}, 72^{\circ} \mathrm{C}$ for $2 \mathrm{~min} . \mathrm{A}$ final extension was made at $72^{\circ} \mathrm{C}$ for $8 \mathrm{~min}$. Program for ITS alone was identical to that for ITS/LSU, except for a shorter extension time of $90 \mathrm{~s}$ at $72^{\circ} \mathrm{C}$ in each cycle. Program for amplification of the $\mathrm{COI}$ region was: $95^{\circ} \mathrm{C}$ for 2 min followed by 35 cycles of $95^{\circ} \mathrm{C}$ for $1 \mathrm{~min}, 55^{\circ} \mathrm{C}$ for $1 \mathrm{~min}, 72^{\circ} \mathrm{C}$ for $1 \mathrm{~min}$. A final extension was made at $72^{\circ} \mathrm{C}$ for 10 $\min$.

\subsubsection{Cloning PCR products}

In some cases, direct sequencing of PCR products from the ITS/LSU region resulted in poor sequence results due to apparent polymerase slippage at polyT or polyA regions, 
or due to the possibility of indels in some copies or alleles of this multicopy locus. Cloning of PCR products and sequencing directly from the cloning vectors was able to overcome this problem. PCR products were purified by mixing $5 \mu \mathrm{L}$ of PCR product with $2 \mu \mathrm{L}$ ExoSAP-IT ${ }^{\circledR}$ (USB), incubating at $37^{\circ} \mathrm{C}$ for $15 \mathrm{~min}$, followed by incubation at $80^{\circ} \mathrm{C}$ for 15 min. Purified PCR products were then poly-adenylated and ligated to the pGEM ${ }^{\circledR}$ T Easy vector (Promega). Transfection of competent cells, selection of transformants, and growth of transformant cultures were performed according to manufacturer's protocols. Isolation of plasmid DNA was performed according to Sambrook and Russel (2001), with omission of the optional phenol/chloroform step. Plasmids isolated from transformants were screened for inserts by PCR with T7 (5'-

TAATACGACTCACTATAGGG-3') and SP6 (5'-TATTTAGGTGACACTATAG-3') plasmid primers. Program for screening PCR was: $95^{\circ} \mathrm{C}$ for 3 min followed by 40 cycles of $95^{\circ} \mathrm{C}$ for $30 \mathrm{~s}, 50^{\circ} \mathrm{C}$ for $45 \mathrm{~s}, 72^{\circ} \mathrm{C}$ for $2 \mathrm{~min} 30 \mathrm{~s}$. A final extension was made at $72^{\circ} \mathrm{C}$ for $8 \mathrm{~min}$.

\subsubsection{Sequencing}

Amplification of PCR products for sequencing was done with ABI Big Dye Terminator v3.1 in a reaction volume of $10 \mu \mathrm{L}$, with Big Dye Seq Mix diluted 1:8 with Seq buffer. Final concentrations of each reagent were $0.875 X$ Sequencing buffer, $5 \%$ trehalose, $0.125 X$ Big Dye Seq Mix, and $0.16 \mu \mathrm{M}$ primer. Reaction volume was brought to $10 \mu \mathrm{L}$ with sterile HPLC water and $1 \mu \mathrm{L}$ of PCR product was added directly from initial PCR amplification without purification. Thermocycler program for ITS/LSU was: $95^{\circ} \mathrm{C}$ for $3 \mathrm{~min}$ followed by 40 cycles of $95^{\circ} \mathrm{C}$ for $30 \mathrm{~s}, 58^{\circ} \mathrm{C}$ for $40 \mathrm{~s}, 60^{\circ} \mathrm{C}$ for $4 \mathrm{~min}$. 
Program for COI was: $95^{\circ} \mathrm{C}$ for 3 min followed by 40 cycles of $95^{\circ} \mathrm{C}$ for $30 \mathrm{~s}, 50^{\circ} \mathrm{C}$ for 20 $\mathrm{s}, 60^{\circ} \mathrm{C}$ for $4 \mathrm{~min}$. Sequencing primers for ITS were UN-up $18 \mathrm{~S} 42$ and UN-lo28S22. Sequencing primers for LSU were UN-up28S40 (5'-

GCATATCAATAAGCGGAGGAAAAG-3') (Schurko, et al., 2003), UN-up28S577 (5'CGTCTTGAAACACGGACCAAGGAG-3') (Bala, et al., 2010), UN-lo28S576B (5'CTCCTTGGTCCGTGTTTCAAGACG-3') (Bakkeren, et al., 2000), and UN-lo28S1220. Sequencing primers for COI were OomCoxI-Levup and Fm85mod or OomCoxI-Levlo.

DNA sequences were generated from sequencing amplification reactions using the ABI Prism 3130xl Genetic analyzer. DNA sequences have been deposited in the Barcode of Life Data Systems (BOLD) and GenBank. Accession numbers for both databases are found in Appendix A.

\subsubsection{Sequence editing, alignment, and cluster analysis}

Sequence results were reviewed and edited using Seqman software (DNAStar) and alignments were made using MUSCLE for COI and MAFFT for ITS and LSU (Edgar, 2004, Katoh, et al., 2005). MAFFT alignment of LSU was performed with the G-INS-i algorithm on the download Mac OS X version. MAFFT alignment of ITS was performed with the L-INS-i algorithm. The default maximum sequence allowance was raised from 1000 to 2000 by opening the MAFFT script in /usr/local/bin and changing line 762 from if [ \$nseq -gt 1000 -a $\$$ iterate -gt 1 ]; then to if [ \$nseq -gt 2000 -a \$iterate -gt 1 ]; then. Alignments in fastA format were converted to nexus format with MacClade 4.06. Alignment of COI contained 680 characters, alignment of ITS contained 2068 characters, and alignment of LSU contained 1395 characters. No characters were excluded from 
analysis of any marker. Calculation of distance matrices and UPGMA hierarchical clustering was performed with PAUP 4.0b10. Bootstrap values were obtained from 1000 reps. Trees were formatted for Fig. 3.2 and Fig. 3.3 using Dendroscope (Huson, et al., 2007).

\subsubsection{Distance matrix statistical analysis}

Uncorrected "p" (percentage) based distance matrices were analyzed using matrix algebra and SAS. The average intraspecific distance was calculated for each species represented by more than one strain and coded as missing data when only one strain could be obtained to avoid having a bias towards zero variation. For each pair of species, the average pairwise distance was calculated for all the possible strain comparisons. A lower triangular uncorrected distance matrix was created with PAUP with the strains shown in Appendix A. The square pairwise distance matrix [PD] was imported into SAS as well as a column for species name and a column for corresponding strain coding. There was no need to keep track of genus names because we did not have the same species name found in two different genera. A 0/1 "dummy" species variable design matrix [SV] was created in SAS using the species name column. The total of the distances [TD] for each species and pairwise comparison was found with the following equation: $[\mathrm{TD}]=[\mathrm{SV}] \mathrm{t} \times[\mathrm{PD}] \times[\mathrm{SV}]$, where the diagonal was the number of pairwise comparisons for each species and the lower triangular matrix the total number of possible pairwise comparisons for each pair of species. A lower triangular matrix with a diagonal of l's [L1] was created with the same number of rows and columns as [PD]. The same equation as above was applied by replacing [PD] by [L1] to find the total number of 
pairwise distance comparisons [ND]. The average of all the pairwise comparisons was found by dividing [TD] by [ND], with the diagonal of the matrix giving the averages of all intraspecific comparisons and the lower matrix the averages of all interspecific comparisons. These values were used for distribution analyses.

\subsection{Results}

\subsubsection{PCR primer performance}

In an initial trial using the Phytophthora primers from Martin and Tooley (2003), consistent amplification of the COI barcode region was not achieved in a set of eight oomycete genera. However, the complete 5 ' end and middle region of $\mathrm{COI}$ was sequenced with various combinations of their primers for Saprolegnia, Achlya and Pythium in addition to Phytophthora. Alignment of these sequences allowed design of new COI primers for the current study, OomCoxI-Levup and Fm85mod, which amplified a $727 \mathrm{bp}$ fragment from the 5' end of COI. For 18 isolates that did not amplify well with Fm85mod, an alternative reverse primer (OomCoxI-Levlo) was used. This amplified a smaller fragment of $680 \mathrm{bp}$ compared to using Fm85mod (Fig. 3.1). Introns were not present in any COI sequence of the species studied. ITS fragments of varying length were used; from partial fragments as short as 402 bp from some Pythium isolates, up to 1351 bp from Eurychasma. In Basidiophora, Plasmopara and Plasmoverna, only the ITS 1 region was sequenced due to long insertions in the ITS2 region. The LSU fragments ranged between $1246 \mathrm{bp}$ and $1343 \mathrm{bp}$, although for three Saprolegnia isolates, partial fragments between $700-850$ bp were used due to lack. of high sequence quality for the entire D1-D3 region. 


\section{COI}

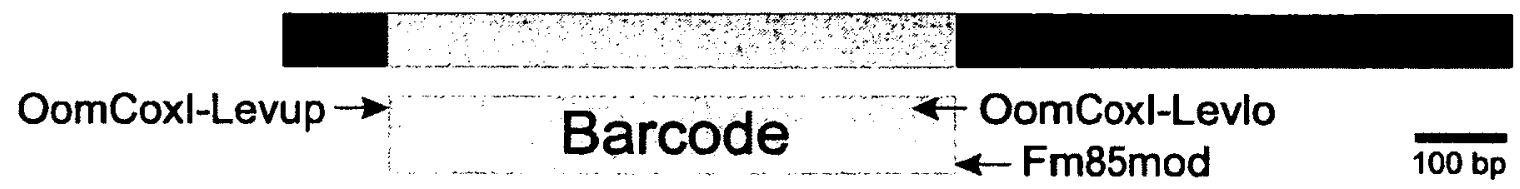

Figure 3.1. Diagram illustrating $\mathrm{COI}$ gene region, barcode segment of $\mathrm{COI}$ (grey), and $\mathrm{COI} P C R$ primer locations. Reprinted with permission of the Minister of Agriculture and Agri-Food, Canada, 2012. 


\subsubsection{Sequence distances}

For each marker, distance matrices were used to calculate intraspecific (within species) variation, as well as interspecific (between species) variation. A graphical representation of the data and a table summarizing the results for all markers is shown in Fig. 3.2. The mean intraspecific variation for COI, ITS, and LSU was $0.0048,0.0046$, and 0.0017 , respectively. The mean interspecific variation was $0.1050,0.2899$, and 0.1037 , respectively.

\subsubsection{Cluster analyses}

Trees for each marker are shown in Fig. 3.2. Trees for COI and ITS contain 1205 sequences, including the basal oomycete Eurychasma dicksonii as the outgroup (Sekimoto, et al., 2008). The LSU tree contains 388 sequences, including E. dicksonii as outgroup. Black squares at branch termini in Fig. 3.2 represent a collapsed subtree containing multiple species or in the case of the order Saprolegniales, multiple genera and species. Black rectangles at branch termini represent a clade of unresolved genera and indicate the presence of multiple species from the genera occupying the clade. Direct comparison between COI and ITS trees is shown in Fig. 3.3. Black squares at branch termini in Fig. 3.3 represent a collapsed subtree containing multiple isolates. Black rectangles at branch termini represent a clade of unresolved species and indicate the presence of multiple isolates from the species occupying the clade. Unresolved species with only single isolates are shown within clades represented by vertical lines at branch termini rather than rectangles. In Fig. 3.3, the genera Phytophthora and Pythium are divided and displayed by their previously established phylogenetic clades (Lévesque \& 
de Cock, 2004, Blair, et al., 2008). Genera belonging to the families Saprolegniaceae and Leptolegniaceae are shown under the heading of their respective family. All obligate biotrophs are displayed together. For both COI and ITS, most isolates grouped into conspecific clusters, and the species composition of major clades did not differ between COI and ITS. Exceptions to this trend were Phytophthora katsurae, Phytopythium aff. vexans, Pythium kunmingense, and Pythium okanoganense, which all appeared in different terminal nodes depending on the marker used. LSU sequences were more highly conserved and did not vary between some closely related species that were distinctly separate with COI and ITS. In some cases, two or more species shared identical or highly similar COI and ITS sequences, consistent across both markers, which invites further discussion of the possible synonymy of those species. 

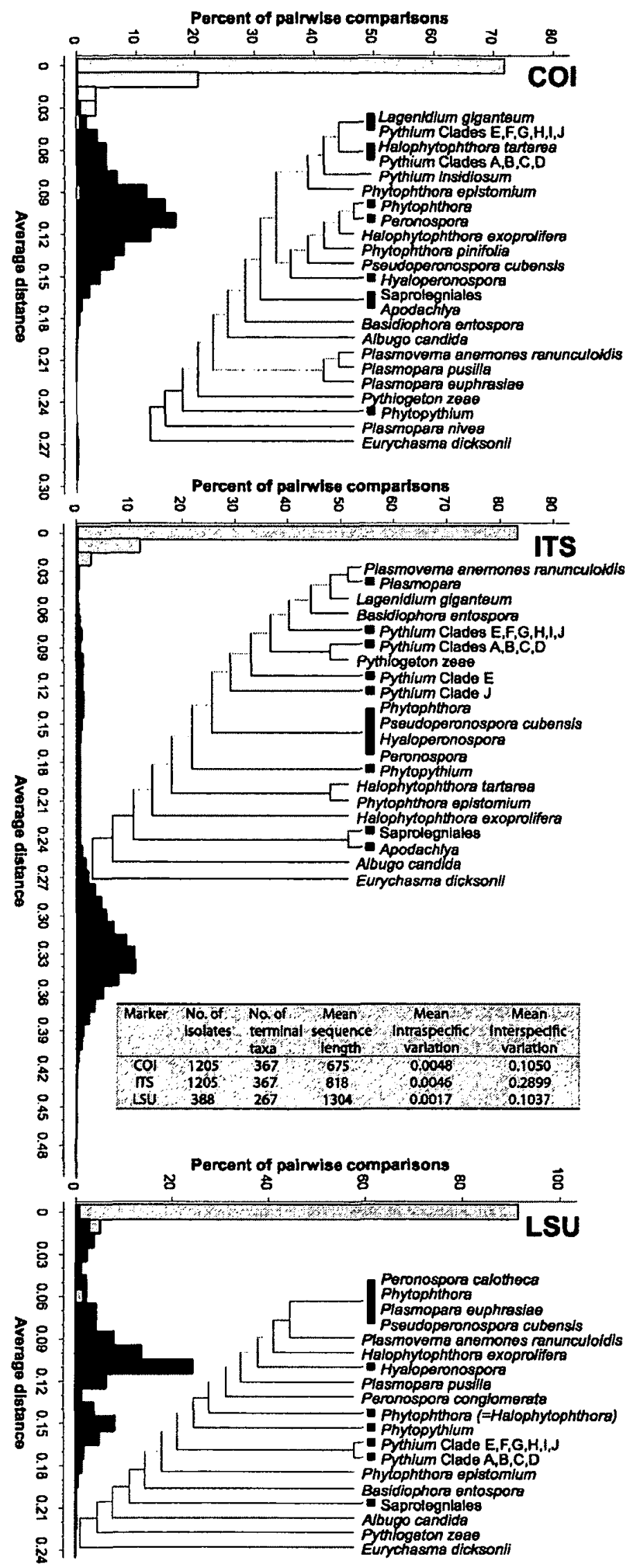
Figure 3.2. Phylograms and distance histograms for each marker. Black boxes at phylogram branch termini indicate multiple species. Branches with less than $50 \%$ bootstrap support are greyed out. Branch lengths are not to scale. Histograms display intraspecific variation in grey and interspecific variation in black. Inset table summarizes distance data. Reproduced with the permission of the Minister of Agriculture and Agri-Food, Canada, 2012. 
(a)

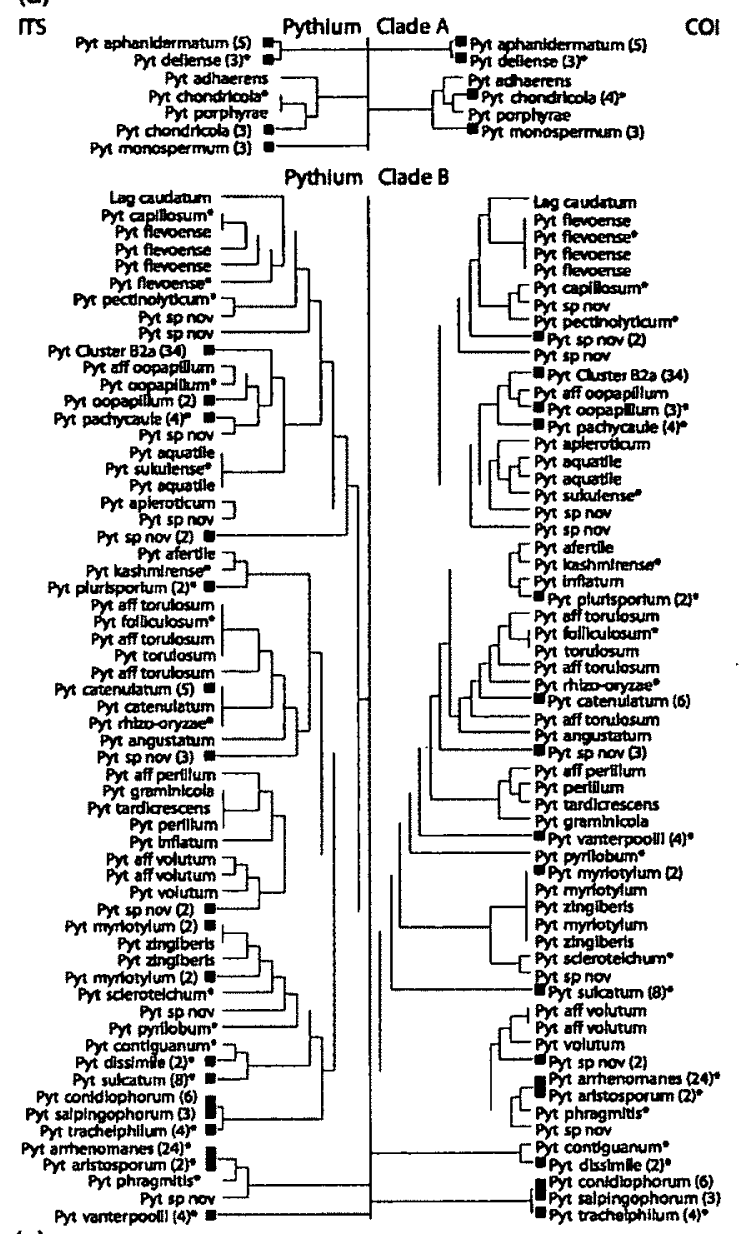

(C)

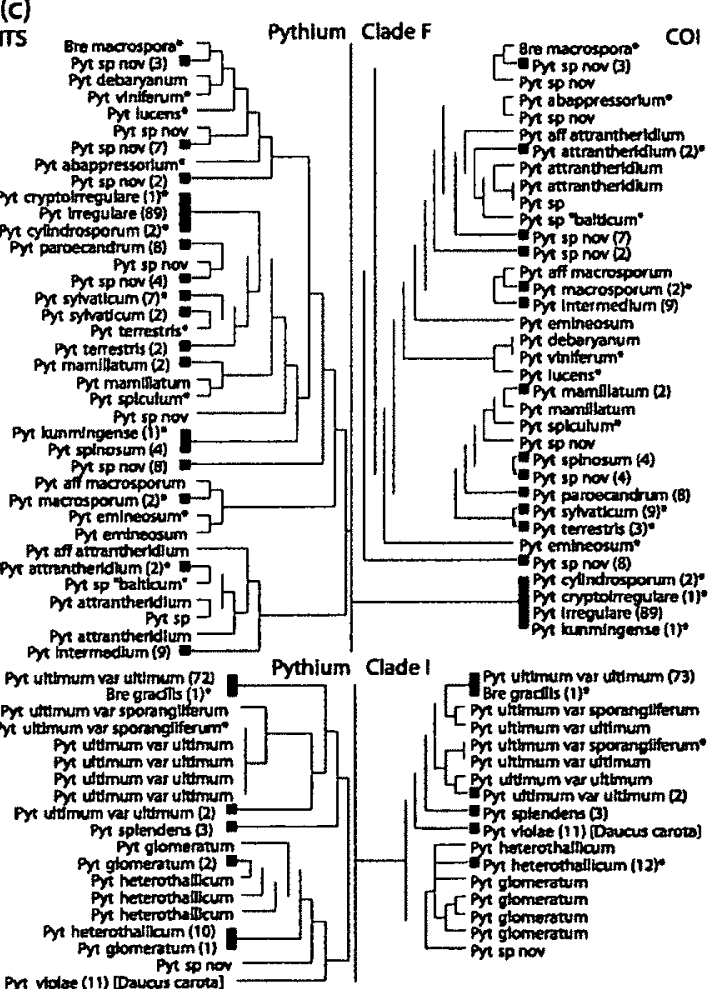

(b)
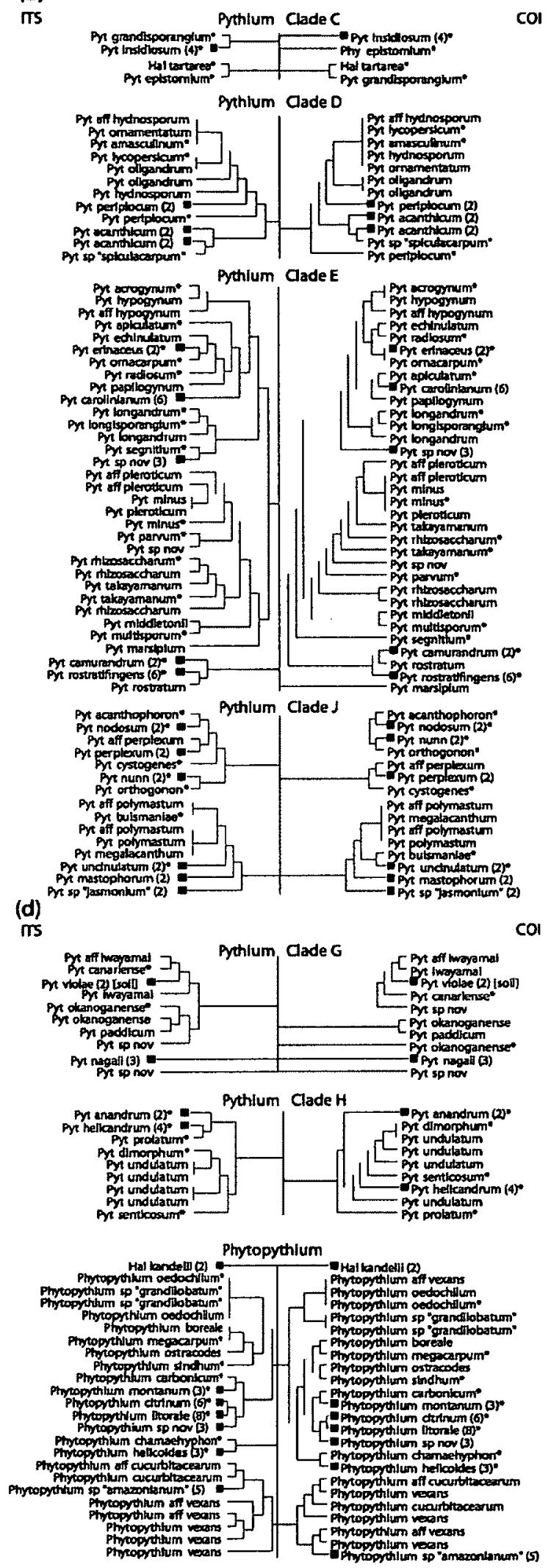
(e)

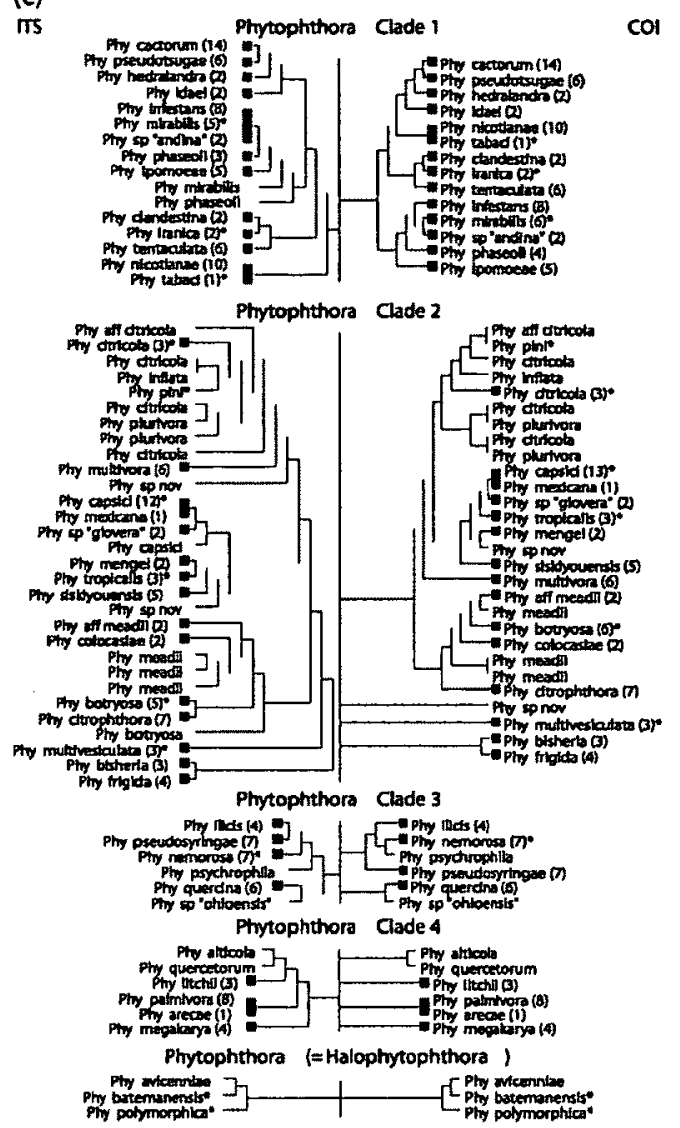

(g)

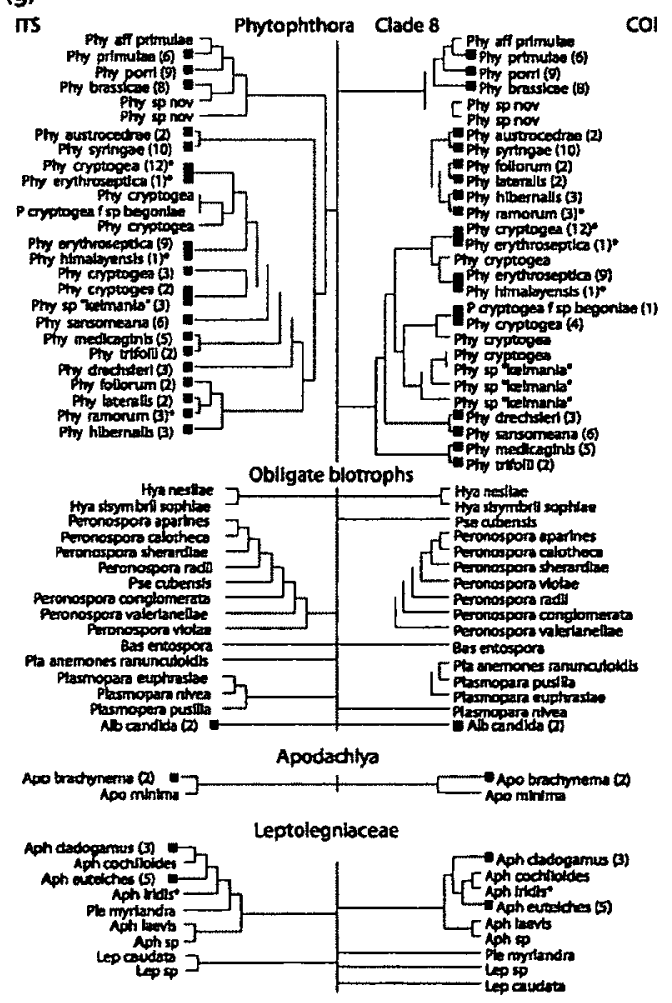

(f)

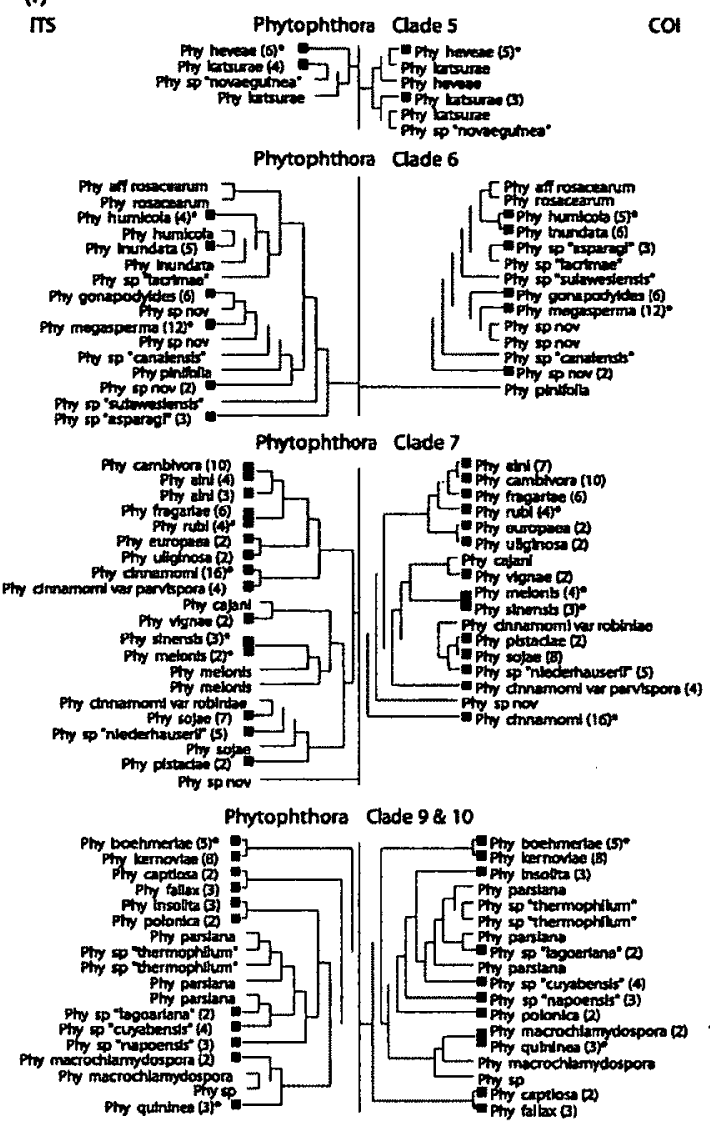

(h)

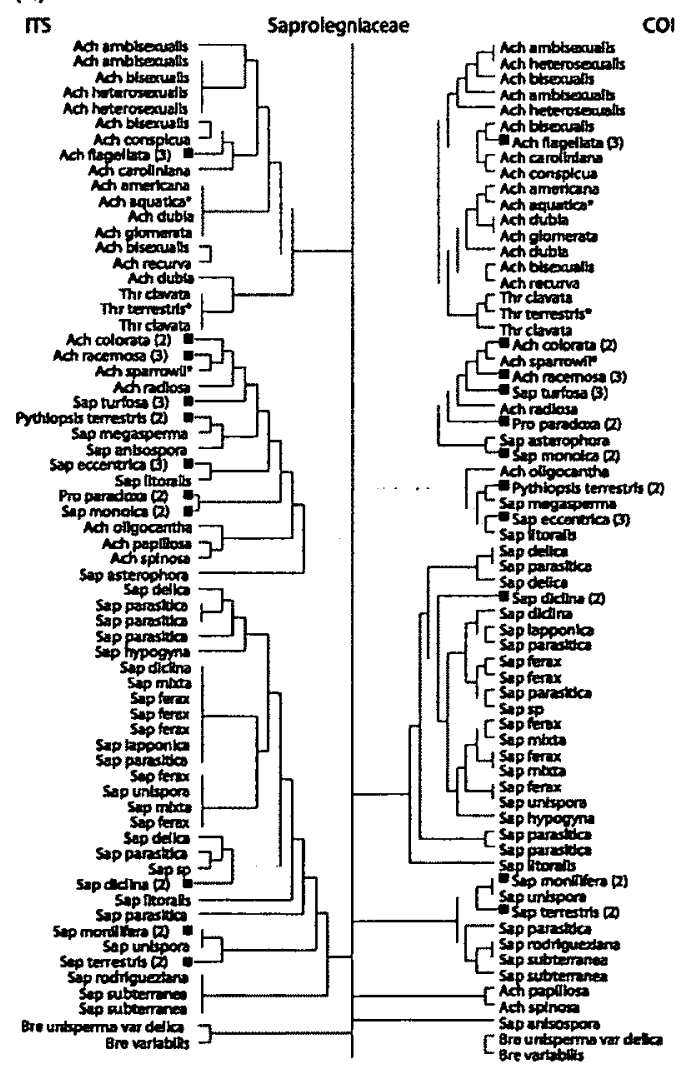


Figure 3.3. Direct comparison of ITS and COI phylograms by clade. ITS is shown on the left and $\mathrm{COI}$ on the right of an artificial vertical backbone. Black boxes at phylogram branch termini represent multiple isolates, with number of isolates shown in brackets. Asterisks denote ex-type specimen. Branches with less than $50 \%$ bootstrap support are greyed out. Branch lengths are not to scale. Most genus names are abbreviated to the first three letters. See Appendix A (Supporting information) for full names. (a) Pythium Clades A and B. (b) Pythium Clades C, D, E and J. (c) Pythium Clades F and I. (d) Pythium Clade G, H and Phytopythium. (e) Phytophthora Clades 1, 2, 3, 4 and (=Halophytophthora). (f) Phytophthora Clades 5, 6, 7, 9 and 10. (g) Phytophthora Clade 8 , Obligate biotrophs, Apodachlya and Leptolegniaceae. Note that grouping of all obligate biotroph isolates is superficial as they do not represent a coherent phylogenetic group. $(h)$ Saprolegniaceae. Reproduced with the permission of the Minister of Agriculture and Agri-Food, Canada, 2012.

\subsection{Discussion}

The primary purpose of the current study was to compare a validated oomycete de facto DNA barcode (ITS) with the default barcode (COI) which is officially accepted as the DNA barcode for eukaryotic groups unless proven ineffective. Our results indicate that both ITS and COI can be valid and useful barcodes for accurate identification of many oomycetes, whereas LSU more often lacks sufficient resolution between species. The genera Pythium and Phytophthora were almost completely covered by this study, and several other genera representing a wide range of oomycetes, including some obligate biotrophs, were partially covered. Intraspecific variation of $\mathrm{COI}$ is at par with that of ITS, although ITS does provide greater interspecific variation than COI. The benefit of COI barcoding is the ease of sequencing and aligning a relatively short fragment which has uniform length and can be amplified with degenerate primers throughout the entire oomycete class. This advantage over ITS is especially evident in the downy mildew genera Basidiophora, Plasmopara, Plasmoverna and relatives, which contain insertions in the ITS 2 resulting in ITS sequences often longer than $2 \mathrm{~kb}$ (Thines, 2007), this raises difficulty in amplifying, sequencing and aligning the complete ITS region. LSU had the lowest interspecific variation of the three markers (Fig. 3.2), and the 
use of LSU as an oomycete barcode does not always provide enough resolution for identification to the species level. LSU appears to be better suited for studying genus- and family-level relationships in oomycetes (Riethmüller, et al., 1999, Petersen \& Rosendahl, 2000, Riethmüller, et al., 2002, Voglmayr \& Riethmüller, 2006). A large portion of LSU was used to provide sufficient variation but this precludes amplification and sequencing with a single pair of primers. Barcoding with COI on the other hand, can quickly and easily lend additional evidence to identifications and new species descriptions by complementing nuclear DNA sequencing (ITS) with a mitochondrial DNA sequence (Bala, et al., 2010). The speed and ease of ITS and COI sequencing is also enhanced by the method of PCR amplification used in this study, which employed a minimal concentration of primers, thereby eliminating the need for purification of PCR products before sequencing. This approach, which was carried out in small PCR reaction volumes $(10 \mu \mathrm{L})$, was able to reduce time and cost while still delivering high quality results. Universality of PCR primers is also an important requirement of DNA barcodebased identification. The primers used for oomycete COI amplification (OomCoxI-Levup and Fm85mod) were able to amplify DNA from the entire range of oomycete genera in this study, including the basal genus Eurychasma and genera from the obligate biotrophic white blister rusts (Albugo) and downy mildews (Basidiophora, Hyaloperonospora, Peronospora, Plasmopara, Plasmoverna and Pseudoperonospora): There were however, a few exceptional species of Pythium and Phytopythium (Py. buismaniae, Py. contiguanum, Py. kashmirense, Py. ostracodes, and Ph. cucurbitacearum) that did not amplify with Fm85mod, and were instead amplified and sequenced using the alternative reverse primer OomCoxI-Levlo. Standard use of OomCoxI-Levlo is not recommended 
though, because our alignment of Fm85mod-derived COI sequences revealed that the 3' end of OomCoxI-Levlo is not conserved throughout all Pythium, Phytophthora, and Aphanomyces species.

Proposition of $\mathrm{COI}$ as a complement to ITS for species delimitation is based on the observation that relationships among closely related species and organization of major clades in Pythium and Phytophthora are concordant with the results of previous multilocus molecular studies (Kroon, et al., 2004, Lévesque \& de Cock, 2004, Blair, et al., 2008). Almost every terminal node on the UPGMA tree was composed of the same isolate(s) regardless of the marker used for sequencing. Replicated DNA sequencing of the isolates that did not follow this trend (Phytophthora katsurae P3389, Phytopythium aff. vexans CBS 261.30, Pythium kunmingense CBS 550.88, and Pythium okanoganense CBS 315.81) was performed to rule out the possibility of a DNA mix up during COI sequencing. In attempting to explain these situations biologically, the possibility of hybridization exists as has been well documented in Phytophthora (Érsek \& Nagy, 2008) and recently discovered in Pythium (Nechwatal \& Mendgen, 2008), but evidence of hybridization based on dimorphism in nuclear DNA sequence chromatograms was not found for any isolate mentioned above. An alternative scenario involving horizontal transfer of mitochondrial DNA (mtDNA) is not implausible based on previous findings in filamentous fungi. Mobile mitochondrial plasmids are prominent in filamentous fungi and they are known to recombine with mtDNA (Griffiths, 1996). The presence of mitochondrial plasmids has not been documented in oomycetes, although it is interesting to note that a mobile plasmid derived from an intron of $\mathrm{COI}$ exists in the ascomycete fungus Podospora anserina (Osiewacz \& Esser, 1984). Fusion of hyphae (anastomosis), 
as has been reported in Phytophthora (Stephenson, et al., 1974), could be a rare natural event that enables horizontal transfer of mtDNA in oomycetes. Although the true nature of the aforementioned results is unknown, it is worth stating that the use of both ITS and $\mathrm{COI}$ rather than one or the other, is recommended for taxonomic identification of oomycetes.

Considering that new species descriptions are a demanding process involving detailed morphological study, the ability to predict candidacy for a new species description with additional DNA sequence data will be very valuable and time-saving, providing more confidence so as to avoid questionable or synonymous species descriptions. Several putative new species are present in the isolates used for this study, denoted by the species epithet "sp. nov."

The augmented species resolution that COI provides is evident for arguably the most economically important oomycete, Phytophthora infestans. This species, which causes late blight of potato and tomato, has an ITS sequence that is indistinguishable from the closely related species $P$. sp. "andina" and $P$. mirabilis. COI on the other hand, separates these three species into individual terminal nodes. The same situation has been seen between the strawberry pathogen Phytophthora fragariae and the recently circumscribed raspberry pathogenic species $P$. rubi (Man in 't Veld, 2007), originally classified as $P$. fragariae var. rubi. While the ITS sequences do not vary between these two species, a clear distinction exists between their COI sequences. A similar example of species resolution by $\mathrm{COI}$ in Pythium is between the marine algal pathogens $P$. chondricola and P. porphyrae. Other examples of species resolution by $\mathrm{COI}$ are listed in Appendix $\mathrm{B}$. The initial recognition of individuality between these species can be credited to examination 
of morphological characters and confirmation of these species descriptions by $\mathrm{COI}$ sequencing acknowledges the accuracy of morphological observation.

Though the use of COI sequencing is able to reinforce some species boundaries, there are several cases where formally described species are indistinguishable with either ITS or COI. Cases of apparent conspecificity are listed in Appendix C. Our results also implicate the existence of species complexes where gene flow may be occurring between species. In some cases there are several described species included in a complex, or alternatively a single described species may display substantial intraspecific variation, thus suggesting that a complex of multiple species exists within the single described species. For example, there is a large species complex referred to here and in Fig. 3.3a as Pythium Cluster B2a which includes $P$. coloratum, $P$. diclinum, $P$. cf. dictyosporum, $P$. dissotocum, P. lutarium, P. sp. "Group F", and P. sp. "tumidum". Other examples of species complexes in Achlya, Phytophthora, Pythium, Phytopythium, and Saprolegnia are listed in Appendix D. Such complicated taxonomic situations are inextricable with a single marker, and it is therefore important to have additional evidence from other markers such as $\mathrm{COI}$ for taxonomic identification of oomycetes. Ultimately, multigene phylogenies will be required to resolve taxonomic issues.

The conclusion drawn from this study is that $\mathrm{COI}$ sequencing is a very useful addition to the oomycete molecular toolbox which can now be used for identification of many oomycete species using the reference data generated by this study. In some of the most difficult cases of species concept in Phytophthora and Pythium, COI provides better resolution and support for current taxonomy than ITS does. However, because both markers provide an acceptable resolution when used individually, because of the history 
of using ITS in mycology and for oomycetes, and because it is desirable to have the complement of mitochondrial and nuclear markers, we have proposed that ITS be added to $\mathrm{COI}$ as a DNA barcode for oomycetes in GenBank. For any oomycete species that is not included in this study or for any new species to be described, both markers should be sequenced and deposited as barcodes. 


\section{Chapter: COMPARATIVE GENOMICS AND PHYLOGENETIC STUDY OF OOMYCETE FLAGELLAR GENE EVOLUTION}

\section{Adapted from:}

Lévesque CA, Brouwer H, Cano L, Hamilton JP, Holt C, Huitema E, Raffaele S, Robideau GP, Thines M, Win J, Zerillo MM, Beakes GW, Boore JL, Busam D, Dumas B, Ferriera S, Fuerstenberg SI, Gachon CM, Gaulin E, Govers F, Grenville-Briggs L, Horner N, Hostetler J, Jiang RH, Johnson J, Krajaejun T, Lin H, Meijer HJ, Moore B, Morris P, Phuntmart V, Puiu D, Shetty J, Stajich JE, Tripathy S, Wawra S, van West P, Whitty BR, Coutinho PM, Henrissat B, Martin F, Thomas PD, Tyler BM, De Vries RP, Kamoun S, Yandell M, Tisserat N, Buell CR (2010). Genome sequence of the necrotrophic plant pathogen Pythium ultimum reveals original pathogenicity mechanisms and effector repertoire. Genome Biology 11: R73.

Robideau GP, Rodrigue N, Lévesque CA (to be submitted). Codon substitution modeling of flagellar gene evolution in oomycetes introduces novel molecular markers and a compelling approach to phylogenetic reconstruction with protein-coding genes. Molecular Biology and Evolution.

\subsection{Introduction}

Oomycetes are ubiquitous fungus-like protists which can cause disease in a wide range of plants and animals. Many oomycetes are serious pathogens of agricultural, horticultural, and aquatic commodities. The oomycete lineage belongs to the heterokont phylum among brown algae and diatoms, and includes well-known genera such as Phytophthora, Pythium, and Saprolegnia. Oomycete evolution has been well studied (Sparrow, 1960, Beakes, 1989, Dick, 2001), and continuing efforts are being made towards the most realistic reconstruction of phylogenetic relationships within this group. Studies of molecular evolution and oomycete systematics have generally relied upon mitochondrial cytochrome oxidase subunit II (cox2) (Hudspeth, et al., 2000, Hakariya, et al., 2007, Sekimoto, et al., 2008) and ribosomal RNA (rRNA) sequences from the $18 \mathrm{~S}$ small subunit (SSU), internal transcribed spacer (ITS), or the $28 \mathrm{~S}$ large subunit (LSU) to 
provide phylogenies (Cooke, et al., 2000, Petersen \& Rosendahl, 2000, Riethmüller, et al., 2002, Beakes, et al., 2012).

Prior to DNA sequencing, systematic studies were heavily reliant on ultrastructural characteristics to infer phylogenetic relationships. Some of the most influential work in this area came from studies of the flagellar apparatus (Barr, 1981, Moestrup, 1982, Barr \& Allan, 1985). Flagellar hairs, also known as mastigonemes, were consistently cited as an important morphological feature of heterokont flagella (Bouck, 1971, Leadbeater, 1989). The organization of the flagellar rootlet system is also highly conserved throughout stramenopiles (Barr \& Désaulniers, 1989), which added to the evidence that led to the eventual distinction of these organisms from true fungi. In fact, the term "stramenopile" used to describe the entire heterokont phylum, is derived from the straw-like hairs present on the so-called "tinsel" flagellum. Since flagellar ultrastructure has traditionally been regarded as such an important character in heterokont systematics, this tradition is now continued on a molecular level using flagellar gene sequences to study oomycete systematics and evolution. This represents the first study of oomycete flagellar evolution on a molecular scale, where the results will be interpreted in comparison to the oomycete evolutionary framework established primarily with ribosomal RNA and mitochondrial genes. Through involvement with the Pythium ultimum genome project, available oomycete genomes were searched for putative flagellar genes in order to shed light on P. ultimum's flagellar gene repertoire, and to find suitable candidates for an oomycete-wide study of flagellar evolution.

The oomycete Pythium ultimum is a notorious and ubiquitous plant pathogen responsible for root rot and damping off of many different crops and ornamentals. The $P$. 
ultimum genome project provided the first Pythium genome to be fully sequenced and opened the door to comparison of the Pythium gene repertoire with those of related oomycetes Phytophthora and Hyaloperonospora. Since $P$. ultimum does not produce zoospores in culture, an important question to be asked was whether it is genetically capable of producing zoospores. Has its flagellar gene repertoire been reduced or has transcription of flagellar genes been suppressed? These questions were addressed by comparison to the genomes of known zoospore-producers Phytophthora infestans, Phytophthora ramorum, and Phytophthora sojae, as well as the non-zoospore-producing downy mildew Hyaloperonospora arabidopsidis. The results of these comparisons show that $P$. ultimum does not lack any of the compared flagellar genes, but there are several potentially suppressed genes that were not expressed in growth conditions which typically induce zoospore production in oomycetes. The results also provided a list of flagellar genes that are conserved in Pythium and Phytophthora, of which two genes were found to be particularly amenable to a molecular evolution study: the axoneme central apparatus protein PF16, and the tubular mastigoneme protein OCM1. These genes harbor conserved DNA sequences at their 5' and 3' termini, which enabled the design of PCR primers capable of amplifying these genes from a wide range of oomycetes.

The axoneme central apparatus is involved in flagellar dynein regulation and is a core component of the eukaryotic flagellum (Smith, 2002). It is comprised of several known proteins including PF16 (Smith \& Lefebvre, 1996, Smith \& Lefebvre, 1997), which is highly conserved among very diverse eukaryotes (Straschil, et al., 2010). Tubular tripartite mastigonemes are a defining feature of heterokont flagella, and their number, thickness, and length have been observed to be consistent for a taxon (Hill \& 
Outka, 1974, Moestrup, 1982). Most studies of mastigonemes have relied on the golden alga Ochromonas, which possesses only tinsel flagella rather than the combination of whiplash and tinsel flagella found in most heterokonts. To date, four distinct proteins named OCM1, OCM2, OCM3, and OCM4 have been isolated from the mastigonemes of Ochromonas (Yamagishi, et al., 2007, Yamagishi, et al., 2009). Orthologs of PF16, OCM1, OCM2, and OCM4 proteins are present in the published genomes of Pythium and Phytophthora (Lévesque, et al., 2010), and the OCM2 ortholog has been studied in detail in Phytophthora nicotianae (Blackman, et al, 2011). Access to these flagellar gene sequences now makes the study of their evolution in oomycetes possible.

Since the advent of DNA sequencing, studies of molecular evolution have typically relied on nucleotide or amino acid substitution models, but the analysis of protein coding sequence evolution has significantly advanced since the introduction of codon substitution models (Goldman \& Yang, 1994, Muse \& Gaut, 1994). In contrast to nucleotide-based or amino acid-based models, codon-based substitution models use coding DNA triplets as the unit of evolution. These models were originally developed to measure selective pressures, and their adoption in phylogenetic frameworks has been slow due to their high computational demands. Now, recent advances in computing technology combined with algorithmic refinements have created renewed interest and utilization of this approach in phylogenetics (Ren, et al., 2005, Rodrigue, et al., 2010, Chang, et al., 2012), since their advantage over nucleotide and amino acid models has been demonstrated (Seo \& Kishino, 2009).

Here a genomic comparison of oomycete flagellar genes is reported, as is DNA sequencing of novel markers PF16 and OCM1 from a variety of oomycetes using newly 
designed degenerate PCR primers. The coding DNA sequences are analyzed using a codon-based model of sequence evolution to produce a molecular phylogeny. The evolution of PF16 and OCM1 among oomycetes is explored, and their utility in species delimitation is demonstrated.

\subsection{Materials and Methods}

\subsubsection{Comparative genomics and genome annotation}

Available genome assemblies were accessed to compare oomycete flagellar gene repertoires and to obtain full length predicted PF16 and OCM1 sequences. Predicted PF16 and OCM1 sequences were retrieved by performing tBLASTN on genomic DNA assemblies using Chlamydomonas reinhardtii PF16 protein (GenBank: AAC49169) and Ochromonas danica OCM1 protein (GenBank: BAF65668) as queries. Sequences were obtained from the genomes of: Albugo candida (Links, et al., 2011), Albugo laibachii (Kemen, et al., 2011), Ectocarpus siliculosus (Cock, et al., 2010), Hyaloperonospora arabidopsidis (Baxter, et al., 2010), Phytophthora capsici (These sequence data were produced by the US Department of Energy Joint Genome Institute http://www.jgi.doe.gov/ in collaboration with the user community), Phytophthora infestans (Phytophthora infestans Sequencing Project, Broad Institute of Harvard and MT, http://www.broadinstitute.org/), Phytophthora ramorum, Phytophthora sojae (Tyler, et al., 2006), Pythium aphanidermatum (C.R. Buell, unpublished), Pythium ultimum (Lévesque, et al., 2010), and Saprolegnia parasitica (Saprolegnia parasitica Sequencing Project, Broad Institute of Harvard and MIT, http://www.broadinstitute.org/). 
Using the tBLASTn algorithm to search a translated nucleotide database with protein query sequences, the genome assembly of Pythium ultimum DAOM BR 144 was searched for orthologues of known flagellar proteins or flagellum-associated proteins retrieved from GenBank. The majority of query protein sequences were from the green alga Chlamydomonas reinhardtii, and others were from the golden alga Ochromonas danica, as well as various animals such as Homo sapiens and the mouse Mus musculus. Significant tBLASTn matches from $P$. ultimum were annotated based on query protein description. Both the whole genome assembly and the predicted gene models of $P$. ultimum were inspected to produce the most accurate annotation of each flagellar gene. Comparative genomics of flagellar gene repertoires was performed using the genome sequences of $P$. ultimum, Phytophthora infestans, Phytophthora ramorum, Phytophthora sojae, and Hyaloperonospora arabidopsidis.

\subsubsection{Pythium ultimum genome assembly and $m R N A$ transcription profiling}

P. ultimum (DAOM BR144 $=$ CBS $805.95=$ ATCC 200006) was sequenced using a whole-genome shotgun sequencing approach. Sequencing reads from three Sanger libraries and three full runs of 454 FLX pyrosequencing were assembled by a pipeline (Lévesque, et al., 2010) and annotated using the MAKER program (Cantarel, et al., 2008). The gene expression profile of $P$. ultimum was derived from various growth conditions described by Lévesque et al. (2010). cDNA libraries were reverse-transcribed from mRNA extract and sequenced by Illumina Genome Analyzer (GA) II. Expression values were calculated using reads per kilobase of exon model per million mapped reads (RPKM) (Mortazavi, et al., 2008). 


\subsubsection{DNA extraction}

For cultures grown from the Centraalbureau voor Schimmelcultures (CBS isolates) and the Canadian Collection of Fungal Cultures (BR isolates), DNA extractions were performed as previously described (Robideau, et al., 2011). DNA extraction from Plasmopara halstedii (Lev 5881 isolate) was identical to BR isolate extractions except that the starting material was $\sim 150 \mu \mathrm{l}$ of crushed dried Helianthus annuus leaves that were infected with $P$. halstedii race 2 (Rashid, 1993).

\subsubsection{DNA amplification}

PCR primers were designed based on alignments of predicted PF16 and OCM1 sequences from assembled Phytophthora, Pythium, and Saprolegnia genomes (Ph. infestans, Ph. ramorum, Ph. sojae, Py. aphanidermatum, Py. ultimum, and S. parasitica). Standard primers designed for PF16 amplification were ACAup13 (5'TCCGTGCTSCAGCAYTTYGAGGTGTA-3') and ACAlo1475 (5'TGHGGCGAGTAGTACTCGACGATCTC-3'). Standard primers designed for OCM1 amplification were OCM1 up130B (5'-ATGTGCRAMTGCTAYAARAACTAC-3') and OCM1lo1842B (5'-CARTTRTCGTTVGTGTADCCCTTG-3'). Alternative primers were designed which amplified species that did not amplify well with the standard primers. Alternative OCM1 primers were OCM1up124 (5' - AAGGAYATGTGCAACTGCTA-3') and OCMllol 853 (5'- TCTGBGTGTYRCARTTGTCGTT-3'). Pythium insidiosum OCM1 sequences were amplified using OCM1oomup1 (5'TWYAARAACTACVHVGGVAACGACTG-3') and OCMloomlo1 (5'- 
TGBRYRTYRCARTTSTCRTTVGTGTA-3'). Pythium porphyrae OCM1 sequences were amplified with OCM1 up145B (5'-RRRSTWCVWRGSSAACGACTGC-3') and OCM1lo1842B. Apodachlya brachynema OCM1 sequences were amplified with OCM1Oomup2C (5'-TGYVDVSMNHRNGATATGTGC-3') and OCM1Oomlo1E (5'TCRYTNGTRTANCCTTTGAAACA-3'). Dictyuchus monosporus OCM1 sequences were amplified with OCM1Oomup2D (5'-TGYVDVSMNHRNGATATGTGT-3') and OCM1Oomlo1A (5'-TCRYTNGTRTANCCTTTGAAGCA-3'). PCR volume was $10 \mu \mathrm{L}$ containing final concentrations of $1 \mathrm{X}$ Titanium Taq buffer (with $3.5 \mathrm{mM} \mathrm{MgCl} 2$ ), 0.1 $\mathrm{mM}$ dNTPs, $0.08 \mu \mathrm{M}$ each of forward and reverse primer, $0.5 \mathrm{X}$ Titanium Taq polymerase, and approximately $0.1-1.0 \mathrm{ng} / \mathrm{uL}$ of DNA. Reaction volume was brought up to $10 \mu \mathrm{L}$ with sterile HPLC water. Thermocycler program for amplification of PF 16 was: $95^{\circ} \mathrm{C}$ for $3 \mathrm{~min}$ followed by 40 cycles of $95^{\circ} \mathrm{C}$ for $30 \mathrm{~s}, 69^{\circ} \mathrm{C}$ for $45 \mathrm{~s}, 72^{\circ} \mathrm{C}$ for $1 \mathrm{~min}$ $30 \mathrm{~s}$. A final extension was made at $72^{\circ} \mathrm{C}$ for $10 \mathrm{~min}$. Program for amplification of OCM1 was: $95^{\circ} \mathrm{C}$ for $3 \mathrm{~min}$ followed by 40 cycles of $95^{\circ} \mathrm{C}$ for $30 \mathrm{~s}, 60^{\circ} \mathrm{C}$ for $45 \mathrm{~s}, 72^{\circ} \mathrm{C}$ for 2 min. A final extension was made at $72^{\circ} \mathrm{C}$ for $10 \mathrm{~min}$.

\subsubsection{PCR product isolation}

PCR products were run on $1.0 \%$ agarose gel in $0.5 \mathrm{X}$ TBE buffer at $60 \mathrm{~V}$ for $40 \mathrm{~min}$ to verify presence of a single band at desired length $(\sim 1.5 \mathrm{~kb}$ for PF $16, \sim 1.8 \mathrm{~kb}$ for OCM1). In a few samples the desired band was not present, or multiple bands were present in the PCR product. In such cases, the PCR was repeated using a more robust PCR mixture containing final concentrations of $1 \mathrm{X}$ Titanium Taq buffer (with $3.5 \mathrm{mM}$ $\mathrm{MgCl}_{2}$ ), $0.2 \mathrm{mM} \mathrm{dNTPs}, 0.5 \mu \mathrm{M}$ each of forward and reverse primer, $1 \mathrm{X}$ Titanium Taq 
polymerase, and approximately $0.1-1.0 \mathrm{ng} / \mathrm{uL}$ of DNA. Reaction volume was brought up to $20 \mu \mathrm{L}$ with sterile HPLC water. The desired band was then isolated from the PCR product using E-Gel ${ }^{\circledR}$ CloneWell ${ }^{\mathrm{TM}} 0.8 \%$ SYBR Safe ${ }^{\mathrm{TM}}$ gels run in the $\mathrm{E}-\mathrm{Gel} \circledast \mathrm{iBase}^{\mathrm{TM}}$ Power System (Invitrogen).

\subsubsection{Sequencing}

Sequencing of PCR products was done with ABI Big Dye Terminator v3.1 in a reaction volume of $10 \mu \mathrm{L}$, with Big Dye Seq Mix diluted 1:8 with Seq buffer. Final concentrations of each reagent were $0.875 \mathrm{X}$ Sequencing buffer, $5 \%$ trehalose, $0.125 \mathrm{X}$ Big Dye Seq Mix, and $0.16 \mu \mathrm{M}$ primer. Reaction volume was brought to $10 \mu \mathrm{L}$ with sterile HPLC water and either $1 \mu \mathrm{L}$ of PCR product directly from initial PCR amplification or $1 \mu \mathrm{L}$ of Clonewell ${ }^{\mathrm{TM}}$ isolated PCR product was added. Forward and reverse sequences were generated for each gene using internal primers in addition to the standard PCR primers. Sequencing primers used for PF16 were ACAup13, ACAup109 (5'- ATGCAGAAYGCMGGYGTGATGCAG-3'), ACAup156 (5'CAACGTGCCVAGYATCCAGCAGTC-3'), ACAup829PP (5'GARRTYGCNAAGCACAC-3'), ACAlo800 (5'- ACRGTGTGGTCRATRTCCTTGAG3'), ACAlo854PP (5'- AGYTCNGGNGTGTGCTT-3'), ACAlo1445PP (5'GGGTARCAGTTGTTGAT-3'), ACAlo1453 (5'TCTCVGGBGGGTARCAGTTGTTGA-3'), ACAlo1472 (5'GGCGAGTAGTACTCGACGATCTC-3'). Primers designed to sequence PF16 from Aphanomyces cladogamus and A. cochlioides were ACAsapupl (5'TNCCBAGCATCCARCARTCGGCGG-3'), ACAsapup3 (5'- 
CAWYACBACMAARGGYATYGCGCC-3'), ACAsaplo1 (5'-

ACTCGACRATYTCSGGBGGGTAGC-3'), and ACAsaplo3 (5'-

SGCRCTSGCNGCCTTRATGTGGTC-3'). Sequencing primers used for OCM1 were OCM1 up124, OCM1up130B, OCMlup145B, OCM1up331 (5'-

GSSCAYTTYTAYATGGARTGCTC-3'), OCM1 up631 (5'-

TGCAARRTBGGYGTKGATCC-3'), OCM1lo643 (5'-

GGATCMACRCCVAYYTTGCA-3'), OCM1lo1842B, OCM1lo1853. Primers designed to sequence OCM1 from Pythium insidiosum and $P$. porphyrae were OCMlipup2 (5'GATCCTCRKCAACTCGCAGCA-3') and OCM1iplol (5'AGCACTCGGASACGTAGTTGTA-3'). OCM1 was sequenced from Apodachlya brachynema and Dictyuchus monosporus using their respective OCM1 PCR primers. Thermocycler program for both PF 16 and OCM1 was: $95^{\circ} \mathrm{C}$ for 3 min followed by 40 cycles of $95^{\circ} \mathrm{C}$ for $30 \mathrm{~s}, 55^{\circ} \mathrm{C}$ for $40 \mathrm{~s}, 60^{\circ} \mathrm{C}$ for $4 \mathrm{~min}$. Most sequences of LSU used in this study have been previously published, otherwise they were amplified and sequenced as previously reported (Robideau, et al., 2011).

DNA sequences were generated from sequencing amplification reactions using the ABI Prism $3130 x l$ Genetic analyzer. GenBank accession numbers of DNA sequences are found in Appendix F.

\subsubsection{Sequence assembly and alignment}

DNA sequences were assembled using Seqman (DNAStar). Introns were detected by aligning translated sequences to predicted protein sequences from the Pythium ultimum genome assembly. All detected introns contained canonical splice sites. Introns were 
removed if present and coding DNA sequences were translated using BioEdit (Hall, 1999). PF16 sequences were aligned based on amino acid sequence using ClustalW. Four isolates in the study did not yield PF16 sequences due to lack of PCR amplification. Therefore the final concatenated alignment contained only OCM1 sequences for Aphanomyces euteiches, Apodachlya brachynema, Plasmopara halstedii, and Pythium grandisporangium. OCM1 sequences were aligned by first generating a rough alignment of amino acid sequences using MAFFT (G-INS-i algorithm). The relatively conserved amino acid sequence at the 5' end of the alignment (first 212 characters) was used to generate a neighbour joining guide tree in Paup 4.0b10. Guide tree was rooted with Ectocarpus as outgroup and then converted to MAFFT format using the newick2mafft ruby script distributed by MAFFT. Guide tree was used in G-INS-i alignment of full OCM1 amino acid sequences. OCM1 amino acid alignment was reverse translated to DNA alignment using RevTrans 1.4 server (Center for Biological Sequence Analysis). Sites containing gaps in $>95 \%$ of the taxa were deleted from the OCM1 alignment. After alignment of each gene, PF16 and OCM1 alignments were concatenated for phylogenetic analysis. LSU sequences were aligned using MAFFT under default settings of G-INS-i.

\subsubsection{Sequence distances}

Amino acid distance matrices were calculated in PHYLIP using the PROTDIST v3.68 program under the Jones-Taylor-Thornton mutation matrix. Mean amino acid distances including standard deviation were calculated from intraspecific and interspecific pairwise comparisons. Intraspecific amino acid distances were calculated for Phytophthora infestans (3 isolates), Phytophthora sojae (6 isolates), Pythium irregulare 
(6 isolates), and Pythium oligandrum (3 isolates). Interspecific distances were calculated by comparing each of the above mentioned species with the two closest relatives included in this study. Mean amino acid distance of the entire dataset was also calculated from interspecific pairwise comparisons of all isolates. DNA distance matrices were calculated in PHYLIP using the DNADIST v3.68 program under the Kimura 2-parameter model. Mean DNA distance was calculated from interspecific pairwise comparisons of all isolates.

\subsubsection{Phylogenetic inference and distribution of selection coefficients}

We used the site-heterogeneous mutation-selection model based on the Dirichlet process (Rodrigue, et al., 2010), implemented in the MPI version of PhyloBayes (Lartillot et al., submitted), to infer the phylogeny based on the concatenation of the PF16 and OCMl genes. We ran two independent Markov chain Monte Carlo calculations for 11,000 cycles (each including multiple updates on the tree topology, branch lengths, and substitution model parameters), discarded the first 1,000 draws as burn-in, and used the remaining to obtain the $60 \%$ consensus tree. The largest discrepancy of bipartition frequencies between each independent chain (maxdiff) was $\sim 0.2$, meaning the two chains had reached reasonable convergence (Lartillot, et al., 2009).

The mutation-selection model utilized allows for the calculation of site-specific distribution of selection coefficients of mutations at stationarity under the evolutionary process (see, e.g., Yang \& Nielsen, 2008). We averaged these distributions across sites of the PF16 and OCM1 segments of the alignment separately, in order to summarize the strength of selection operating on each gene. 
PF16-OCM1 phylogenies were also constructed using nucleotide and amino acid substitution models in Phylobayes 3.3b (Lartillot, et al., 2009). The PF16-OCM1 alignment was analyzed in both nucleotide and amino acid form under the CAT-GTR model by running two simultaneous chains. Constant sites were deleted, and sites containing gaps for $>95 \%$ of the taxa were also deleted. In both the nucleotide and amino acid analyses, the maxdiff was below 0.2 . The burn-in used to create the consensus tree was $1 / 5^{\text {th }}$ of the total cycles. The total number of cycles was 9000 in the nucleotide analysis, and 4500 in the amino acid analysis. LSU phylogeny was constructed using maximum likelihood with Phyml 3.0 (Guindon, et al., 2010) under the GTR model with default settings and bootstrap analysis of 1000 replicates. Additional support of maximum likelihood tree topology was obtained by Bayesian MCMC sampling using Phylobayes. LSU alignment was analyzed under the CAT-GTR model by running two simultaneous chains until the largest discrepancy of bipartition frequencies between the two independent runs was below 0.3 . The burn-in used to create the consensus tree was $1 / 5^{\text {th }}$ of the total 6000 cycles.

\subsubsection{Evolutionary rate of codon positions}

Evolutionary rates of each codon position in PF16 and OCM1 were calculated in MEGA5. The rates were scaled such that the average evolutionary rate across all sites was 1 , meaning that sites showing a rate $<1$ are evolving slower than average, and those with a rate $>1$ are evolving faster than average. These relative rates were estimated under the General Time Reversible model. Mean evolutionary rate of each codon position in 
each gene was determined and rate comparison between genes was performed by unpaired t-test.

\subsection{Results}

\subsubsection{Comparative genomics and P. ultimum flagellar gene expression}

The 43 megabase genome of Pythium ultimum contains over 15,000 genes (Lévesque, et al., 2010).Overall, approximately 80 putative whiplash and tinsel flagellum gene orthologs were identified in $P$. ultimum, with corresponding orthologs present in $P$. infestans, $P$. sojae, and $P$. ramorum (Appendix E). Putative orthologs were defined as those yielding a tBLASTn expect value (E-value) less than $1.0 \mathrm{E}^{-10}$. The E-value describes the likelihood that another sequence of equivalent match will occur in the database by chance. Low E-values therefore indicate significant matches. Most flagellar genes were absent in $H$. arabidopsidis as evidenced by the relatively high $\mathrm{E}$-value for most flagellar gene queries. Gene expression analysis of $P$. ultimum flagellar orthologs in zoosporeinducing growth conditions of hypoxia and Arabidopsis infection showed that many flagellar orthologs were expressed under these conditions, although several putative flagellar orthologs for axonemal dynein and kinesin and intraflagellar transport did not show expression (Appendix E). Expression was quantified by the RPKM value, which is assumed to have a positive correlation to the level of expression, and a value of zero indicates no detectable expression.

Significant matches to OCM1 and PF16 were found in all the oomycetes searched except $H$. arabidopsidis. These genes were found to be particularly amenable to further phylogenetic study due to their length, apparent lack of introns, and conserved terminal 
sequences. This enabled design of PCR primers which amplified nearly the entire genes from a wide variety of oomycetes.

\subsubsection{Primer performance}

The standard PF 16 primers were very robust in Pythium, Phytophthora, Halophytophthora, Phytopythium, Dictyuchus, Lagenidium, and Myzocytiopsis. These primers were less robust in Achyla, Aphanomyces, and Saprolegnia, amplifying some but not all species attempted. The primers did not amplify PF 16 from Apodachlya or Plasmopara. Similar to PF16, the standard OCM1 primers were generally robust in Pythium, Phytophthora, Halophytophthora, Phytopythium, Lagenidium, and Myzocytiopsis, although some Phytophthora, Phytopythium and Pythium species did not amplify. Interestingly, the standard OCM1 primers yielded robust amplification of Aphanomyces and Plasmopara. They amplified some but not all species attempted from Achyla and Saprolegnia. The primers did not amplify OCM1 from Apodachlya or Dictyuchus. Amplification of OCM1 and PF16 from Albugo was not attempted, as the sequences used in this study were obtained from whole genome sequencing. The complete list of isolates used along with DNA sequence accessibility information is shown in Appendix F.

\subsubsection{Sequence features}

As determined from the available genome sequences, the predicted amino acid sequence length of PF16 was uniform at 509 amino acids among all species. The predicted sequence length of OCM1 in contrast was variable, ranging from 551 to 706 
amino acids. The length variation occurred predominantly in the $\mathrm{C}$-terminal half of the OCM1 amino acid sequences. Sequence alignments of PF16 and OCM1 are depicted in Appendix G. N-terminal signal peptides were not present in PF16 sequences, but were identified in each genomic OCMl sequence using the SignalP 4.0 server (Petersen, et al., 2011). Size of the OCM1 signal peptide sequences ranged from 17 to 27 amino acids. Stop codons in PF16 or OCM1 were found in three species of Pythium. A stop codon was present in the reading frame of PF16 from Pythium splendens and Pythium rhizosaccharum, as well as in the reading frame of OCM1 from Pythium violae. Predicted introns were present in the PF16 sequences of both Achlya spp., Dictyuchus monosporus, all three Saprolegnia spp., Ectocarpus siliculosus, and Aphanomyces astaci.The full genomic PF16 sequence of Ectocarpus contained 11 predicted introns, whereas the PCR amplified partial PF16 sequences of the other species contained two predicted introns, occurring at the same amino acid positions in each species. Predicted intron presence in OCM1 was limited to Ectocarpus siliculosus and Aphanomyces astaci. The full genomic OCM1 sequence of Ectocarpus contained 5 predicted introns, whereas the PCR amplified partial OCM1 sequence of $A$. astaci contained only one predicted intron. The amino acid sequences of PF 16 and OCM1 were searched for conserved protein domains using InterProScan 4.8 (European Bioinformatics Institute). PF16 contained Armadillo repeats whereas OCM1 contained four Epidermal Growth Factor like (EGF) domains. A representative diagram of PF16 and OCM1 amino acid sequences including relative positions of PCR primers is shown in Figure 4.1. The percent homology among the repeats within the different sequences was not determined. 


\subsubsection{Sequence evolution}

Estimations of distributions of selection coefficients under the mutation-selection model indicate that PF16 is evolving under stronger purifying selection than OCM1 since the distribution of scaled selection coefficients for PF16 is centered at a lower value of S than that of OCM1 (Fig. 4.2). The majority of codon sites in each gene are subject to purifying selection $(S<0)$, but the values of $S$ were distributed closer to 0 in $O C M 1$. The mean rates of nucleotide evolution at the first and second codon positions were significantly higher in OCM1 than in PF16 $(\mathrm{p}<0.0001)$. Conversely, the mean rate of evolution at the third codon position was significantly higher in PF16 $(\mathrm{p}<0.0001)$. The rate of evolution within each gene was significantly different between all codon positions $(\mathrm{p}<0.0001)$ (Fig. 4.3).

\subsubsection{Species delimitation}

Interspecific sequence distances were higher in OCMI than in PF16. The mean interspecific amino acid distance in OCM1 was 1.354 versus 0.097 in PF16. The mean interspecific nucleotide distance in OCM1 was 0.79 versus 0.223 in PF16. The amino acid sequences of PF16 were highly conserved within and between species, meaning the utility of PF 16 in species delimitation is limited to the DNA sequence level. Amino acid sequences of OCM1 were highly conserved within species, but varied significantly between species (Fig. 4.4), showing that OCM1 is a useful marker of species boundaries in oomycetes at both the amino acid and DNA level. 


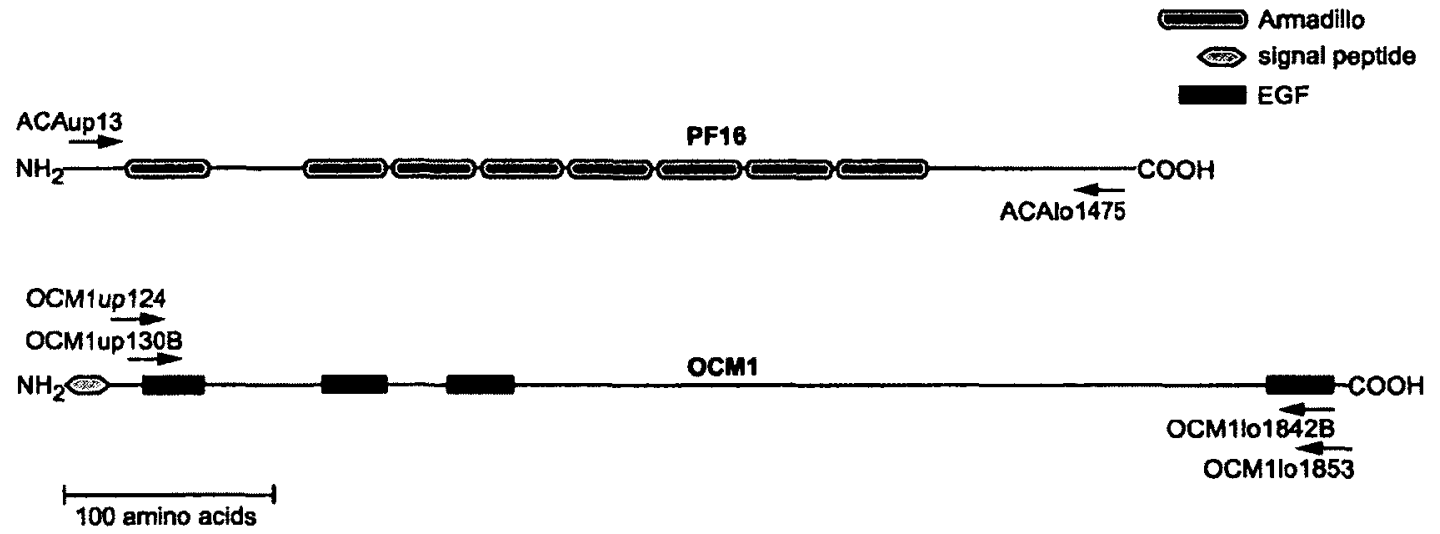

Figure 4.1. Schematic illustration of PF16 and OCM1 protein sequences displaying conserved protein domains and relative positions of PCR primers. 


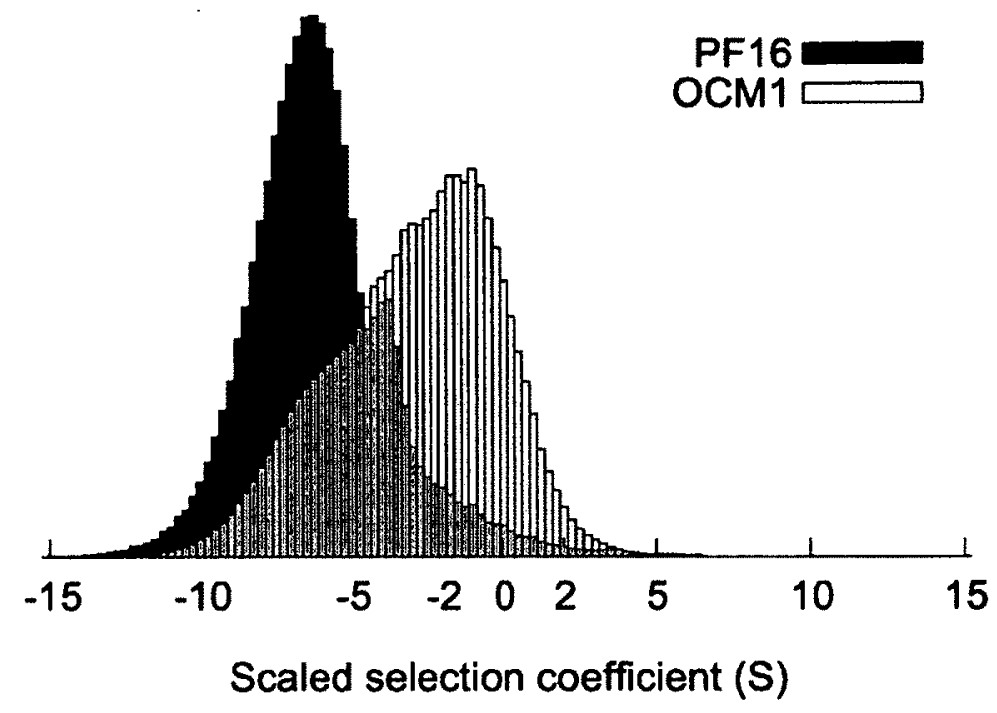

Figure 4.2. Distribution of scaled selection coefficients (S) from sequence alignments of PF16 and OCM1. 


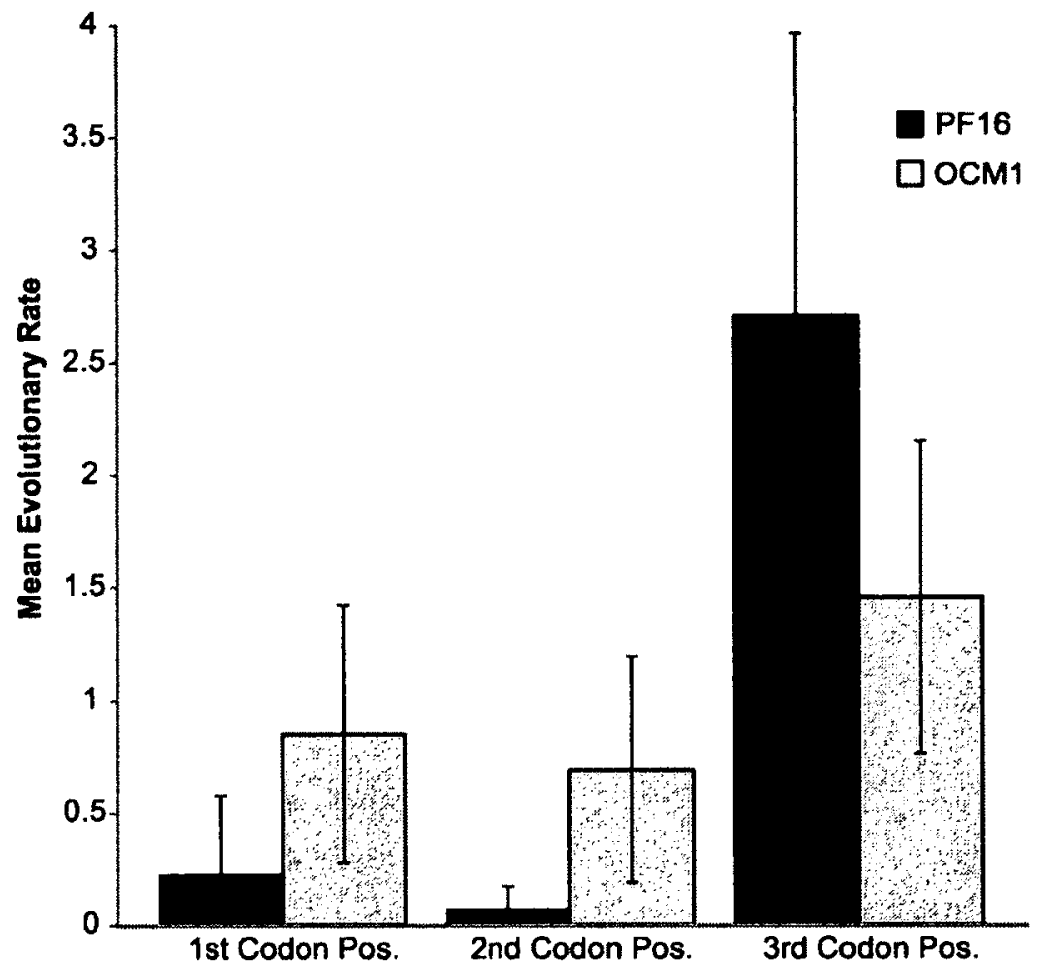

Figure 4.3. Mean evolutionary rate of each codon position in PF16 and OCM1. Difference between PF16 and OCM1 was significant $(p<0.0001)$ at all three codon positions. Error bars represent standard deviation of evolutionary rate among sampled codons. 


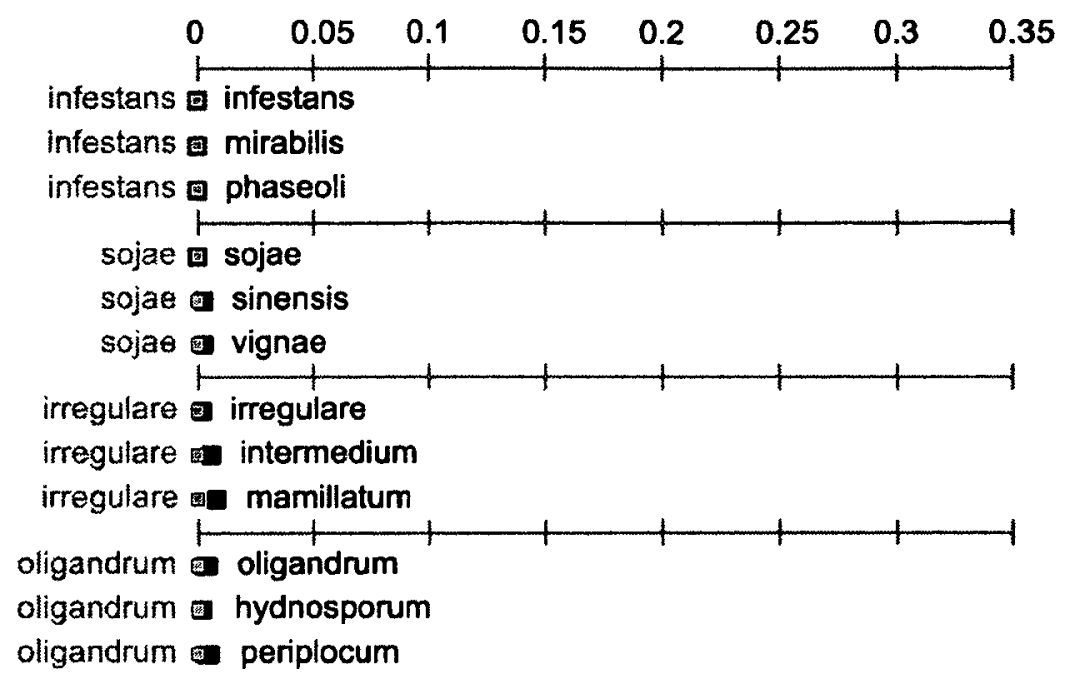

B

OCM1 Amino Acid Distance

infestans infestans

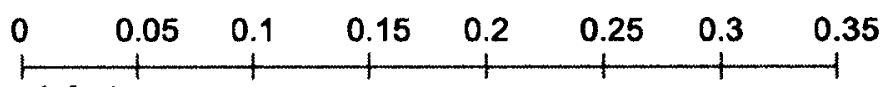

infestans $\bullet$ mirabilis

infestans o phaseoli

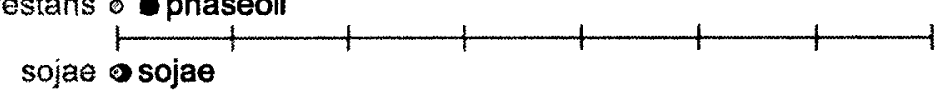

sojae - sinensis

sojae

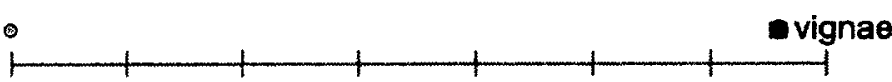

irregulare irregulare

irregulare $\odot \quad$ intermedium

oligandrum $\stackrel{\circ}{\text { irregulare oligandrum }}$

oligandrum $\bullet \bullet$ hydnosporum

oligandrum $\bullet \quad \bullet$ periplocum

Figure 4.4. Intraspecific and interspecific amino acid distances of PF16 (A) and OCM1 (B). Distances are represented by the distance between grey and black symbols in each pairwise comparison. Scale indicates the fraction of amino acids differing in pairwise sequence alignments. Each displayed distance is an average over pairwise comparisons of multiple isolates from each species and standard deviations are shown with error bars. Only species names are displayed. The species infestans, sojae and their interspecific counterparts are members of the genus Phytophthora. The species irregulare, oligandrum and their interspecific counterparts are members of the genus Pythium. 


\subsubsection{Phylogeny reconstruction}

The Bayesian phylogram produced by the codon-based mutation-selection model using PF16 and OCM1 showed clade structures that reflect zoospore ontology (Fig. 4.5). The distinction between zoospore dimorphism and monomorphism is evident, as is the difference between monomorphic taxa whose zoospore cleavage is intrasporangial versus extrasporangial. Sporangial morphology of Pythium species is also represented in the tree topology, and the suppression of zoospore production in Pythium species is confined to the globose sporangia clade. The overall topology of the PF16-OCM1 tree is comparable to that of the LSU tree (Fig. 4.6), which represents the currently accepted view of oomycete organismal evolution. The genera Aphanomyces, Phytophthora, and Pythium have been previously divided into phylogenetic clades (Lévesque $\&$ de Cock, 2004, Blair, et al., 2008, Dieguez-Uribeondo, et al., 2009), which are represented in the codon model PF16-OCM1 tree. Compared to the codon model tree, the PF16-OCM1 trees constructed by nucleotide and amino acid substitution models introduced alternative clade structures and polyphyly into the tree topology (Fig. 4.7). 


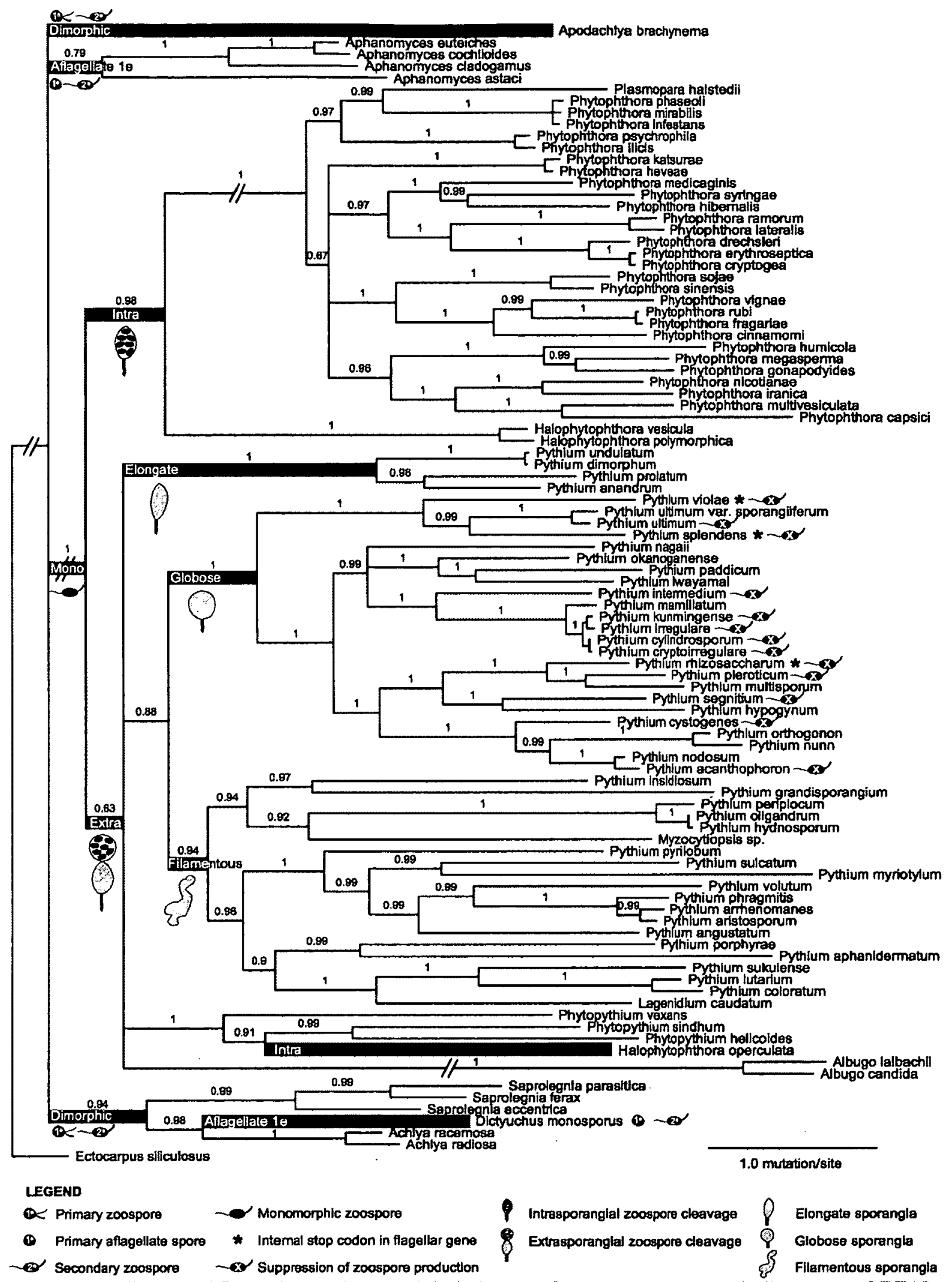

Figure 4.5. Illustrated Bayesian codon model phylogram from a concatenated alignment of PF16 and OCM1 DNA sequences. Posterior probabilities are displayed along branches. Branches with posterior probability $<0.6$ have been collapsed. 


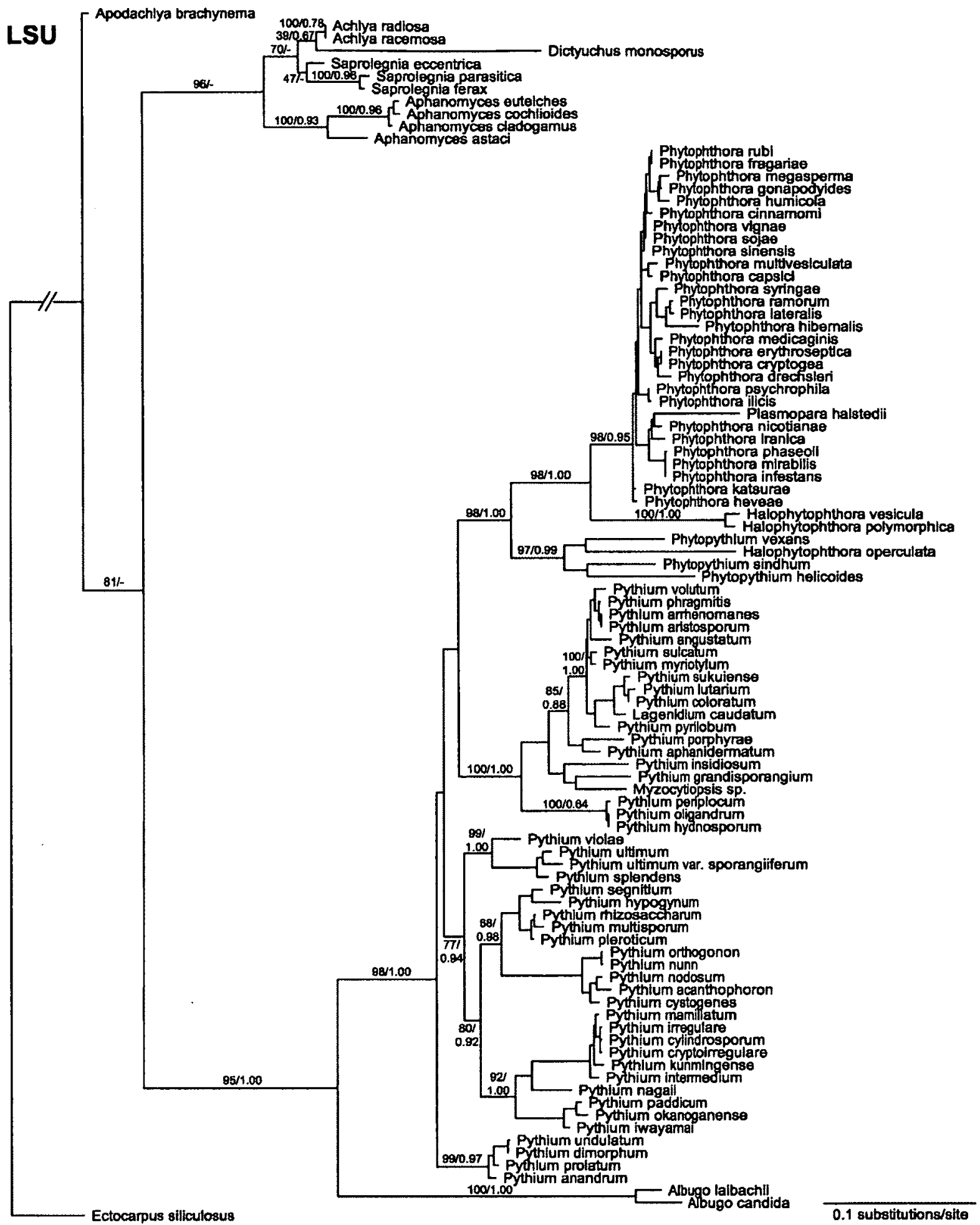

Figure 4.6. Phylogram reconstructed from LSU sequences of each species represented in the study. Tree is based on maximum likelihood analysis, with major nodes showing support values from maximum likelihood bootstrap/bayesian posterior probability. 
A) Codon substitution model

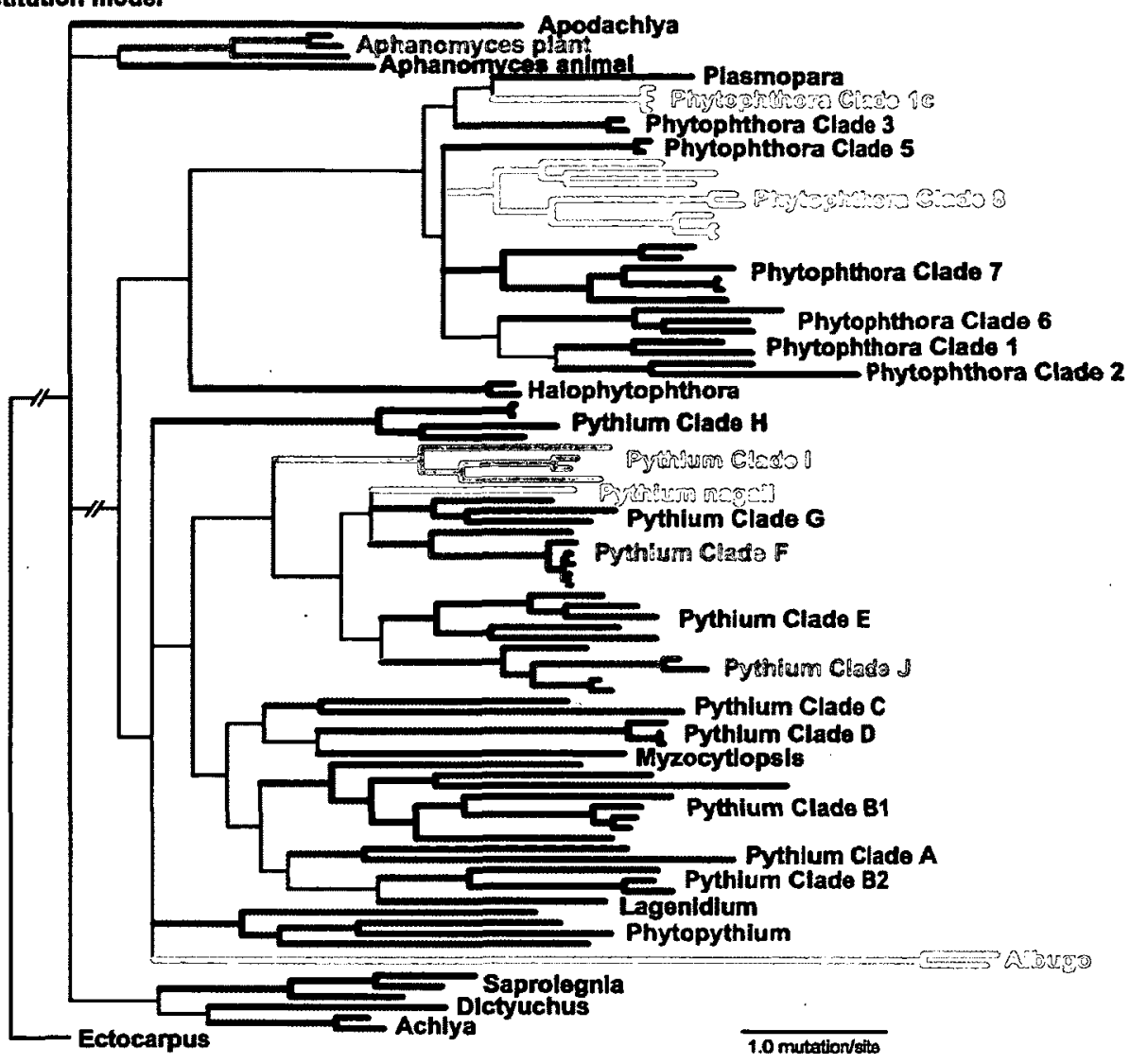

B) Amino acld substitution model

C) Nucleotide substitution model
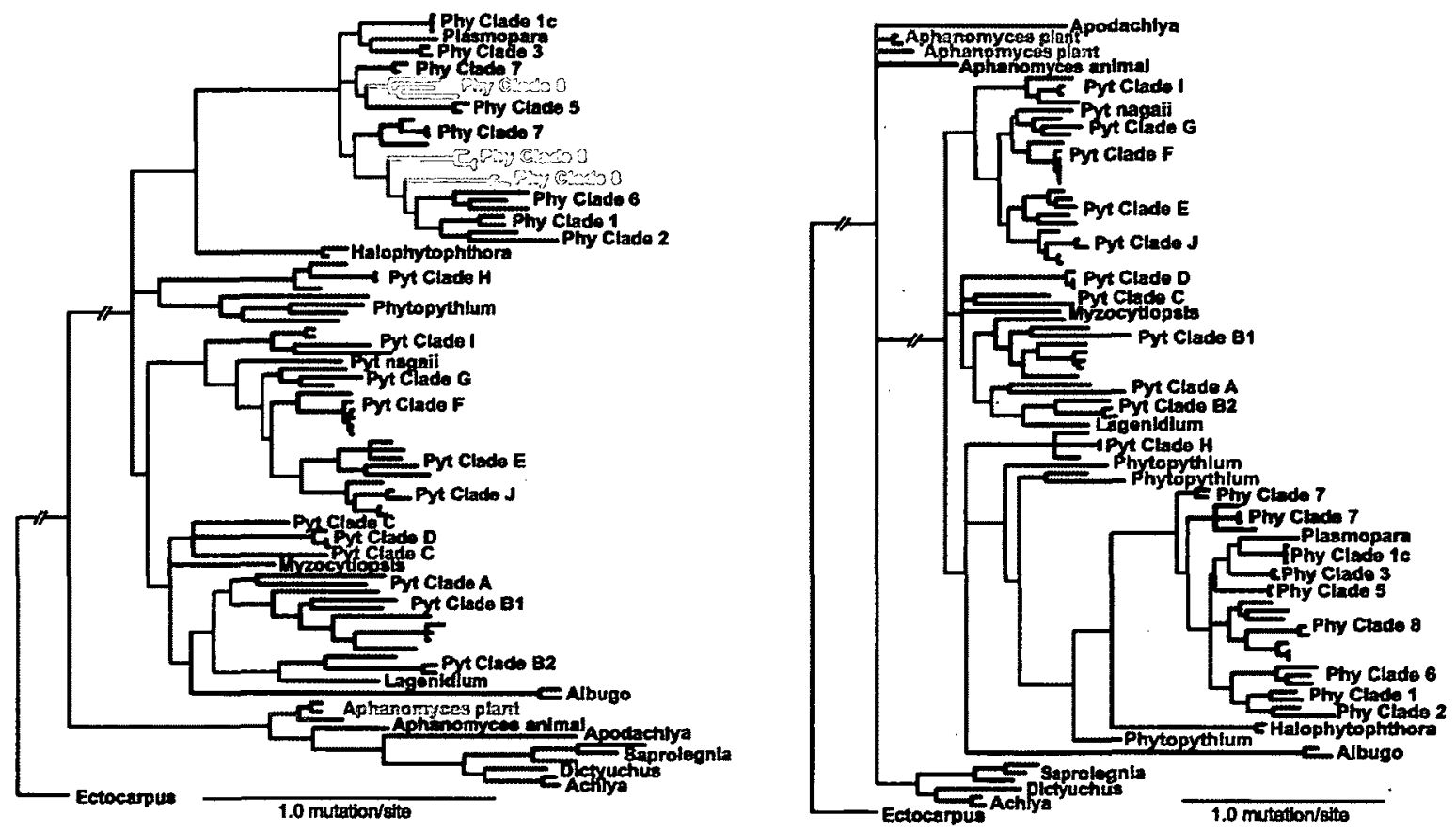

Figure 4.7. Colour-coded comparison between codon (A), nucleotide (B), and amino acid (C) Bayesian substitution model phylogenies from concatenated alignment of PF16 and OCM1. Grey branches in $B$ and $C$ represent unchanged clades with respect to $A$. Coloured clades in $B$ and $C$ represent clades where polyphyly is introduced in nucleotide and amino acid models. 


\subsection{Discussion}

\subsubsection{Overview}

Through comparative genomics and identification of putative oomycete flagellar genes in Pythium and Phytophthora, this study introduces novel protein-coding taxonomic markers to oomycete systematics. Previous studies have used nuclear proteincoding markers to study either a single genus (Blair, et al., 2008) or to study several modestly sampled genera (Blum, et al., 2012). Presented here is the first report of using protein-coding nuclear genes to study molecular evolution across a broad range of wellsampled oomycete genera. Also demonstrated is the utility of a recently developed codon-based model for studying long-range patterns of molecular evolution (Rodrigue, et al., 2010). The biological realism of codon substitution modeling is shown by the congruence between reproductive morphology and flagellar gene evolution. The accuracy of the codon model in phylogenetic reconstruction is also demonstrated by the congruence of the codon model tree with well-established theories of oomycete evolution. In addition to systematic and phylogenetic analyses, the molecular evolution of PF16 and OCM1 was examined to provide context to the discussion of their known and plausible functions.

\subsubsection{Pythium ultimum flagellar gene repertoire}

P. ultimum does not typically exhibit release of zoospores from sporangia in culture (van der Plaats-Niterink, 1981) but zoospore release directly from aged oospores has been reported (Dreschler, 1946). Comparative genomics with well studied whiplash 
flagellar proteins from the green algae Chlamydomonas reinhardtii and other model organisms indicates that indeed $P$. ultimum does have the necessary genetic complement for flagella. Orthologs of tinsel flagellar mastigoneme proteins have also been identified in P. ultimum through comparison to those studied in the golden alga Ochromonas danica.

\subsubsection{Phylogram topology and zoospore ontology}

Asexual reproduction via the release of zoospores from sporangia is arguably the most informative and defining morphological feature of oomycetes (Sparrow, 1960, Johnson, et al., 2002). The phylogram reconstructed from our analysis displays congruence between flagellar gene evolution and zoospore ontology in oomycetes (Fig. 4.5). Such a connection between genotype and phenotype has been previously shown in primates, where the evolution of a semen gene is significantly associated with mating systems (O'Connor \& Mundy, 2009). Similarly, the molecular evolution of tissue-specific genes in chordates correlates well with the fossil record of morphological tissue evolution (Iwabe, et al., 1996). Correlation of genotypic and phenotypic changes in phylogenetic reconstruction is recognized as a means for detecting functionally evolving genes such as those involved in disease resistance (Habib, et al., 2007) or viral phenotype (Parker, et al., 2008), so the evolution of flagellar genes in our study may reflect a functional evolution of PF 16 and/or OCM1.

\subsubsection{Evolution and function of PF16 and OCMI}


The two flagellar genes in our study have been shown to differ in their patterns of molecular evolution. These genes are located on disparate genomic scaffolds, which precludes genetic linkage and implies independent assortment. Despite their differing evolutionary patterns, concatenation of PF16 and OCM1 genes was considered appropriate for analysis with the mutation-selection model and the CAT-GTR model due to the fact that these models account for heterogeneity of the amino acid and nucleotide replacement process across the positions of an alignment, therefore accounting for the heterogeneous regimes of selection that would occur in the concatenated alignment. PF16 is predicted to be highly conserved at the amino acid level, which was evident in the low rates of DNA sequence evolution in the first and second codon positions. The third codon position of PF16 had a much higher rate of evolution, which is expected in genes that are subject to purifying selection since variation at the third codon position can occur with less impact on the amino acid translation (Graur $\& \mathrm{Li}, 2000$ ). It is not surprising that PF16 is under such constraint, given that this protein has an essential role in flagellar bending and is an integral component of the flagellar axoneme, a structure which has been highly conserved over the course of eukaryotic evolution (Inaba, 2011). In contrast to PF16, OCM1 is predicted to be highly variable at the amino acid level. This translated into a scaled selection coefficient distribution with values of $\mathrm{S}$ around 0 , implying that OCM1 is under relaxed selection. Relaxed selection is a process by which the constraint on genetic mutation is relaxed, allowing divergence to occur. This is different than positive selection, where advantageous mutations are selectively fixed. Under relaxed selection, neutral mutations are more likely to become fixed. Relaxed selection can be the result of gene duplication, whereby the functional redundancy of a duplicated gene 
permits mutation, and the mutation may ultimately lead to new interactions of the duplicated gene, causing renewed selective pressure favouring synergistic interactions of the mutated duplicate gene (Deacon, 2010). Relaxed selection therefore contributes to phenotypic plasticity, and genes evolving under relaxed selection are more likely to be differentially expressed between developmental stages (Hunt, et al., 2011). The stagespecific expression of OCM1 during asexual sporulation (Randall, et al., 2005) is therefore a trait that this gene shares with other genes evolving under relaxed selection. If OCM1 is subject to relaxed selection, this brings into question the true function of this protein in oomycetes. Early work on tinsel flagellum mastigonemes had concluded that they are mechanical appendages, responsible for reversal of thrust to propel zoospores forward (Markey \& Bouck, 1977, Cahill, et al., 1996). Further investigation showed calmodulin to be present in tinsel flagella of Phytophthora (Gubler, et al., 1990), implying that tinsel flagella may function somehow in calcium signaling. Such signaling could be an indication of a sensory or recognition capacity of tinsel flagella. The ortholog of OCM1 in the diatom Thalassiosira is thought to be involved in gamete recognition (Armbrust \& Galindo, 2001), and the tinsel flagella of brown algae zoospores are involved in substrate binding (Toth, 1976), while the tinsel flagella of spermatozoids are involved in attachment to the egg surface (Friedmann, 1961). Therefore, it is plausible that OCM1 could be involved in host recognition and/or attachment in oomycete zoospores. The presence of multiple EGF domains in OCM1 also implies this, as the EGF domain is commonly found in extracellular proteins and is involved in cell recognition (Campbell, et al., 1990). Recent work has been done to characterize a mastigoneme 
protein in Phytophthora (Blackman, et al., 2011), but more research is required to further elucidate the role of tinsel flagella and mastigoneme proteins in the oomycete zoospore.

\subsubsection{Oomycete systematics}

From a systematics standpoint, the evolution of PF16 and OCM1 as modeled here (Fig. 4.5) is in general accord with the views of oomycete evolution, and the tree sustains previously determined clade organization within the genera Aphanomyces, Phytophthora, and Pythium (Lévesque \& de Cock, 2004, Blair, et al., 2008, Dieguez-Uribeondo, et al., 2009). A broad phylogeny of oomycetes using additional protein coding genes still remains to be constructed, since additional genes can alleviate stochastic error caused by lack of signal in the dataset (Rokas \& Carroll, 2005). A multigene approach has been used with success in the oomycete genus Phytophthora (Blair, et al., 2008), but difficulty in amplifying these protein coding genes, even within Phytophthora, is a limiting factor that applies to multigene phylogenies in general. One reason why LSU has proven so useful in phylogenetic studies is its ease of amplification from diverse taxa. Now that PF16 and OCM1 sequences have been obtained from diverse oomycete taxa, our tree illustrates some notable points to consider with respect to current views. The placement of Albugo as a sister clade to Pythium does not agree with the LSU placement of Albugo as an early-diverging Peronosporomycete genus which has been circumscribed to a separate order (Thines \& Spring, 2005). This is possibly due to long-branch attraction in the dataset. Addition of another early-diverging genus to the dataset such as Sapromyces may have been able to alleviate such long-branch attraction, but attempts to sequence PF16 and OCM1 from Sapromyces elongatus were unsuccessful. Also of note is the 
placement of Phytopythium as a sister clade to Pythium (Pythiaceae). This is in contrast to Phytopythium's recent assignment to the family Peronosporaceae (Hulvey, et al., 2010). Although Phytopythium does share extrasporangial zoospore cleavage with the Pythiaceae, it has other characteristics such as papillate sporangia that support its inclusion in the Peronosporaceae. Our analyses placed Halophytophthora operculata within Phytopythium, affirming the known polyphyletic nature of the genus Halophytophthora, but $H$. operculata actually exhibits Phytophthora-like intrasporangial zoospore cleavage rather than the extrasporangial zoospore cleavage seen in other Phytopythium species. This further exemplifies the true intermediary nature of the genus Phytopythium between Phytophthora and Pythium. Like Phytopythium, Clade H Pythium species are represented as a sister clade to the rest of the genus Pythium. This is underlain by the unique sporangial morphology of Clade $\mathrm{H}$, which led to its recent proposition as a new genus Elongisporangium (Uzuhashi, et al., 2010). Another interesting observation in Fig. 4.5 is the suppression of zoospore production in many species of Pythium within the globose sporangia clade. This is exemplified by the apparent loss of function of PF16 or OCM1 in a few members of this clade, implied by the presence of internal stop codons in these genes. Ecological studies of Pythium have shown that freshwater habitats are dominated by species of Pythium with filamentous sporangia (Hallett \& Dick, 1981, Abdelzaher, et al., 1995), whereas terrestrial habitats are dominated by Pythium species with globose sporangia (Ali-Shtayeh, et al., 1986). Apparently the transition of globose Pythium species to a terrestrial lifestyle has lessened their dependency on zoospore dissemination to find suitable hosts or substrates. Such evolution and flexibility of dissemination strategies is common in oomycetes (Jeger \& Pautasso, 2008). The amino 
acid sequences of the flagellar genes containing internal stop codons have not significantly diverged from those of closely-related zoospore-producing species, indicating that these mutations probably occurred recently on an evolutionary timescale. In the phylogenetic framework of the mutation-selection model used in the current study, the mutation of an amino acid to a stop codon violates the assumption that the regime of purifying selection at a coding site is constant over time, although this violation appears to be confined to the individual stop codon sites since sites surrounding the stop codons have not significantly diverged.

In terms of the utility of flagellar genes for species delimitation, OCM1 is clearly a useful addition to the oomycete molecular toolbox, showing low intraspecific variation coupled with high interspecific variation. PF16 also has low variability within species, and its DNA variation between species is at par with that of currently utilized DNA barcodes for oomycetes (Robideau, et al., 2011). Although OCM1 and PF 16 are not always as easily PCR-amplified as the barcodes COI and ITS, they do have potential as markers of asexual sporulation in mRNA sequencing/detection assays. The expression of these genes in Phytophthora infestans has been shown to occur within developing sporangia, and is induced by nitrogen starvation (Randall, et al., 2005), a condition which is expected to encourage dissemination of zoospores. This stage-specific expression of PF 16 and OCM1 could be applicable in monitoring asexual sporulation in the field or greenhouse. For example, the transcription profile (transcriptome) of a diverse oomycete population could potentially be probed using PF16 and OCM1 primers to determine the conditions where species of interest are releasing zoospores, thereby creating disease pressure. 


\subsubsection{Conclusion}

The molecular evolution of PF16 and OCM1 provides new insight into oomycete systematics and the evolution of flagellar function in oomycetes. There is potential for these novel molecular markers in future research, as we have demonstrated that PF16 and OCM1 are useful taxonomic and phylogenetic markers whose stage-specific expression in the life cycle could be applicable to studies of oomycete epidemiology. These flagellar genes are expected to be present in the genomes of all zoospore-producing oomycetes, and they can be amplified from a wide range of oomycete genera using the PCR primers introduced here. This study also provides a compelling argument for continued development and implementation of codon model-based phylogenetic tools, which may enable the exploitation of protein-coding genes previously determined to be phylogenetically unreliable. 


\section{Chapter: INVESTIGATION OF THE POSSIBLE ROLE OF OOMYCETE FLAGELLAR PROTEIN AND PLANT C-TYPE \\ LECTIN IN HOST-PATHOGEN INTERACTION}

\subsection{Introduction}

The plant infection process of oomycete zoospores is a subject of intense interest from two standpoints: how zoospores find host plants in the environment, and how the host is penetrated at the early stage of infection. The former point involves chemotactic and electrotactic zoospore behaviour, while the latter point involves zoospore cyst adhesion and gene-for-gene interaction with the host. Zoospores are known to exhibit directional movement towards concentrated chemical compounds that are found in root exudate such as amino acids, polysaccharides, and organic compounds (Bimpong \& Clerk, 1970, Donaldson \& Deacon, 1993, Rand \& Munden, 1993, Tyler, et al., 1996, Leano, et al., 1998). They are also known to migrate towards weak electric fields such as those generated by plant roots in the rhizosphere (Morris \& Gow, 1993, van West, et al., 2002). Upon reaching a suitable host, zoospores swim in close contact to the host before they adhere and encyst on the surface of the host. Adhesion and encystment involves orientation of the zoospore such that the ventral surface from which the flagella emerge is in contact with the host (Hardham \& Gubler, 1990). Flagella are then shed or retracted (Reichle, 1969), and vesicles containing adhesive compounds are extruded from the ventral surface while the cyst wall is formed (Sing \& Bartnicki-Garcia, 1975, Robold \& Hardham, 2005). The orientation of zoospores prior to docking on a host is such that the flagella are expected to be in contact with the host before adhesion and encystment occur. Zoospore flagella have been observed in contact with host stomata in a study of the 
downy mildews Plasmopara and Pseudoperonospora (Royle \& Thomas, 1973), so it is plausible that zoospore flagella are involved in a signalling process whereby a suitable docking site on a host is sensed by the flagella, triggering the encystment process. Sensory functions of microbial flagella are well known (Mitchell, 2007, Maric, et al, 2010), and the significant presence of calmodulin in the tinsel flagellum of Phytophthora indicates that this organelle may indeed have a sensory role (Gubler, et al., 1990) since calmodulin is involved in proper functioning of sensory hair cells (Seiler \& Nicolson, 1999), chemosensory organs (Spehr, et al., 2009), and sensory neurons (Milikan, et al., 2002).

The heterokont tinsel flagellum is somewhat of a mystery compared to the wellstudied whiplash flagellum commonly found in eukaryotes. Studies of tinsel flagellum function have been sparse, implying the mechanical nature of this appendage in zoospore motility (Markey \& Bouck, 1977, Cahill, et al., 1996), but also implying the role of the tinsel flagellum in substrate attachment and encystment (Friedmann, 1961, Toth, 1976, Hardham \& Suzaki, 1986, Jones, et al., 1991). Recently, four mastigoneme proteins from the tinsel flagellum of golden algae were isolated and characterized (Yamagishi, et al., 2007, Yamagishi, et al., 2009), providing much needed molecular evidence of tinsel flagellum composition. Orthologues of three of the four golden algae proteins, OCM1, OCM2, and OCM4, are found in oomycetes. It is assumed that these predicted mastigoneme proteins are extracellular, since the mastigonemes of golden algae are found on the surface of the flagellum (Bouck, 1971). The oomycete orthologues contain epidermal growth factor (EGF) - like domains and share similarity with vertebrate tenascin proteins. Tenascins are extracellular matrix glycoproteins with various functions, 
one of which involves calcium-mediated interaction with C-type lectins (Aspberg, et al., 1995, Aspberg, et al., 1997, Lundell, et al., 2004). If the tinsel flagellum is somehow involved in host recognition, then perhaps the tenascin-like proteins of the mastigonemes are involved in an interaction with host C-type lectin.

C-type lectins are calcium-dependent carbohydrate-binding proteins which selectively bind a wide variety of ligands in the presence of calcium (Zelensky \& Gready, 2005). C-type lectins are particularly well known for their role in immune systems (Weis, et al., 1998). C-type lectins are responsible for pathogen detection and the initiation of immune response, but in some cases these lectins are targeted by pathogens as a binding site for entry into the host (Alvarez, et al., 2002, Takada, et al., 2004, de Witte, et al., 2006, Gunn, et al., 2012). While there are many different C-type lectins found in animals, plants typically contain only one or two C-type lectins (Jiang, et al., 2010) whose function in the plant is currently unknown (Bouwmeester \& Govers, 2009). Plant C-type lectins consist of an extracellular C-type lectin domain, a transmembrane helix, and an intracellular kinase domain. In Arabidopsis thaliana there is only one predicted C-type lectin. A representative diagram of the A. thaliana C-type lectin is given in Figure 5.1.

The hypothesis that plant C-type lectin is targeted as a binding site by oomycete zoospores is plausible and is substantiated by the fact that during the encystment process, zoospores extrude calcium (Irving \& Grant, 1984), which would be necessary for binding with C-type lectin. Recognition of C-type lectin by zoospores may also enable differentiation between host and non-host plants, since lectins have long been suggested as determinants of host specificity (Sequeira, 1978). To test the hypothesized interaction between oomycete mastigoneme protein and plant C-type lectin, several experiments 
have been performed involving purification of recombinant OCM1 protein from Pythium aphanidermatum, as well as recombinant C-type lectin from cucumber Cucumis sativus and wheat Triticum aestivum. Recombinant OCM1 protein was used to treat cucumber seedlings to induce a potential defense response. Recombinant C-type lectin from cucumber and wheat were used to test a possible interaction with zoospores of Pythium aphanidermatum and Pythium arrhenomanes, under the assumption that zoospores of these two species would react differentially to the two lectins since $P$. aphanidermatum is more aggressive on cucumber whereas $P$. arrhenomanes is more aggressive on wheat. A transgenic Arabidopsis thaliana knockout line lacking C-type lectin expression was also employed in pathogenicity trials to assess susceptibility to infection by $P$.

aphanidermatum zoospores. The experiments described herein test the hypotheses that A) OCM1 may be involved in host-pathogen interaction, and therefore may be recognized by the plant host, inducing a host response, B) plant C-type lectin may be recognized by oomycete zoospores, inducing encystment, possibly in a host-specific manner, C) this recognition may be mediated by OCM1 interaction with C-type lectin, and D) the lack of C-type lectin in a host plant may decrease susceptibility to zoospore infection. 


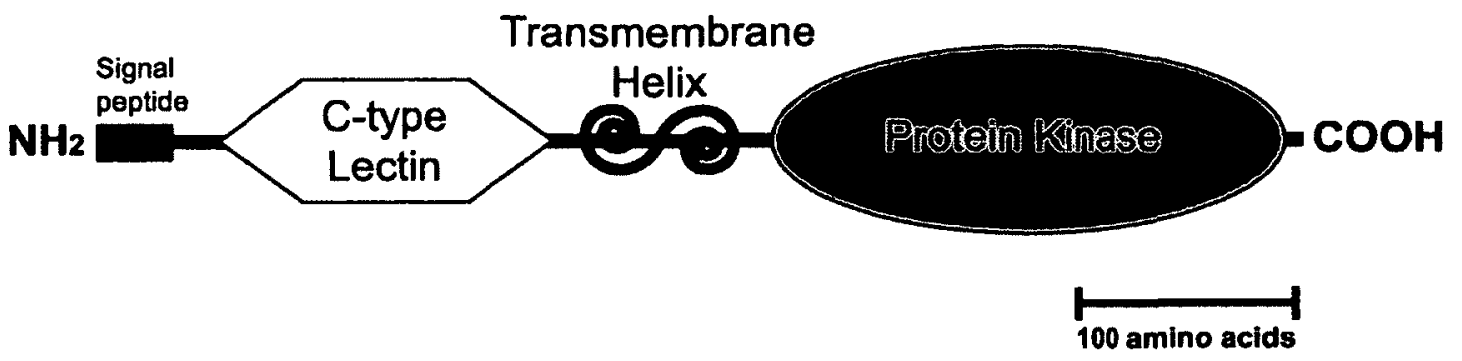

Figure 5.1. Schematic illustration of Arabidopsis thaliana C-type lectin gene. 


\subsection{Materials and Methods}

\subsubsection{Pythium cultures and zoospore production}

Pythium aphanidermatum isolate DAOM BR 444 was grown on $2.5 \%$ V8 vegetable juice agar and Pythium arrhenomanes isolate CBS 324.62 was grown on corn meal agar (CMA). For zoospore production, two agar plugs were transferred to a petri dish containing sterile distilled water and several autoclaved grass blades. Petri dishes were incubated at room temperature under ambient light for 3 days to allow colonization of grass blades. Colonized grass blades were removed from petri dishes, rinsed in sterile distilled water, and single grass blades were placed on a fresh plate of V8 agar for $P$. aphanidermatum, or CMA for $P$. arrhenomanes. Plates were incubated at room temperature in the dark for one week to produce sporangia. To induce zoospore release, plates were flooded with sterile mineral salt solution (MSS) $(1.75 \mathrm{mM} \mathrm{CaCl}, 1 \mathrm{mM} \mathrm{KCl}$, $1 \mathrm{mM} \mathrm{MgSO} 4, \mathrm{pH} 6.5$ ) and incubated at $16^{\circ} \mathrm{C}$ under fluorescent light. MSS was changed after one hour, and again after another hour. Plates were left overnight in the third change of MSS. Zoospores were collected the following day by pouring MSS from the plates through a sterile nylon mesh ( $50 \mu \mathrm{m}$ pore). Zoospores were quantified by vortexing a 1 $\mathrm{mL}$ aliquot of zoospore suspension for 5 minutes to induce encystment. Encysted zoospores were then counted in a haemocytometer to estimate zoospore concentration.

\subsubsection{Plant species and growth conditions}

Plants used were cucumber (Cucumis sativus cv National Pickling), wheat (Triticum aestivum cv Chinese Spring), and Arabidopsis thaliana ecotype Columbia. For cucumber and wheat, seeds were surface sterilized in a $50 \mathrm{~mL}$ Falcon tube by gentle rocking in a 40 
$\mathrm{mL}$ solution of $2.5 \%$ Clorox $^{\circledR}$ bleach (which contains $6 \% \mathrm{NaOCl}$ ) and $35 \% \mathrm{EtOH}$ for 5 min. Seeds were then rinsed three times in sterile distilled water. Arabidopsis seeds were surface sterilized in a $2 \mathrm{~mL}$ tube by inverting to $\mathrm{mix}$ in $1 \mathrm{~mL}$ of $70 \%$ EtOH solution for 5 min. EtOH solution was removed, $1 \mathrm{~mL}$ of $30 \%$ Clorox $^{\circledR}$ bleach, $0.05 \%$ Tween 20 solution was added and tube was inverted to mix for $5 \mathrm{~min}$. Bleach-Tween solution was removed and seeds were rinsed in five changes of sterile distilled water for 3 min each change. Seeds of all plants were stratified after sterilization by incubation for 3 days at $4^{\circ} \mathrm{C}$ without light. For growth of cucumber and wheat seedlings, stratified seeds were placed in sterile Magenta ${ }^{\mathrm{TM}}$ boxes (Magenta Corporation, Chicago, IL) containing two layers of $3 \mathrm{MM}$ chromatography paper soaked with $5 \mathrm{~mL}$ of sterile distilled water. Seedlings were grown at $24^{\circ} \mathrm{C}$ with $18 \mathrm{~h}$ photoperiod for 7 days before further use in pathogenicity trials, or grown for 10 days to be used for RNA extraction. Stratified Arabidopsis seeds were sown in autoclaved Pro-Mix BX (Premier Tech Horticulture, Rivière-du-loup, QC) and grown at $24^{\circ} \mathrm{C}$ with $16 \mathrm{~h}$ photoperiod for 7 days before further use in pathogenicity trials. Verification of homozygous C-type lectin knockout in mutant Arabidopsis was performed by PCR using gene-specific primers and a T-DNA insertspecific primer. DNA was isolated from single leaves of transformant lines by grinding in liquid nitrogen and extracting in $200 \mathrm{mM}$ Tris $\mathrm{pH} 8.0,250 \mathrm{mM} \mathrm{NaCl}, 25 \mathrm{mM}$ EDTA, $0.5 \%$ SDS. DNA was precipitated from extract using isopropanol and pellet was resuspended in $0.1 \times$ TE buffer containing $20 \mu \mathrm{g} / \mathrm{mL}$ RNase A. Atlg52310 N-terminus primer LP1 (5'-TTATGAGTTCATAGCTAGTGGACC-3') and C-terminus primer RP1 (5'-GAACTTTCTTTAATACGACATCGG-3') were each used in PCR with T-DNA 
insert primer LBbl (5'-GCGTGGACCGCTTGCTGCAACT-3') to verify homozygous insertion mutagenesis.

\subsubsection{Recombinant protein expression}

Recombinant C-type lectin from Cucumis sativus, herein referred to as CsCL, and Triticum aestivum, herein referred to as TaCL, as well as recombinant OCM1 and PF16 from $P$. aphanidermatum, were expressed using the Gateway ${ }^{\circledR}$ E. coli expression system (Life Technologies Inc., Carlsbad, CA). Both CsCL and TaCL were amplified from cDNA of their respective plant, which was reverse transcribed from mRNA extract using SuperScript ${ }^{\mathrm{TM}}$ III Reverse Transcriptase (Life Technologies Inc., Carlsbad, CA). mRNA was extracted from 10-day-old seedlings using TRIzol (Life Technologies Inc., Carlsbad, $\mathrm{CA}$ ). Only the $\mathrm{N}$-terminal extracellular domain of $\mathrm{CsCL}$ and $\mathrm{TaCL}$ were amplified for expression. The transmembrane domain and intracellular kinase domain were not included in the expression vector. Both OCM1 and PF16 were amplified from total-DNA of P. aphanidermatum DAOM BR 444 with PCR-incorporated c-myc epitopes (Evan, et al., 1985) at their C-termini. OCM1 primers were designed such that the cloned gene would be lacking the first 23 amino acids of the $\mathrm{N}$-terminus predicted to be a signal peptide. Amplified C-type lectin and flagellar genes were cloned into entry vector pENTR $^{\mathrm{TM}} / \mathrm{D}-\mathrm{TOPO}^{\circledast}$ (Life Technologies Inc., Carlsbad, CA).The PCRs for cloning into the $\mathrm{pENTR}^{\mathrm{TM}}$ vector were performed in two steps to enable PCR-incorporation of the $c$ myc epitope in PF16 and OCM1, or a translation stop codon in CsCL and TaCL, as well as the 5'-CACC nucleotides needed for topoisomerase incorporation into the vector. PCR products from the first step were diluted 100x for use as template DNA in the second 
step. PCR primers used for the first step of CsCL amplification were CsCL_cDNA_sense (5'-GATACTATGTTTAACGAGTCAGGAATTGGG-3') with CsCL_cDNA_antisense (5'-CTCCTTGTGACAGTGCATTCGGTGG-3'), and for the second step were CsCL_gate_sense (5'-CACCATGGATACTATGTTTAACGAG-3') with CsCL_gate_antisense (5'-TTACTCCTTGTGACAGTGCATTC-3'). Primers for the first step of TaCL amplification were TaCL_cDNA_sense (5'-

CATACCCCGTCATGCCCCGAC-3') with TaCL_cDNA_antisense (5'CTCCTTGTGGCAGTGATCATGGTAG-3'), and for the second step were TaCL_gate_sense (5'-CACCATGCATACCCCGTCATGC-3') with TaCL_gate_antisense (5'-TTACTCCTTGTGGCAGTGATCATGG-3'). Primers for CsCL and TaCL were based on predicted protein sequences from the genomes of cucumber and wheat (www.plantgdb.org). PCR primers used for the first step of PF 16 amplification were PA_ACA_sense1 (5'-ATGGCGTCCACCTCTGTGCTACAG-3') with PA_ACA_gate_antila (5'-GAGTTTTTGTTCCTTCACTTGCGGTTGG-3'), and for the second step were PA_ACA_gate_senselb (5'CACCATGGCGTCCACCTCTGTG-3') with CMYC_gate_antilb (5' TTACAGATCCTCTTCTGAGATGAGTTTTTGTTC-3'). PCR primers used for the first step of OCM1 amplification were PA_OCM1_sense2 (5'-

GAGTGCCCGAACGGATGCTCG-3') with PA_OCM1_gate_anti2a (5'-

GAGTTTTTGTTCCACCGCCAGGATGTTC-3'), and for the second step were PA_OCM1_gate_sense2b (5'-CACCATGGAGTGCCCGAACGG-3') with CMYC_gate_antilb. PCR products from second step were purified using E-Gel ${ }^{\circledR}$ Clonewell ${ }^{\mathrm{TM}}$ for PF16 and OCM1 or PureLink ${ }^{\circledR}$ for CsCL and TaCL (Life Technologies 
Inc., Carlsbad, CA). Concentration of purified PCR products was estimated using a Nanodrop 1000 spectrophotometer (Thermo Scientific, Wilmington, DE). Second step PCR products were cloned into the $\mathrm{pENTR}^{\mathrm{TM}}$ vector via topoisomerase and $E$. coli Mach $1^{\mathrm{TM}}-\mathrm{T} 1$ chemically competent cells were subsequently transformed with $\mathrm{pENTR}{ }^{\mathrm{TM}}$ constructs according to manufacturer's protocol (Invitrogen/Life Technologies manual part no. 25-0517). Transformant colonies growing on selective media were screened by direct colony-PCR to verify presence of $\mathrm{CsCL}, \mathrm{TaCL}, \mathrm{PF} 16$, and $\mathrm{OCM} 1$ constructs. Plasmids were isolated from Mach $1^{\mathrm{TM}_{-} \mathrm{T} 1}$ colonies containing $\mathrm{pENTR}^{\mathrm{TM}}$ constructs using the QIAprep spin miniprep kit (Qiagen Inc., Toronto, ON). Isolated pENTR ${ }^{\mathrm{TM}}$ constructs were subjected to LR recombination reactions with the destination vector pDEST ${ }^{\mathrm{TM}} 17$ using the LR clonase ${ }^{\circledR}$ II enzyme. pDEST ${ }^{\mathrm{TM}} 17$ incorporates a $6 \mathrm{x}$-histidine tag at the Nterminus of the recombinant protein. Recombinant $\mathrm{pDEST} \mathrm{TM}^{\mathrm{TM}} 17$ constructs were used for transfection of Top 10 E. coli. Plasmids isolated from single Top 10 colonies containing pDEST $^{\mathrm{TM}} 17$ constructs were used for transfection of BL21 pLysS E. coli and single colonies of BL21-CsCL, BL21-TaCL, BL21-PF 16, and BL21-OCM1 were selected for production of recombinant proteins by IPTG induction. Full DNA and amino acid sequences of the recombinant $\mathrm{CsCL}, \mathrm{TaCL}, \mathrm{PF} 16$, and $\mathrm{OCM} 1$ proteins are given in Appendix H.

\subsubsection{Recombinant protein extraction}

Recombinant PF16 and OCM1 were extracted from BL21 E. coli by sonication in a surfactant-detergent buffer (100 mM Tris pH 7.5, $50 \mathrm{mM} \mathrm{NaCl}, 10 \mathrm{mM}$ DTT, 3\% Triton $\mathrm{X}-100,10 \mathrm{mM}$ CHAPS, protease inhibitor cocktail, 10\% N-lauryl sarcosine). 
Recombinant CsCL and TaCL were extracted from BL21 E. coli by isolation of insoluble inclusion bodies using a modified version of a published protocol (Palmer \& Wingfield, 2012). Modifications were the use of sonication rather than French press for cell lysis, centrifugation at $18,500 \mathrm{x}$ g for all steps following lysis, and modified buffers: lysis buffer (100 mM Tris $\mathrm{pH} 7.5,50 \mathrm{mM} \mathrm{NaCl}, 5 \mathrm{mM}$ DTT, protease inhibitor cocktail), wash buffer (100 mM Tris pH 7.5, $50 \mathrm{mM} \mathrm{NaCl}, 5 \mathrm{mM}$ DTT, 2\% N-lauryl sarcosine, $2 \%$ Triton X-100), and rinse buffer (step 9) (100 mM Tris pH 7.5, $50 \mathrm{mM} \mathrm{NaCl}, 5 \mathrm{mM}$ DTT). Recombinant CsCL and TaCL were extracted by resuspending inclusion body pellet in urea $\left(100 \mathrm{mM} \mathrm{NaH}_{2} \mathrm{PO}_{4}, 10 \mathrm{mM}\right.$ Tris, $8 \mathrm{M}$ urea).

\subsubsection{Recombinant protein purification}

Recombinant proteins were purified under denaturing conditions using IMAC. PolyPrep ${ }^{\circledR}$ chromatography columns (Bio-Rad Laboratories, Hercules, CA) were filled with $1.5 \mathrm{~mL}$ of Ni-NTA agarose beads (Qiagen Inc., Toronto, ON). Protein extracts were passed through the column and non-target proteins were eluted by decreasing $\mathrm{pH}$ of urea buffer from 8.0 to 6.3 (100 mM NaH $\mathrm{PO}_{4}, 10 \mathrm{mM}$ Tris, $8 \mathrm{M}$ urea). Recombinant PF16 and OCM1 were eluted from the column by further decreasing $\mathrm{pH}$ to 4.5. Denatured PF16 and OCMl were refolded by dialysis in $20 \mathrm{mM}$ Tris pH 8.0, $5 \mathrm{mM}$ DTT, $20 \%$ glycerol. Recombinant $\mathrm{CsCL}$ and $\mathrm{TaCL}$ were eluted by $\mathrm{pH}$ decrease to 4.5 , or alternatively were refolded on-column on the Ni-NTA agarose beads by incubation of column at $4^{\circ} \mathrm{C}$ in refolding solution $(20 \%$ glycerol, $20 \mathrm{mM}$ Tris pH 7.5, $500 \mathrm{mM} \mathrm{NaCl}, 5$ $\mathrm{mM} \beta$-mercaptoethanol, $0.5 \mathrm{mM}$ PMSF, $0.05 \%$ Tween 20) containing urea. Concentration of urea was decreased after every hour of incubation, from $6 \mathrm{M}$ urea, to 4 
$\mathrm{M}$ urea, to $2 \mathrm{M}$ urea, to $1 \mathrm{M}$ urea. Incubation in $1 \mathrm{M}$ urea was left overnight. Following overnight incubation, column was incubated at $4^{\circ} \mathrm{C}$ for $3 \mathrm{~h}$ in TBS $(25 \mathrm{mM}$ Tris pH 8.0, $125 \mathrm{mM} \mathrm{NaCl}$ ). Recombinant $\mathrm{CsCL}$ and TaCL remained bound to Ni-NTA agarose beads for subsequent zoospore interaction assay. Recombinant OCM1 was refolded in the same manner to be used as a control in the zoospore interaction assay. Purified recombinant $\mathrm{OCM} 1, \mathrm{PF} 16, \mathrm{CsCL}$, and TaCL eluted from columns were verified by SDSPAGE on $10 \%$ gel for OCM1 and PF16, and 14\% gel for CsCL and TaCL. 10\% gels were run at $150 \mathrm{~V}$ for $1 \mathrm{~h}$, and $14 \%$ gels were run at $150 \mathrm{~V}$ for $2 \mathrm{~h}$. Gels were fixed in $45 \%$ methanol, 10\% glacial acetic acid and stained with Coomassie Brilliant Blue R-250.

\subsubsection{Far-western blotting}

Purified CsCL and TaCL were boiled in 1x Laemmli buffer and run on 14\% SDSPAGE at $150 \mathrm{~V}$ for $2 \mathrm{~h}$ in a mini-PROTEAN ${ }^{\circledR} 3$ cell (Bio-Rad Laboratories, Hercules, CA). Two identical gels containing CsCL and TaCL were run concurrently. Transfer from each gel to nitrocellulose was done at $80 \mathrm{~mA}(7 \mathrm{~V})$ for $1 \mathrm{~h}$ in an OWL semi-dry electroblotting system (Thermo Scientific, Wilmington, DE). Membranes were rinsed briefly with Milli-Q water and incubated in TBST (TBS containing $0.05 \%$ Tween 20) with $2 \%$ ECL blocking reagent (GE Healthcare, Baie d'Urfe, QC) for $1 \mathrm{~h}$ with gentle shaking. $50 \mu \mathrm{g}$ of purified $P$. aphanidermatum OCM1 was mixed with $0.5 \mu \mathrm{g}$ Anti-myc antibody (Life Technologies, Carlsbad, CA) and incubated on ice with occasional mixing for $1 \mathrm{~h}$. Membranes were washed twice with TBST, then one membrane was gently shaken for $2 \mathrm{~h}$ in $20 \mathrm{~mL}$ TBST-ECL containing $50 \mu \mathrm{g} \mathrm{OCM1/Anti-myc} \mathrm{and} 1 \mathrm{mM} \mathrm{CaCl}_{2}$, while the other membrane was gently shaken for $2 \mathrm{~h}$ in $20 \mathrm{~mL}$ TBST-ECL containing 1 
$\mu \mathrm{g}$ Anti-His tag antibody (Cedarlane, Hornby, ON). Membranes were then washed 3 times in TBST before incubation with shaking for $1 \mathrm{~h}$ in $20 \mathrm{~mL}$ TBST-ECL containing $0.5 \mu \mathrm{L}$ Anti-mouse IgG HRP-conjugated antibody solution (GE Healthcare, Baie d'Urfe, QC). Membranes were washed 3 times in TBST and covered with $1 \mathrm{~mL}$ Lumigen TMA$6^{\boxplus}$ chemiluminescent substrate (Lumigen Inc., Southfield, MI) for $45 \mathrm{sec}$ exposure on Kodak Biomax MS film (Kodak, Rochester, NY). Control western blot of OCM1 with Anti-myc primary antibody was performed by the same procedure described above for Anti-His tag blot of CsCL and TaCL, except that the SDS-PAGE of OCM1 was run on $10 \%$ gel at $150 \mathrm{~V}$ for $1 \mathrm{~h}$.

\subsubsection{Yeast two-hybrid assay}

Potential interaction between $P$. aphanidermatum OCM1 and CsCL was tested using the ProQuest ${ }^{\text {TM }}$ Two-Hybrid System (Life Technologies, Carlsbad, CA). Interaction between PF16 and CsCL was also tested as a control. Entry vectors pENTR-OCM1, pENTR-CsCL, and pENTR-PF16 described in section 5.2.3 were used in LR recombination reactions with pDEST ${ }^{\mathrm{TM}} 32$ (bait vector) and $\mathrm{pDEST} \mathrm{TM}^{\mathrm{T} 2}$ (prey vector). Interactions were tested in duplicate with bait-prey reversal. Bait and prey pDEST ${ }^{\mathrm{TM}}$ constructs were isolated from transfected DH5 $\alpha^{\mathrm{TM}}$ E. coli (Life Technologies, Carlsbad, CA) using QIAprep spin minikit. Yeast MaV203 competent cells were co-transfected with bait-prey construct pairs and grown on selective SC-Leu-Trp media for selection of transformants. Transformant colonies were suspended in saline solution $(0.85 \% \mathrm{NaCl})$ and serially diluted for testing of $H I S 3$ induction by growth at $30^{\circ} \mathrm{C}$ for 2 days on SCLeu-Trp-His media containing varying concentrations of HIS3 inhibitor 3AT. Testing for 
$\beta$-galactosidase induction was done by $\mathrm{X}$-gal assay. Transformants were spotted on a nitrocellulose membrane overlaid on YPD agar media and grown at $30^{\circ} \mathrm{C}$ for $24 \mathrm{~h}$. Membrane was then removed from YPD, frozen briefly in liquid nitrogen, and incubated at $37^{\circ} \mathrm{C}$ for $24 \mathrm{~h}$ saturated with X-gal solution $\left(60 \mathrm{mM} \mathrm{Na}_{2} \mathrm{HPO}_{4}, 40 \mathrm{mM} \mathrm{NaH}_{2} \mathrm{PO}_{4}, 10\right.$ $\mathrm{mM} \mathrm{KCl}, 1 \mathrm{mM} \mathrm{MgSO}{ }_{4}, 24 \mu \mathrm{M}$ X-gal, 1\% DMF, $86 \mathrm{mM} \beta$-mercaptoethanol).

\subsubsection{Zoospore interaction with refolded agarose-bound C-type lectin}

Interaction of zoospores from $P$. aphanidermatum and P. arrhenomanes with refolded agarose-bound $\mathrm{CsCL}$ and $\mathrm{TaCL}$ was observed by transferring $500 \mu \mathrm{L}$ of $\mathrm{CsCL}$ or TaCL agarose beads to size $60 \times 15 \mathrm{~mm}$ petri dishes. $500 \mu \mathrm{L}$ OCM1 agarose beads were transferred to control petri dishes. Each protein bead-containing dish was flooded with zoospore suspension of either $P$. aphanidermatum or $P$. arrhenomanes, whereby one of each Pythium-protein combination was tested. Interaction of zoospores with proteinbound beads was observed under a dissecting microscope.

\subsubsection{Cucumber pathogenicity trial - host defense response to flagellar protein}

For growth of cucumber seedlings for pathogenicity trials, seedlings were grown in Magenta ${ }^{\mathrm{TM}}$ boxes as described in section 5.2.2, and 7 day - old seedlings were treated with purified protein by dipping the roots in a solution of dialysis buffer $(20 \mathrm{mM}$ Tris $\mathrm{pH}$ 8.0, $5 \mathrm{mM} \mathrm{DTT}, 20 \%$ glycerol) containing $2 \mu \mathrm{g} / \mathrm{mL}$ of either PF16, OCM1, or BSA. Negative control treatment was dialysis buffer. Treated seedlings were then planted in Pro-Mix BX in 6" standard pots, with ten seedlings per pot, and grown at $24^{\circ} \mathrm{C}$ with $18 \mathrm{~h}$ photoperiod. Twenty seedlings were grown for each treatment. Seedlings were grown for 
24h prior to Pythium inoculation to allow potential activation of defense response. One day after planting, agar plugs from a 3-day-old V8 agar culture of $P$. aphanidermatum were placed 1/2" deep in the soil of Pythium treatments, with one plug adjacent to each cucumber seedling. Control treatments were grown without Pythium inoculation. Plants were scored for disease rating and root hair lengths of non-Pythium treatments were measured at 14 days post-inoculation (dpi).

\subsubsection{Arabidopsis pathogenicity trial-C-type lectin knockout}

Arabidopsis seedlings were grown in sterile Pro-Mix as described in section 5.2.2, and 7-day-old seedlings were inoculated with $P$. aphanidermatum zoospores suspended in distilled water at a rate of approximately 800 zoospores per seedling in trial 1 , and 3000 zoospores per seedling in trial 2. Control seedlings were inoculated with sterile distilled water. A total of 96 seedlings were grown in trial 1, and 384 seedlings were grown in trial 2. Potting mix was kept constantly saturated with sterile distilled water and plants were grown at $24^{\circ} \mathrm{C}$ with $16 \mathrm{~h}$ photoperiod for $21 \mathrm{dpi}$. At $21 \mathrm{dpi}$, survival was counted and dry weight of survivors was measured following drying at $40^{\circ} \mathrm{C}$ for $24 \mathrm{~h}$. Two lines of Arabidopsis thaliana were used: the wild type Col-0 (Columbia), and a mutant of Col-0 which had T-DNA insertion in the C-type lectin gene Atlg52310, rendering this gene knocked-out. Atlg52310 insertion mutant seeds of germplasm line SALK_143434C were obtained from the Arabidopsis Biological Resource Center (Ohio State University, Columbus, OH). Wild-type Col-0 seeds were kindly provided by Gislaine Allard at ECORC. 
The experiment was set up as a randomized complete block with two trays of seedlings constituting a block. One tray was inoculated with Pythium and the other was not. Each tray was placed on a separate shelf in the incubator. The light source was in the door of the incubator and distance from the source was recorded and used as a covariate. Analyses were done with R using GLM and logistic regression with default settings for the survival rate and with the linear model for dry weight and leaf counts ( $R$ Development Core Team, 2011).

\subsection{Results}

\subsubsection{Recombinant protein purification}

Recombinant OCM1, PF16, CsCL, and TaCL were successfully purified from induced BL21 E. coli. SDS-PAGE with purified proteins eluted from Ni-NTA column is shown in Figure 5.2.

\subsubsection{Cucumber response to OCMI inoculation}

Cucumber seedlings treated with OCM1 did not have a phenotypic difference in root hair length or Pythium aphanidermatum susceptibility compared to controls of PF16, BSA, and dialysis buffer treatment. All treated seedlings grown without Pythium inoculation were equally healthy, and root hair lengths were $10-20 \mu \mathrm{m}$ on average with comparable hair density between all treatments (Fig. 5.3). All treated seedlings grown with Pythium inoculation were equally unhealthy, with significant yellowing of cotyledons and delayed development compared to treatments lacking Pythium. Disease rating for seedling treatments is given in Table 5.1. Rating of 3 indicates $100 \%$ cotyledon 
yellowing and/or seedling decay, rating of 2 indicates greater than $50 \%$ yellowing, rating of 1 indicates less than $50 \%$ yellowing, rating of 0 indicates no visible yellowing.

A

PF16 PF16 PF16 PF16 OCM1 OCM1 OCM1 OCM1

flow thru wash purified dialyzed flow thru wash

purified dialyzed

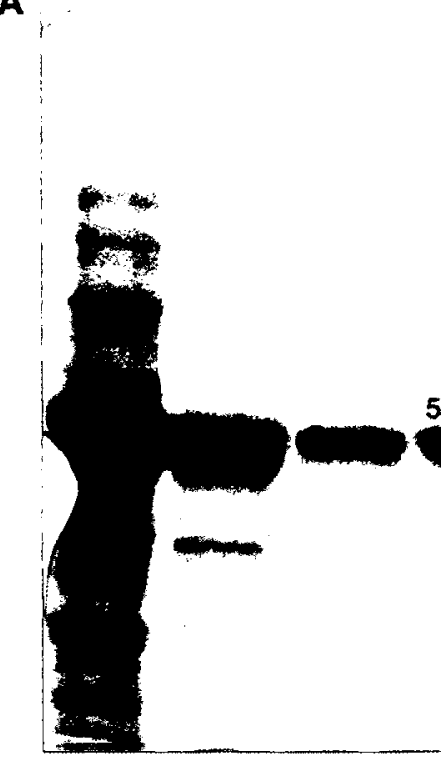

$175 \mathrm{kDa}$ 

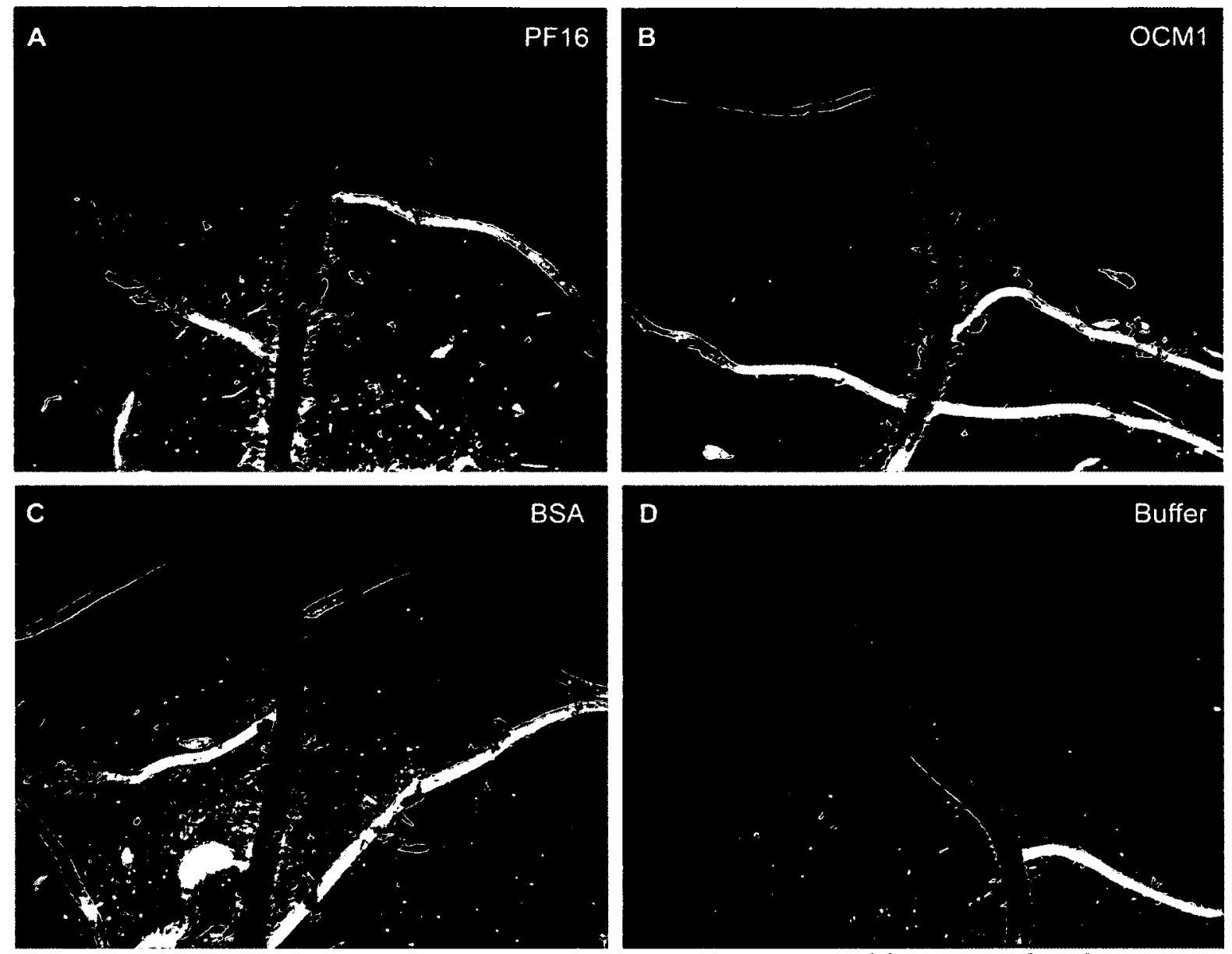

Figure 5.3. Root hairs of cucumber seedlings treated with PF16 (A), OCM1 (B), BSA (C), or dialysis buffer (D). Images are of seedling roots 14 days post-treatment. 
Table 5.1. Disease rating of cucumber seedling treatments.

\begin{tabular}{lccc}
\hline Treatment & $\begin{array}{c}\text { P. aphanidermatum } \\
\text { inoculation }\end{array}$ & $\begin{array}{c}\text { Average } \\
\text { Disease Rating }\end{array}$ & Std. Dev. \\
\hline OCM1 & no & 0 & 0 \\
PF16 & no & 0 & 0 \\
BSA & no & 0 & 0 \\
buffer & no & 0 & 0 \\
OCM1 & yes & 1.8 & 0.70 \\
PF16 & yes & 1.7 & 0.73 \\
BSA & yes & 1.8 & 0.70 \\
buffer & yes & 1.65 & 0.74 \\
\hline
\end{tabular}




\subsubsection{Interaction between OCMI and C-type lectin}

Results of the far-western assay did not indicate any interaction between OCM1 and immobilized CsCL or TaCL due to lack of chemiluminescence (Fig. 5.4 A). The positive control western using Anti-His tag primary antibody showed that protein transfer to nitrocellulose and antibody binding/detection procedure were not at fault (Fig. 5.4 B). Proper binding of Anti-myc to OCM1 is not considered to be at fault since this interaction was verified by western blot prior to far-western assay (Fig. 5.4 C). Yeast two-hybrid assay for OCM1 - CsCL interaction showed a weak interaction based on HIS3 induction (Fig. 5.5 A), but this interaction was not confirmed by $\beta$-galactosidase induction in the $\mathrm{X}$ gal assay (Fig 5.5B).

\subsubsection{Zoospore recognition of refolded $C S C L$ and $T a C L$}

Zoospores of $P$. aphanidermatum and $P$. arrhenomanes did not respond to contact with agarose-bound refolded $\mathrm{CsCL}$ or TaCL, or the control OCM1. Zoospores of both Pythium species swam in close contact with the agarose beads, often coming into direct contact with the surface of the beads. No encystment on the beads or taxis towards the beads was noted in periodic microscopic observation over a $6 \mathrm{~h}$ duration. An image of $P$. aphanidermatum zoospores swimming among CsCL-bound agarose beads is shown in Figure 5.6. 

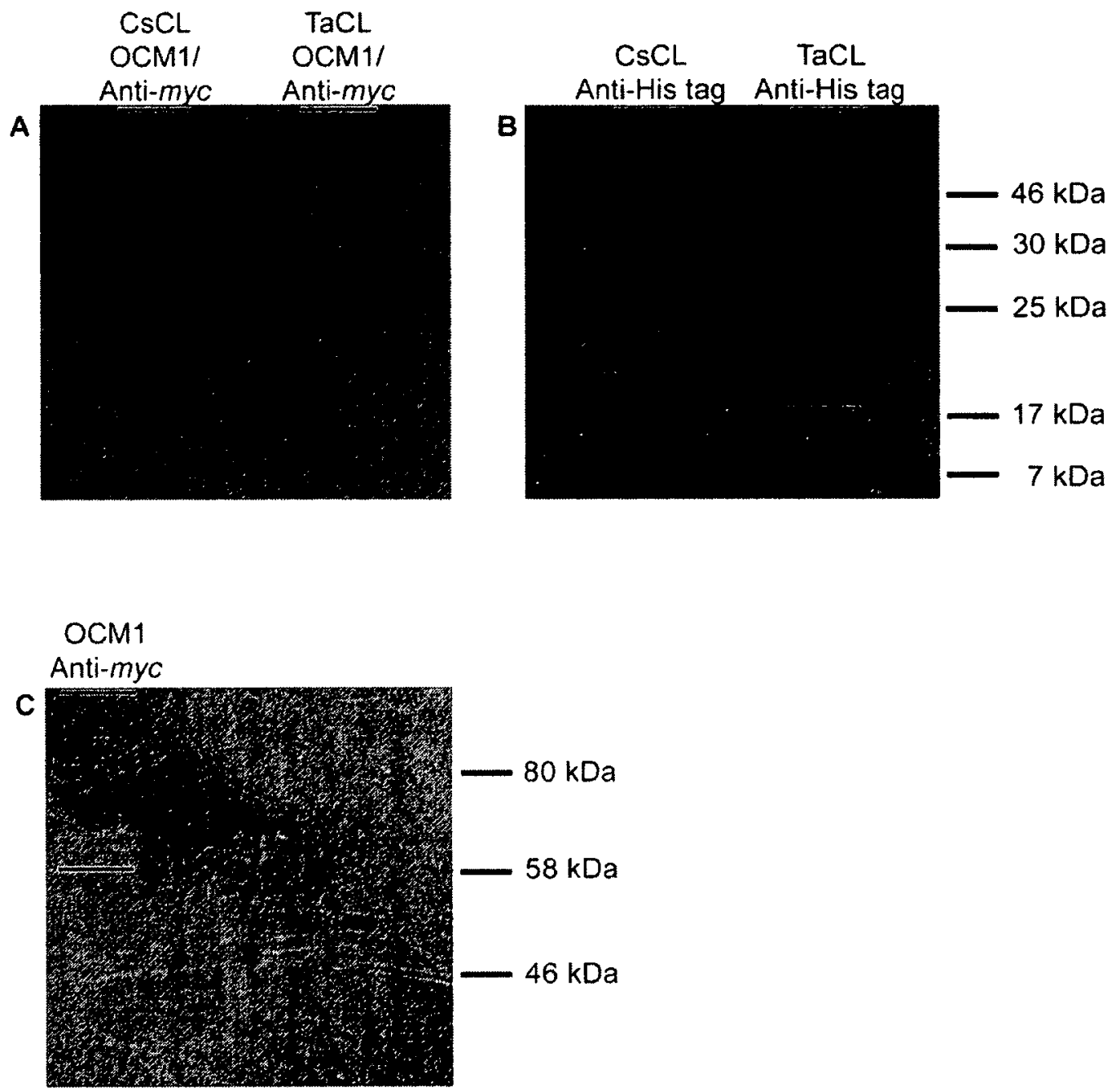

Figure 5.4. Far-western blot of immobilized $\mathrm{CsCL}$ and TaCL using OCM1/Anti-myc as the primary antibody (A). Positive control western blot of $\mathrm{CsCL}$ and TaCL using Anti-His tag primary antibody (B). Western blot of OCM1 using Anti-myc primary antibody (C). Chemiluminescence signals in $B$ and $C$ are underlined. 
A

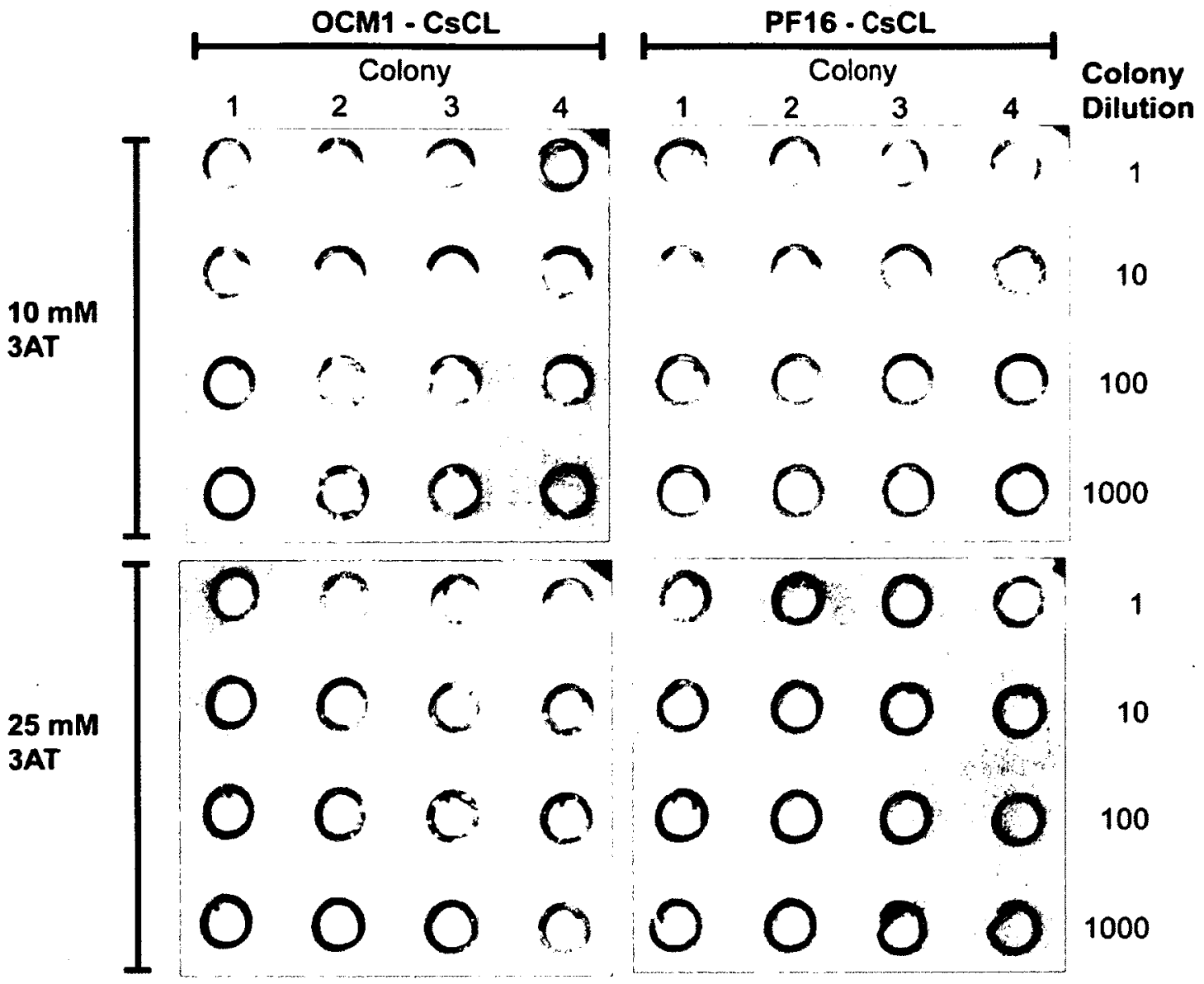

B

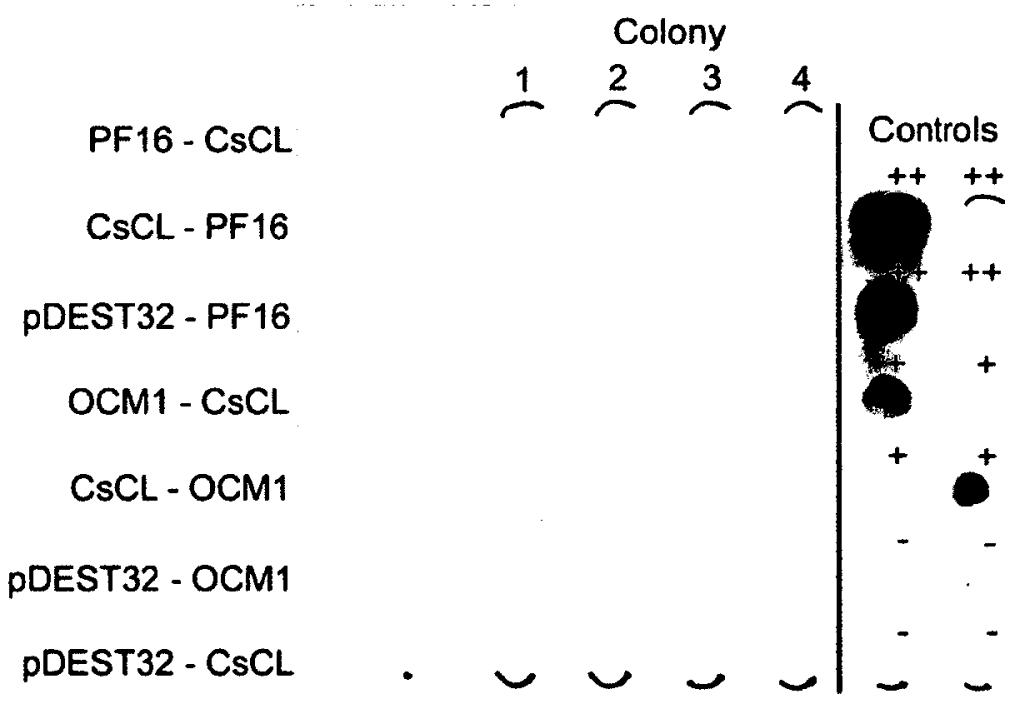

Figure 5.5. Yeast two-hybrid assay. Histidine auxotrophy HIS3 gene induction by bait-prey interaction in the presence of HIS3 inhibitor 3AT (A). $\beta$-galactosidase induction by bait-prey interaction (B). Controls in $B$ are Strong positive interaction $(++)$, Weak positive interaction ( + ), and No interaction (-). 


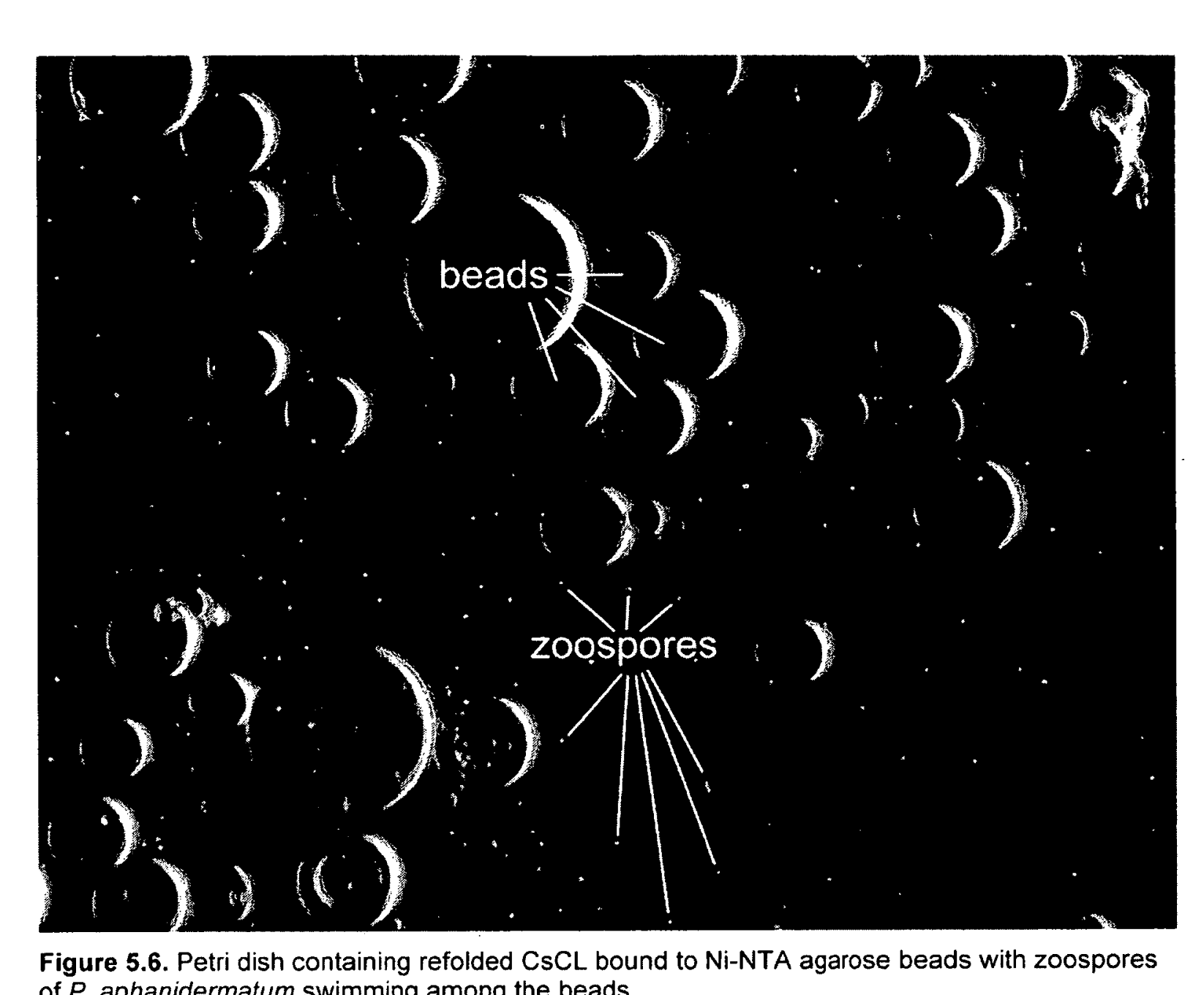




\subsubsection{Pythium susceptibility of C-type lectin knockout Arabidopsis}

Survival of $A$. thaliana mutants lacking C-type lectin was higher than survival of wild-type Col-0 plants in Pythium-inoculated plants. In the first trial with 96 seedlings, this difference was not significant under the logistic regression analysis $(p=0.14)$, whereas in the second trial with 384 seedlings the p-value was 0.055 . Mortality in inoculated plants was much higher in the second trial because of the higher zoospore concentration where 3000 zoospores were used instead of 800 (Fig. 5.7). However, the difference in survival between knockout mutants (KO) and wild-type plants (WT) was consistent in these two trials, which was confirmed by a non-significant interaction between the WT-KO factor and trial. Therefore, we combined the two trials in one pooled logistic regression analysis which gave a p-value of 0.02 (Fig. 5.7). Knockout and wildtype plants did not differ in their dry weight, or developmental stage as measured by leaf count. There was, however an increase in dry weight and leaf count for plants inoculated with Pythium versus non-inoculated (sterile) plants (Fig. 5.8). 


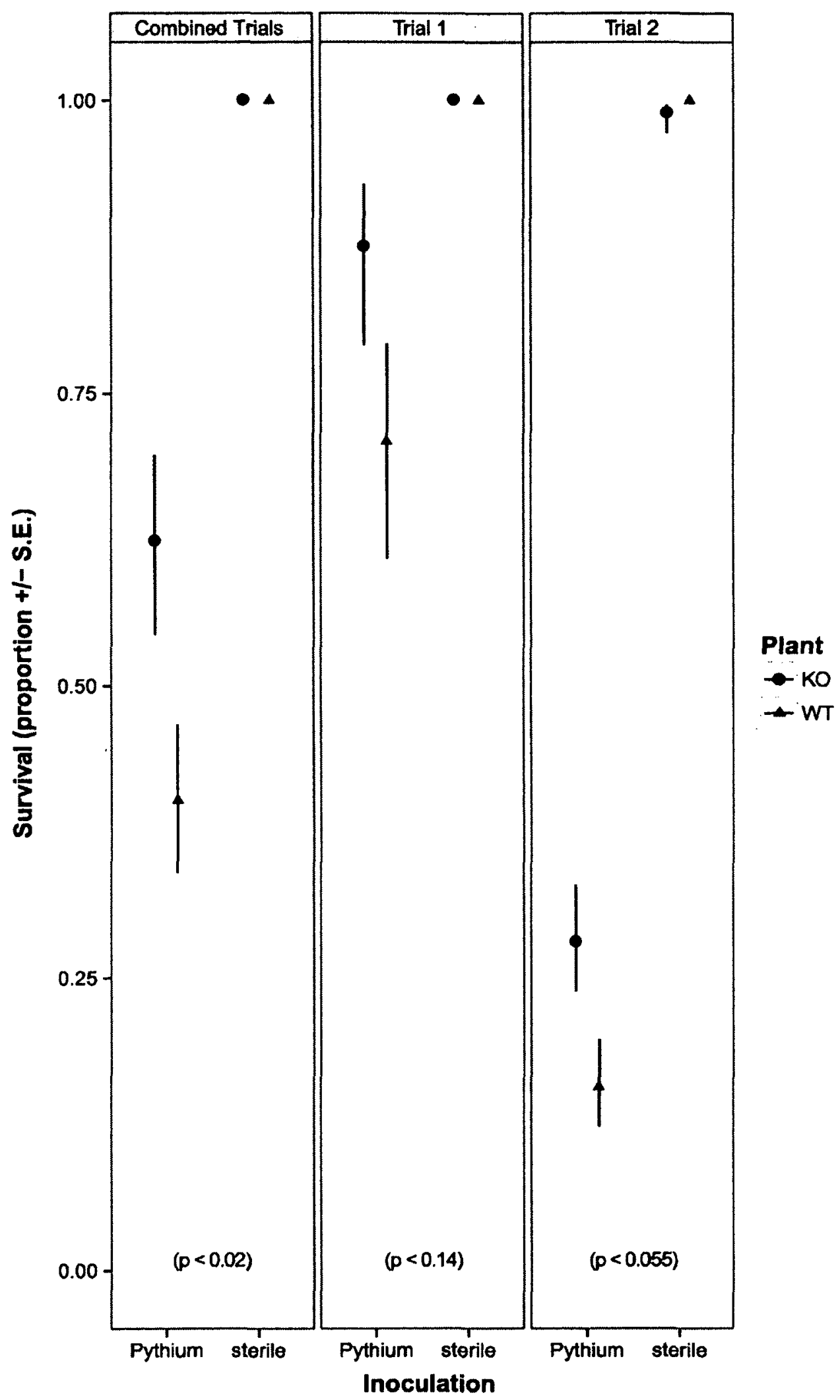

Figure 5.7. Survival of C-type lectin knockouts (KO) and wild-type (WT) Arabidopsis following inoculation with $P$. aphanidermatum zoospores. Plants in sterile condition were inoculated with sterile water as a control. 


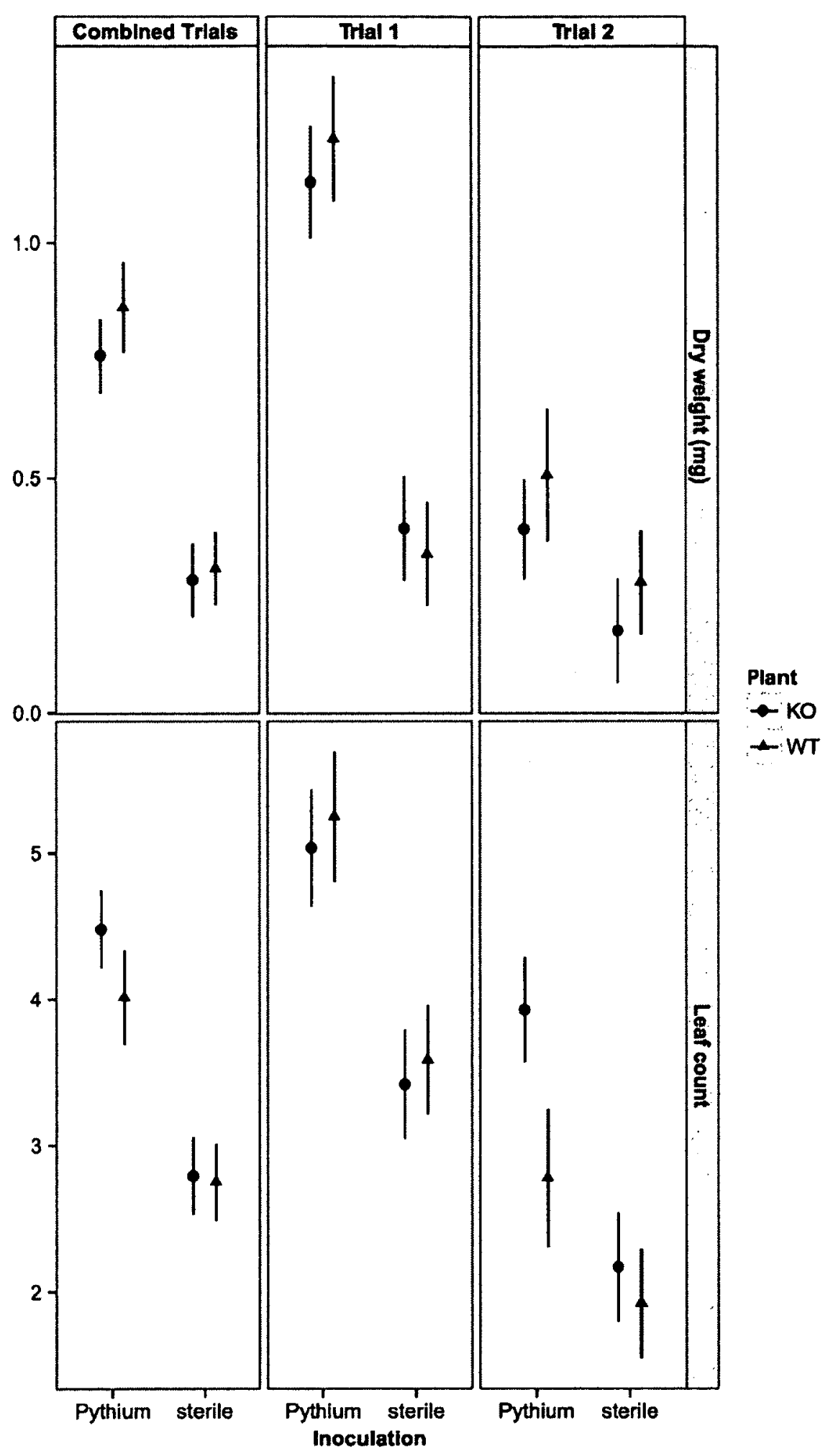

Figure 5.8. Dry weight and leaf count of C-type lectin knockouts (KO) and wild-type (WT) Arabidopsis following inoculation with $P$. aphanidermatum zoospores. Plants in sterile condition were inoculated with sterile water as a control. 


\subsection{Discussion}

The results of this investigation have shown that $\mathrm{C}$-type lectin contributes to infection of Arabidopsis thaliana by Pythium aphanidermatum zoospores. The hypothesized mechanism of OCM1-mediated zoospore interaction with C-type lectin was not conclusively shown in this study, nor was an induction of plant defense by OCM1 treatment, but these mechanisms cannot be ruled out of natural plant-zoospore interactions since the recombinant proteins used in this study did not perfectly mimic those found in nature.

Induction of plant defense in response to contact with microbes is a well known phenomenon that often results from plant recognition of specific pathogen-associated molecular patterns (PAMPs) (Zipfel, 2009). PAMPs are well-studied in pathogenic bacteria and can be found in highly variable cell-surface molecules which contain conserved regions such as membrane lipopolysaccharides (Newman, et al., 2007) or flagellin protein (Ramos, et al., 2004). Since oomycete OCM1 is also a highly variable protein with conserved domains that is found on the surface of zoospores, a role of OCM1 in PAMP-triggered immunity was hypothesized. The host-pathogen system of cucumber and Pythium aphanidermatum was chosen to test this hypothesis because induced systemic resistance (ISR) to $P$. aphanidermatum has been previously demonstrated in cucumber (Chen, et al., 1998), and there is new evidence of rapid cucumber defense induction in response to infection by a downy mildew oomycete (Adhikari, et al., 2012). In the current experiment, cucumber defense response, or lack thereof, was inferred by overall plant health deduced from tissue colouration (Table 5.1), as well as the augmentation of root hair growth (Fig. 5.3) since this occurs as a result of 
defense induction in Arabidopsis (Hernandez-Mata, et al., 2010) and rootlet elongation occurs in microbe-inoculated cucumber (De Bellis \& Ercolani, 2001). The observations of Pythium-inoculated cucumber seedlings did not indicate defense induction, which may have been due to a true lack of OCM1 recognition by cucumber, but it could also have been due to the lack of protein glycosylation of recombinant OCM1.

The tubular mastigonemes of the Ochromonas tinsel flagellum are known to be glycosylated (Bouck, 1971, Chen \& Haines, 1976), and the amino acid sequence of $P$. aphanidermatum OCM1 contains potential glycosylation sites, so it is reasonable to assume that recognition of OCM1 in a protein-protein interaction would include recognition of OCM1 glycosyl residues. This is true in the case of bacterial flagellin perception by the human immune system, which shows a significantly reduced response to non-glycosylated mutant flagella (Verma, et al., 2005). The expression of OCM1 in bacteria was chosen for ease of use, and the lack of post-translational modification in a prokaryotic expression system was a compromise that could have been circumvented by using a eukaryotic expression system such as yeast, although yeast glycosylation is high in mannose and would not necessarily reproduce oomycete-like glycosylation patterns. Yeast expression was attempted prior to bacterial expression but it proved difficult to optimize so it was not pursued further. In the hypothesized interaction of the tenascin-like protein OCM1 with plant C-type lectin, glycosylation may not have been of necessity, since the interaction between rat tenascin and C-type lectin does not rely on carbohydrate moieties (Aspberg, et al., 1997, Lundell, et al., 2004). The negative results of the farwestern assay (Fig. 5.4) may be attributable to the denatured state of the immobilized $\mathrm{CsCL}$ and $\mathrm{TaCL}$, but this was not the case in the yeast two-hybrid assay (Fig. 5.5) or the 
zoospore recognition assay (Fig. 5.6) where supposed proper protein folding still led to inconclusive results.

Although a direct interaction between OCM1 and C-type lectin was not conclusively demonstrated, the role of C-type lectin in plant susceptibility to Pythium infection was shown to be significant. This result is similar to the recent finding that a lectin receptor kinase contributes to infection of Arabidopsis by the oomycete Hyaloperonospora arabidopsidis (Hok, et al., 2011). This apparent high-jacking of host lectins by oomycete pathogens is actually a common tactic employed by viruses, which are known to target Ctype lectins for host entry (Alvarez, et al., 2002, Takada, et al., 2004, de Witte, et al., 2006, Gunn, et al., 2012). With this strategy, the general up-regulation of immune system genes upon pathogen infection would only serve to enhance further infection via upregulated C-type lectin expression. An example of plant virus-induced C-type lectin upregulation occurs in the interaction between Arabidopsis and Cabbage leaf-curl virus (Ascencio-Ibanez, et al., 2008), so perhaps a similar mechanism is exploited by oomycete pathogens. Alternatively, the lack of C-type lectin may have promoted tolerance to Pythium infection in knockout Arabidopsis plants. Infection of plants by oomycetes generally involves many gene-for-gene interactions that result in plant hypersensitive response and cell death (van Damme, et al., 2011). Knockout of a gene involved in the hypersensitive response in Arabidopsis has been shown to induce systemic acquired resistance, leading to enhanced resistance against pathogenic microbes ( $\mathrm{Yu}$, et al., 1998). If C-type lectin is involved in gene-for-gene interaction with pathogens, perhaps a similar defense induction was responsible for the enhanced Pythium resistance of C-type lectin knockout Arabidopsis plants. In the current study, the lack of C-type lectin in 
Arabidopsis had a definite inhibitory effect on Pythium, and this effect was consistent over varying zoospore inoculum concentrations (Fig. 5.7). The observation that Pythium inoculation yielded greater dry weight and leaf count in surviving plants may be related to the fact that Arabidopsis tends to accelerate reproductive development and increase basal branch development in response to oomycete infection (Korves \& Bergelson, 2003). Survival rates were correlated to the concentration of zoospore inoculum, as is typical for Pythium infection (Chen, et al., 1996), showing that C-type lectin knockout did not confer total resistance, but the findings of this study provide a very interesting step towards further understanding of the role of C-type lectins in plant - pathogen interaction which may be applicable to the development of Pythium resistance in crops. 


\section{Chapter: GENERAL CONCLUSION}

It is without doubt that oomycete researchers and society in general will benefit from the ongoing efforts to understand the complex evolutionary relationships between oomycetes, as well as how oomycete evolution relates to their role as pathogenic organisms in the environment. The modern era of molecular biology has revolutionized the way that organisms are studied, where simple sequences of DNA can infer multitudes of biological processes to allow in-depth assessments of ecological roles or evolutionary histories. Now that full genome sequences have been assembled for several important oomycetes, the opportunity to enhance our understanding of these organisms is truly unprecedented.

By using DNA sequence data in a taxonomic and phylogenetic framework, we are able to piece together not only the evolutionary history of oomycetes, but also the puzzle of oomycete ecology. Oomycetes are described ecologically as ubiquitous, cosmopolitan, pervasive, profuse; in other words they're everywhere. But despite their omnipresent nature, we have only a rudimentary understanding of what their ecological niche is. Even when their niche is seemingly obvious, as in the case of plant parasitic oomycetes, there are often alternative habits observed, such as nematode parasitism (nematophagy), that bring into question the primary role of these opportunistic oomycetes in natural ecosystems. Observation and experimentation in the field are imparative to unravelling the ecology of oomycetes, but both the planning and analysis of these experiments can be profoundly supported using molecular data.

The molecular taxonomy and phylogeny of oomycetes described in this thesis aims to augment the resources and knowledge base needed to pursue greater understanding of 
these microbes. Next generation sequencing technologies are increasingly being used to study the ecology of oomycetes. We have provided the largest reference dataset ever generated on oomycetes for two markers that can now be used for such purpose, significantly increasing the probability of matching raw sequences from the field with a vouchered reference sequence. New molecular markers specific to zoospore production have also been described which could be exploited in environmental RNA sequencing to determine factors contributing to asexual sporulation. The phylogenetic utility of these markers was also shown, as was the advantage of using a codon modeling approach to phylogenetic reconstruction. In addition to practical resources, the biological understanding that can be achieved from molecular studies is evident in the results of Chapter 5, where the role of C-type lectin in Pythium susceptibility was discovered by pursuing the inference of molecular data from Chapter 4. This highlights the potential of molecular data to become a catalyst for functional characterization. Certainly, many discoveries in oomycete biology will continue to be made thanks to the hypnotic suggestions of nucleic acid. 


\section{Appendices}

Appendix A - List of isolates used and their DNA sequence accession numbers. Asterisks denote ex-type specimens.

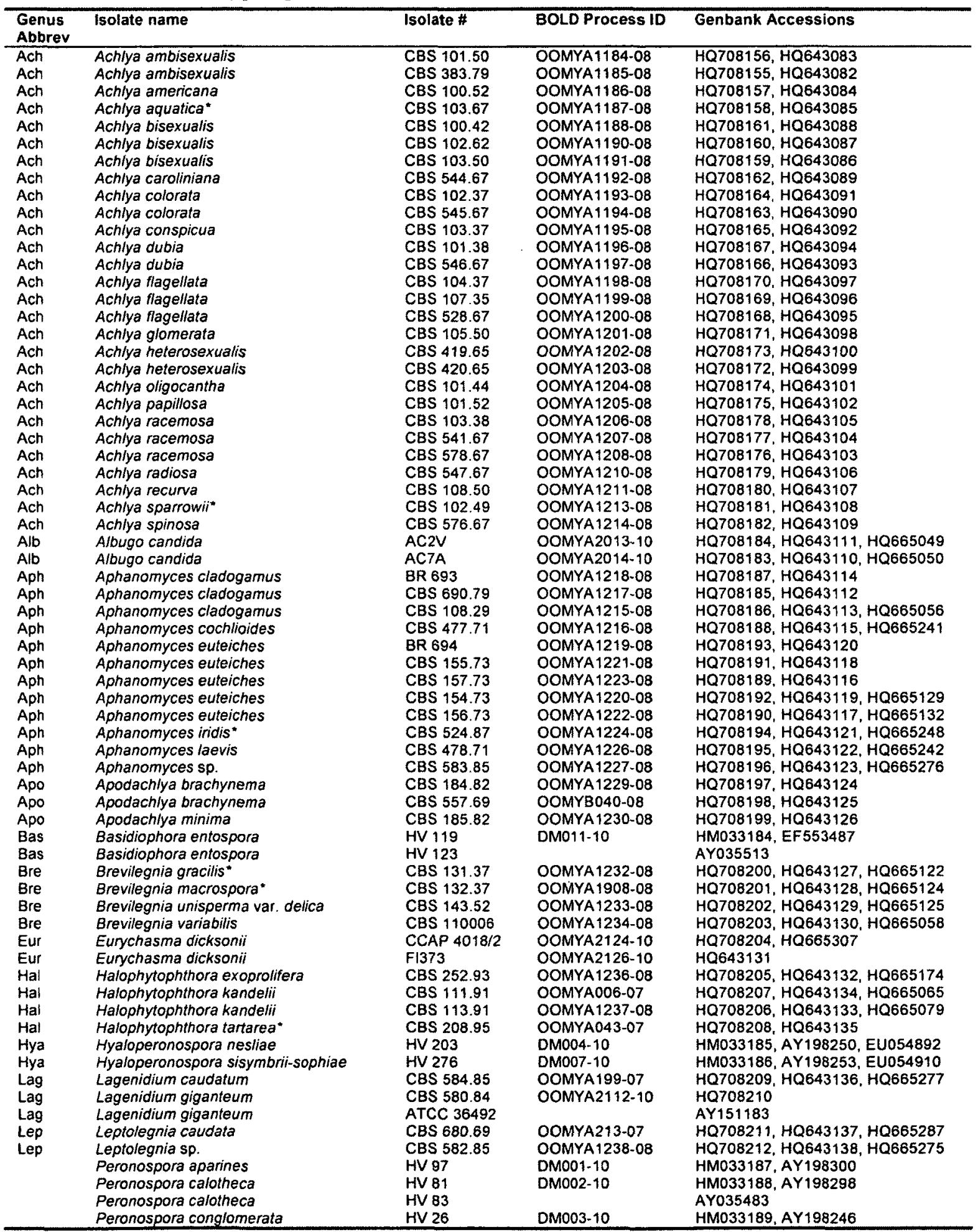




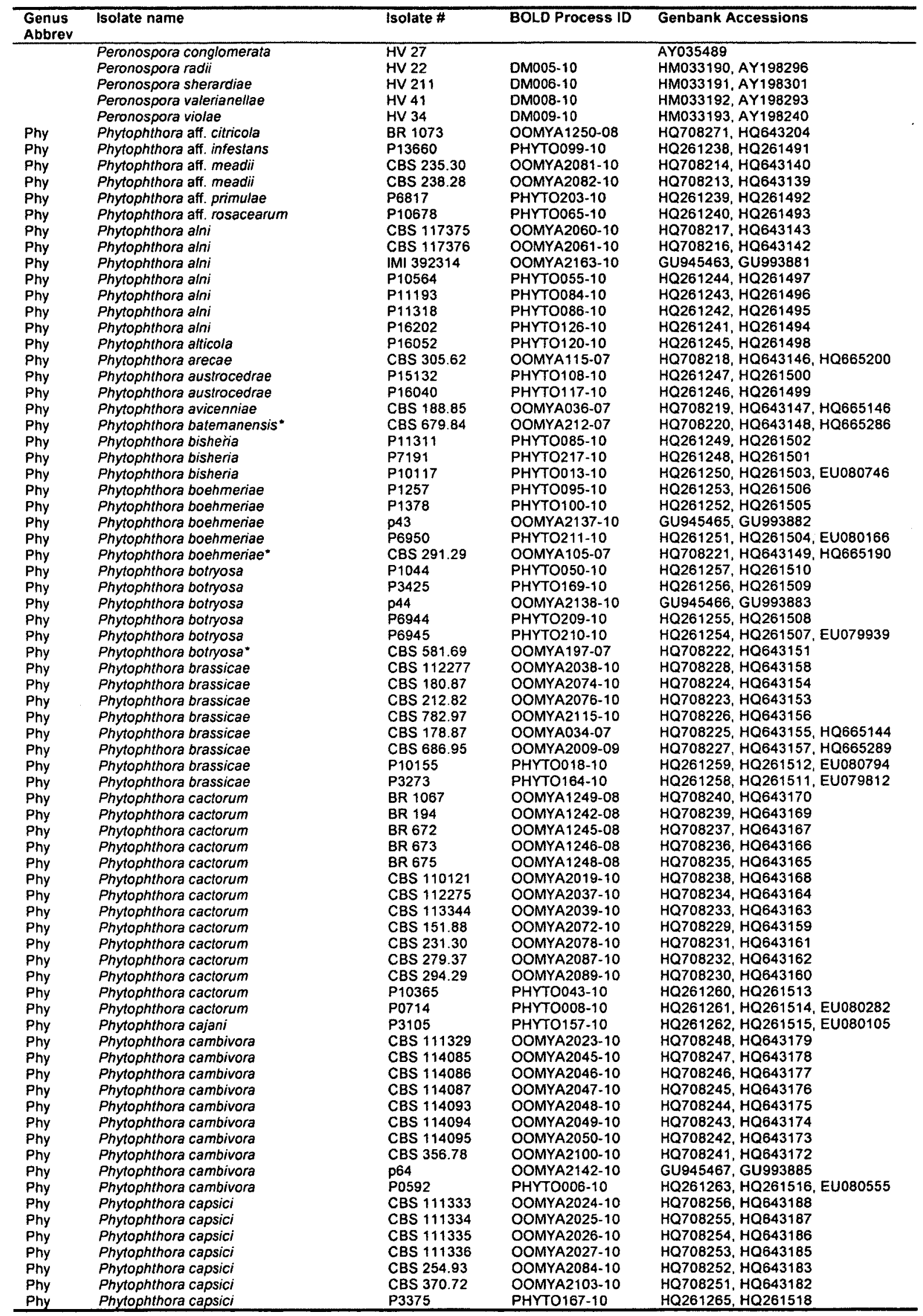









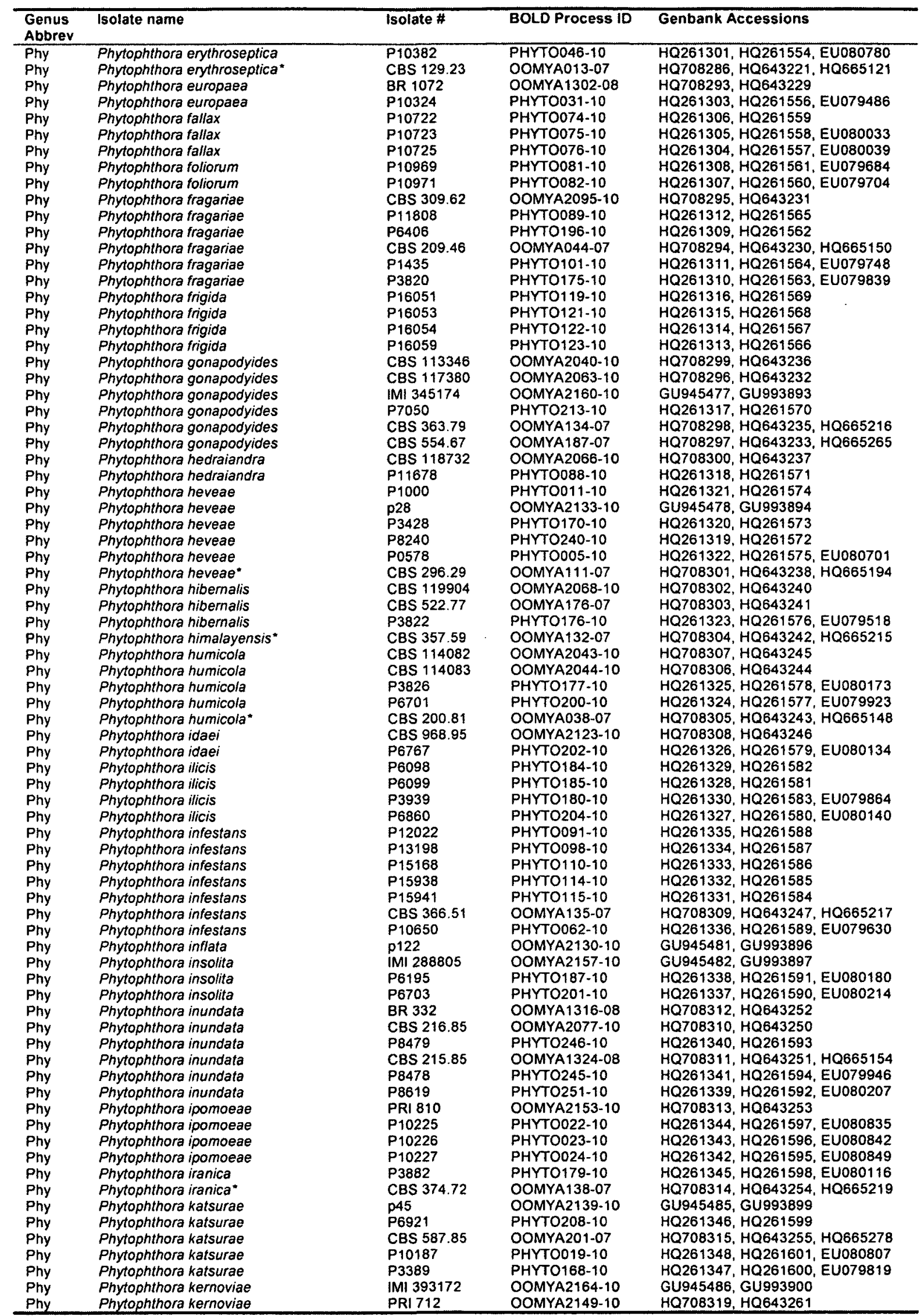




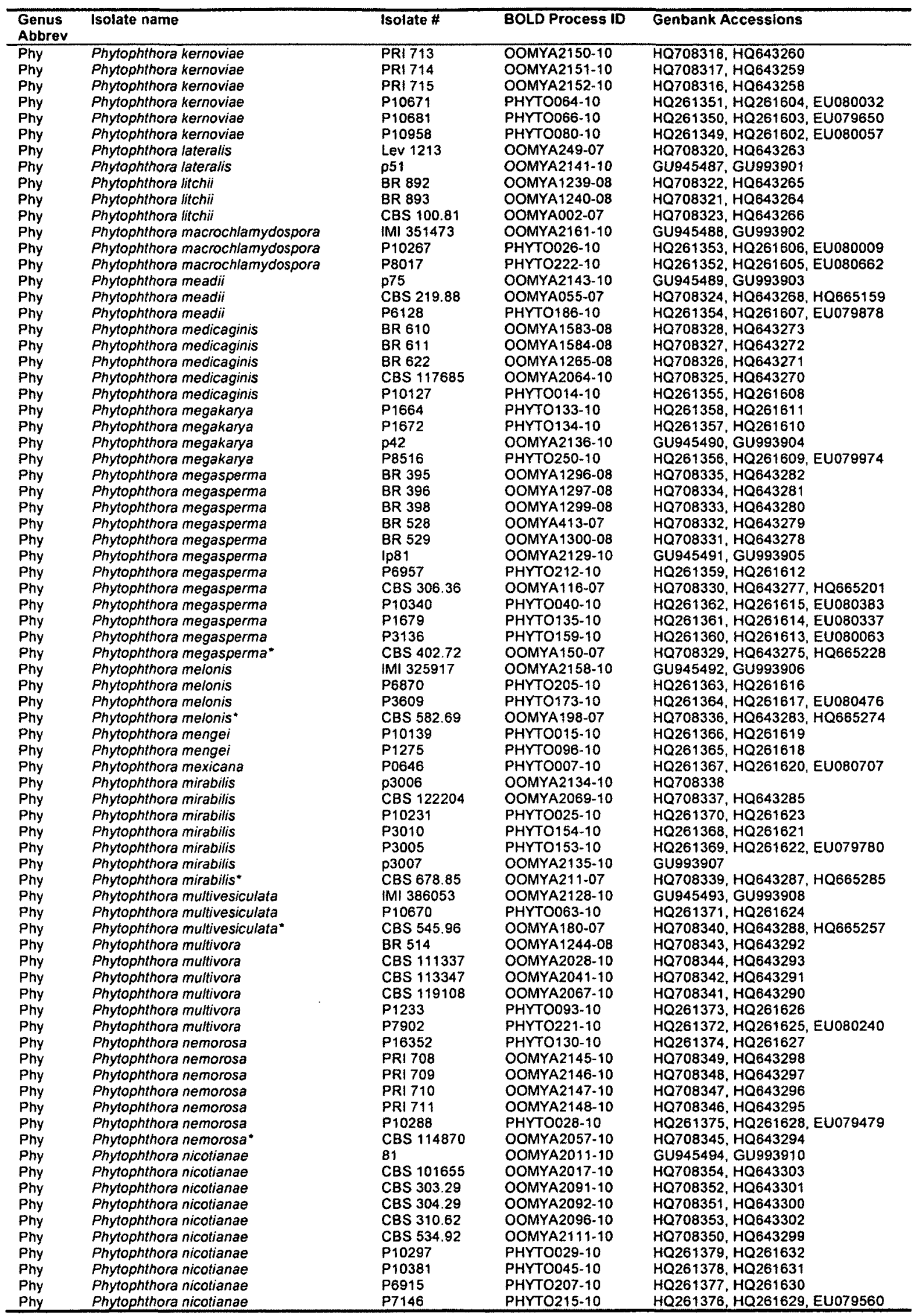




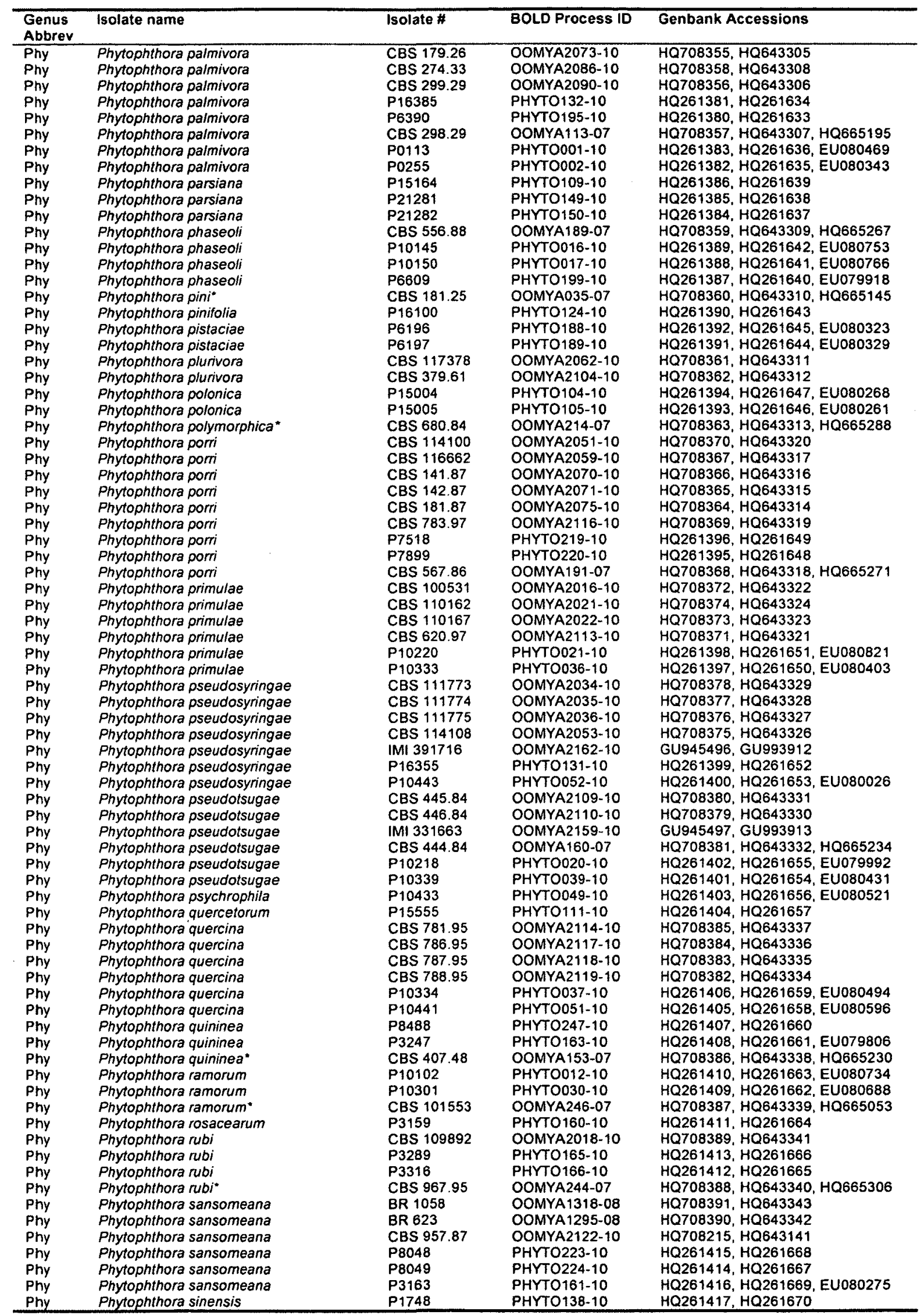




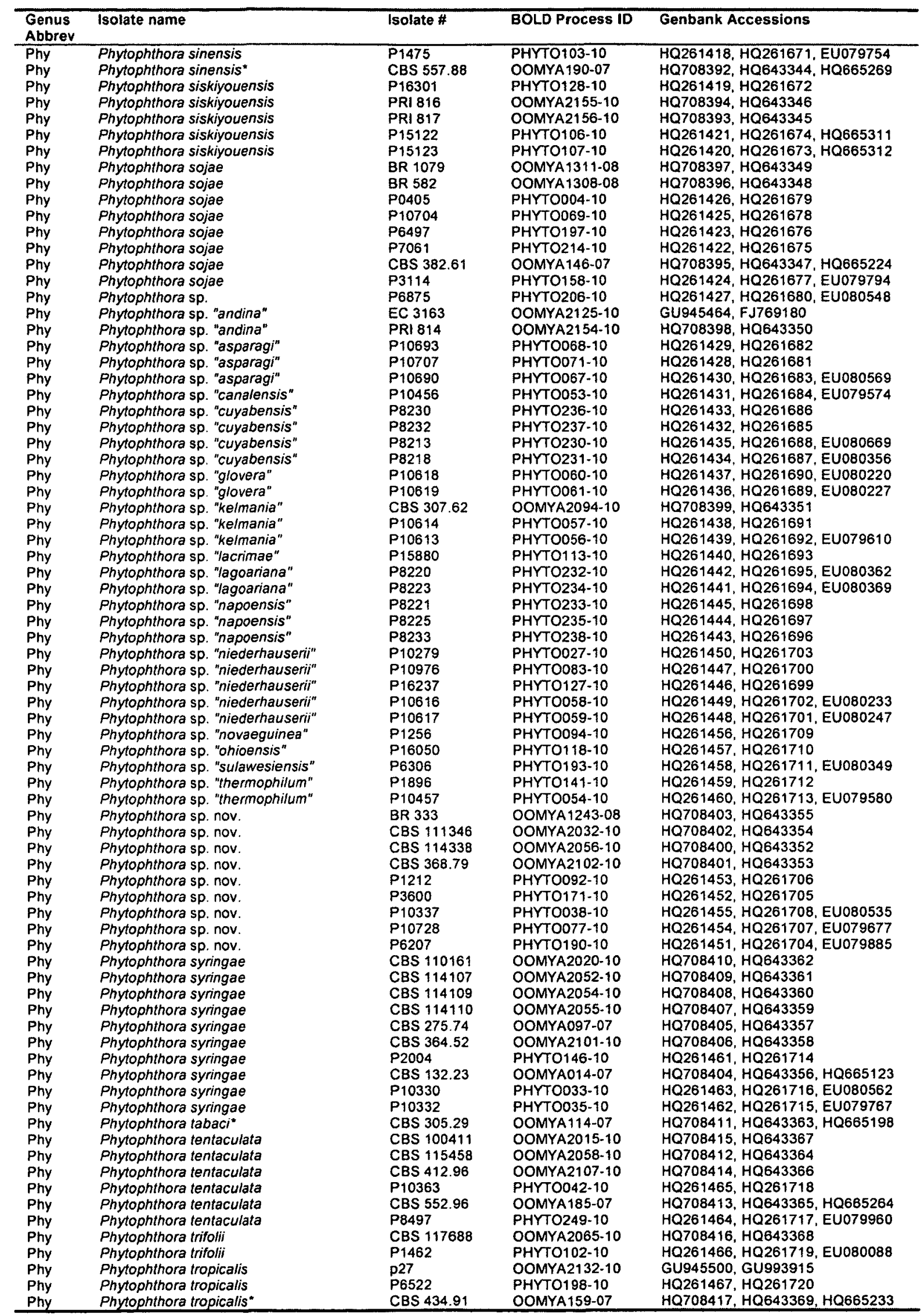




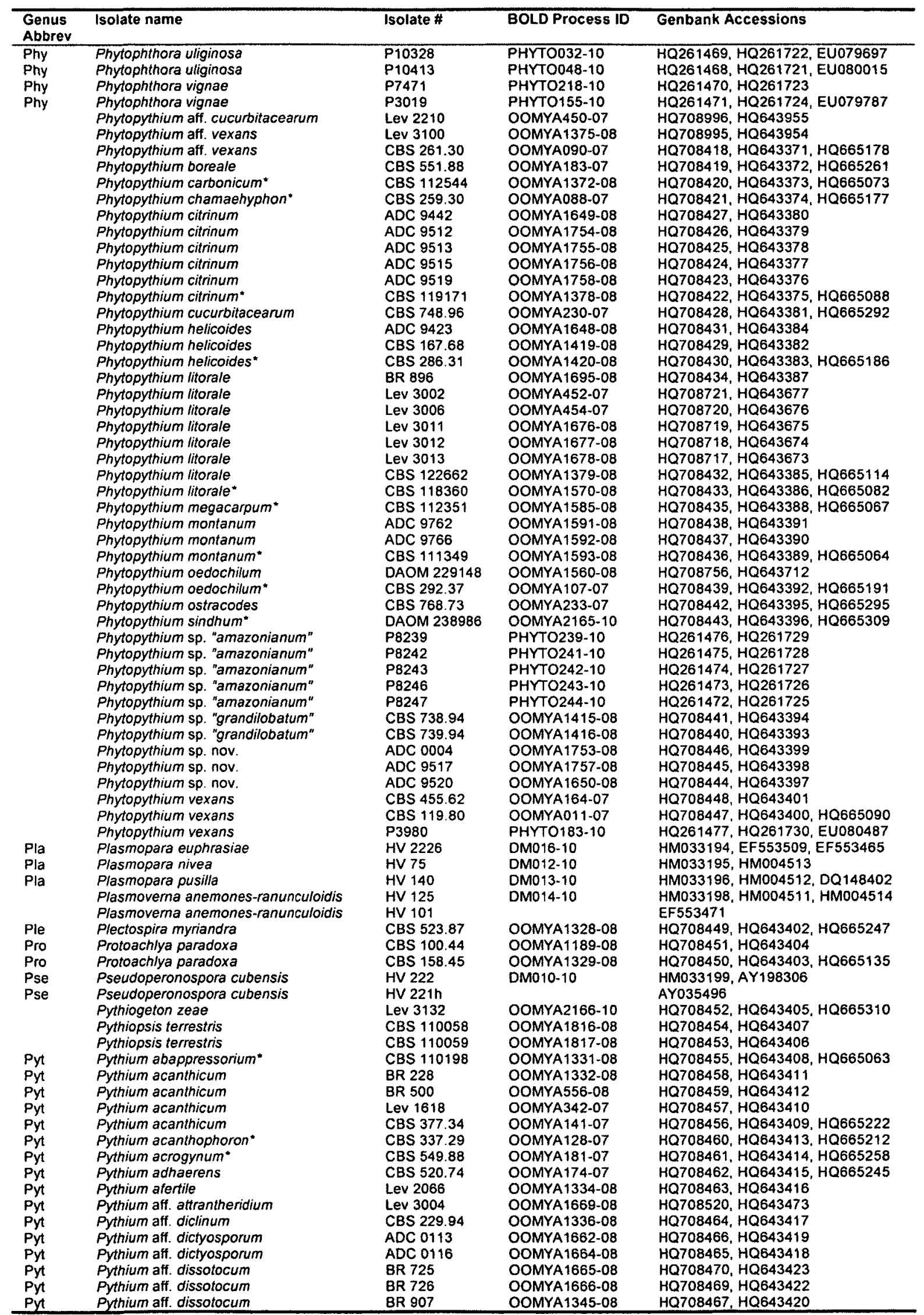




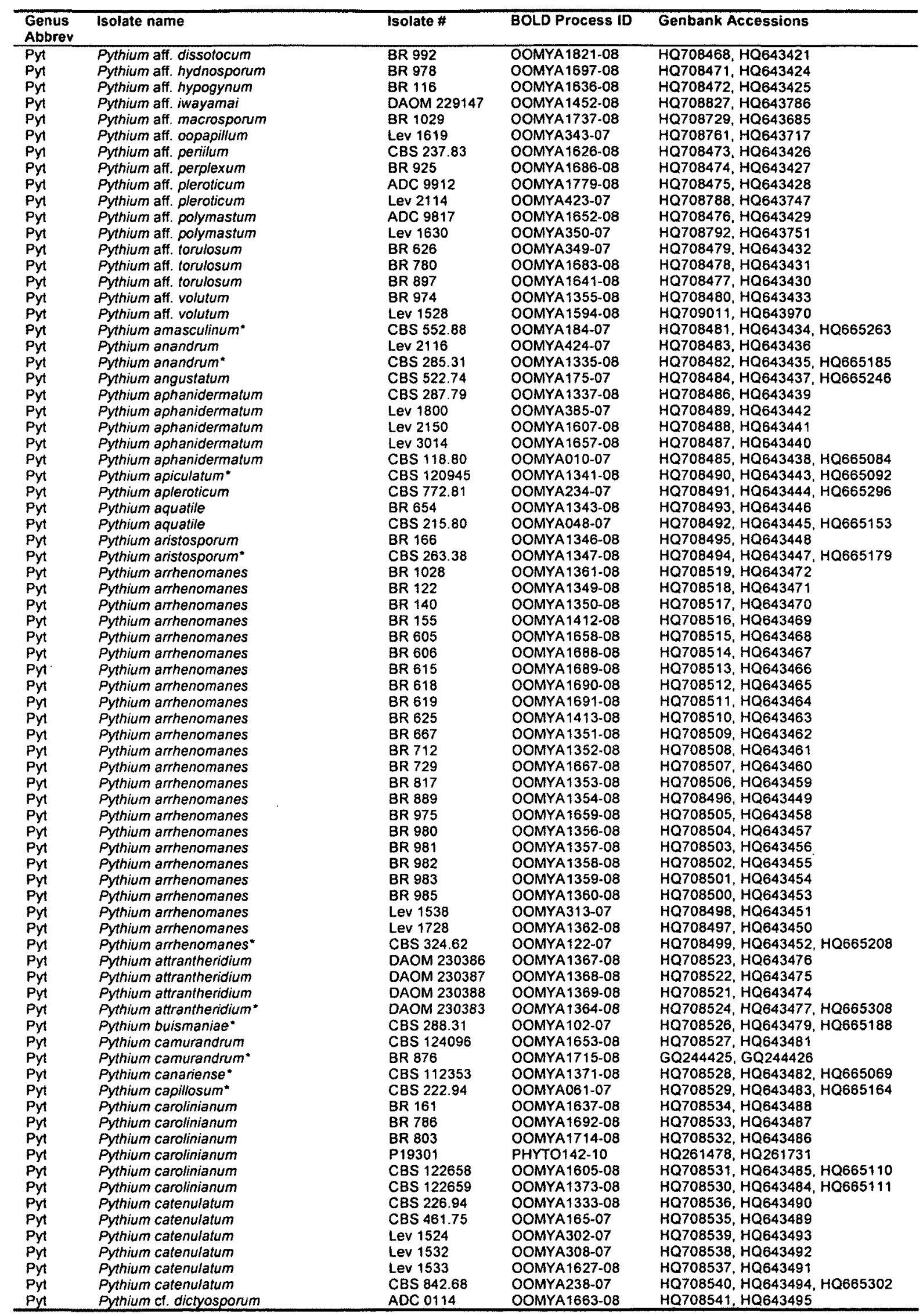




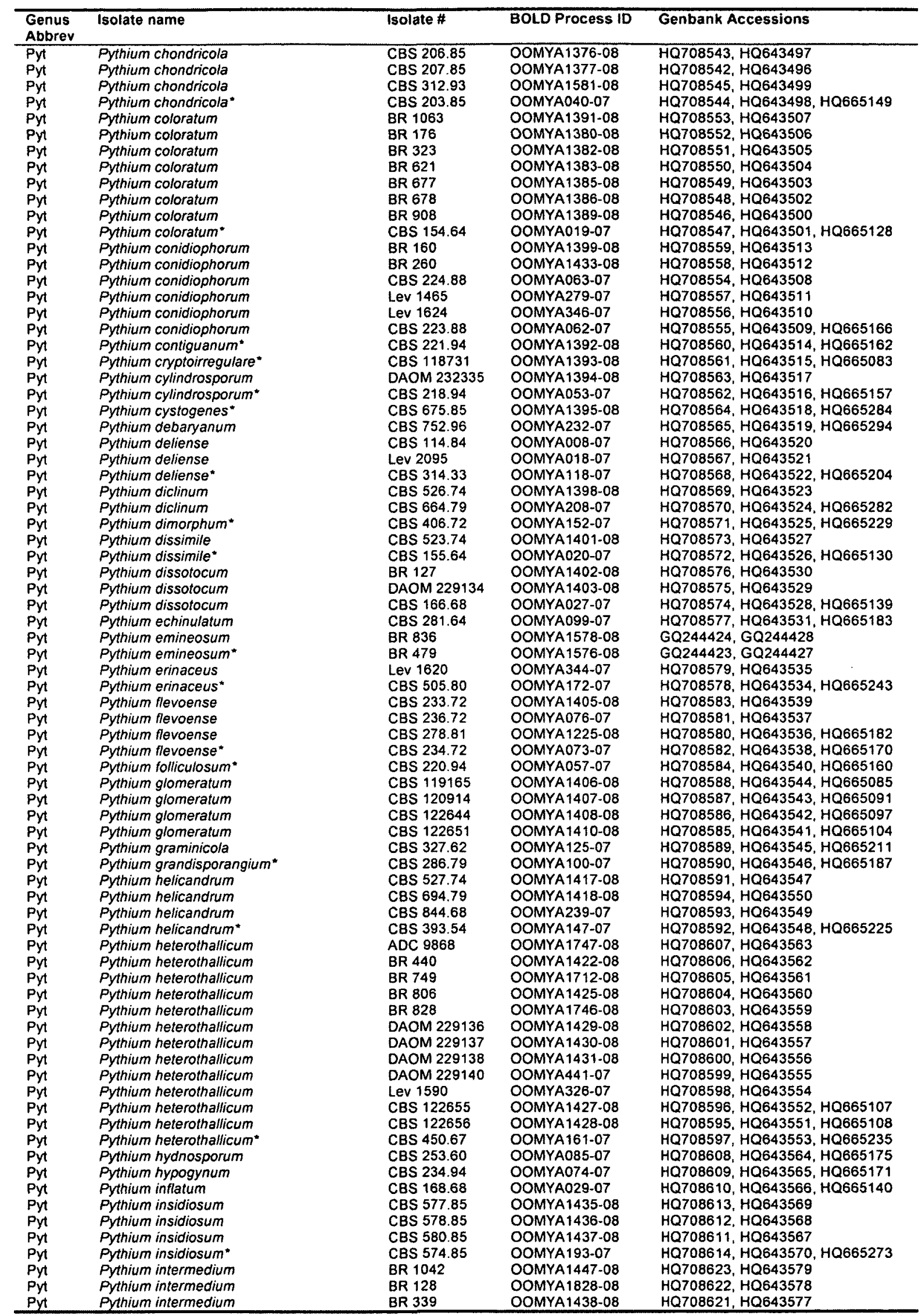




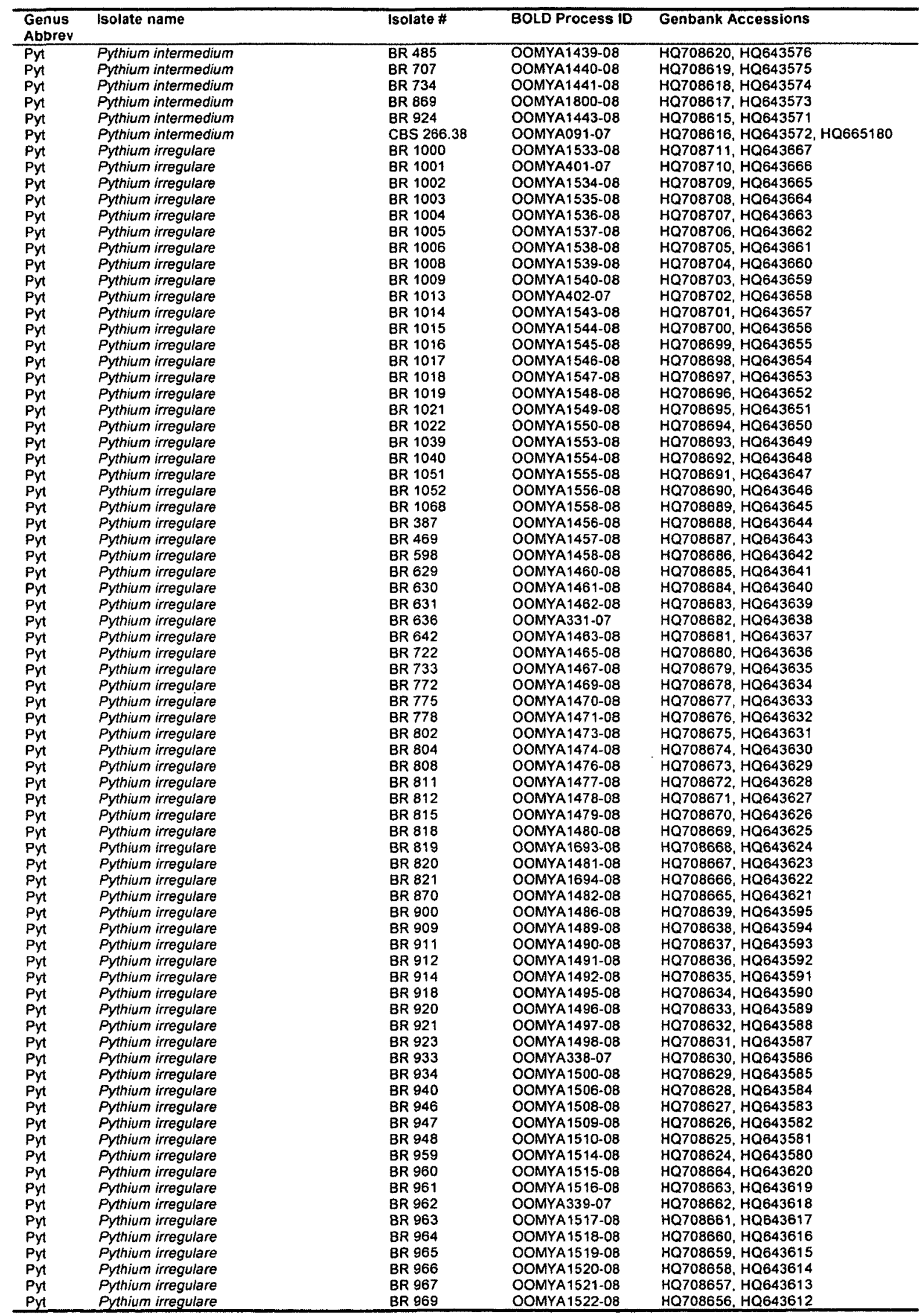




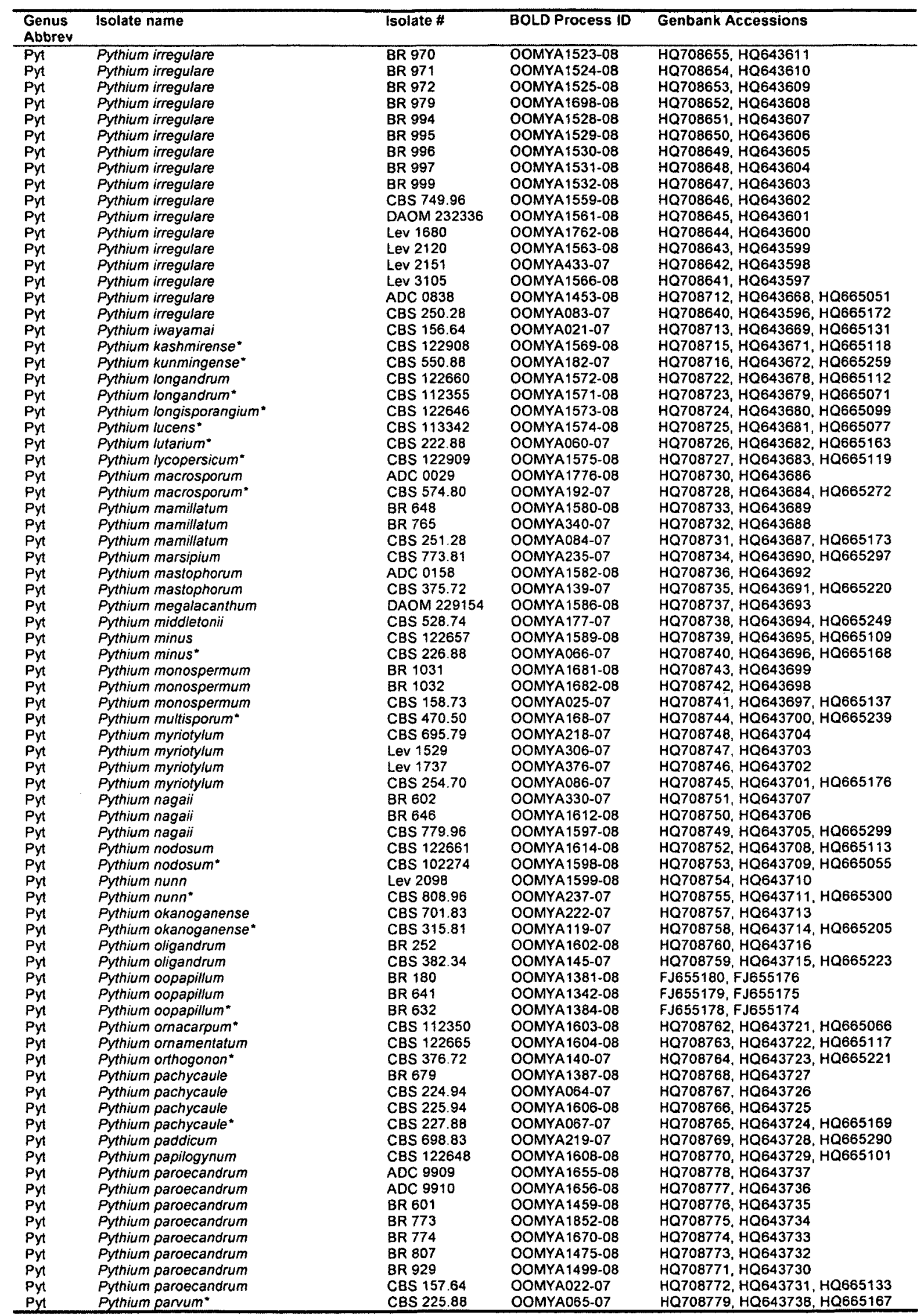









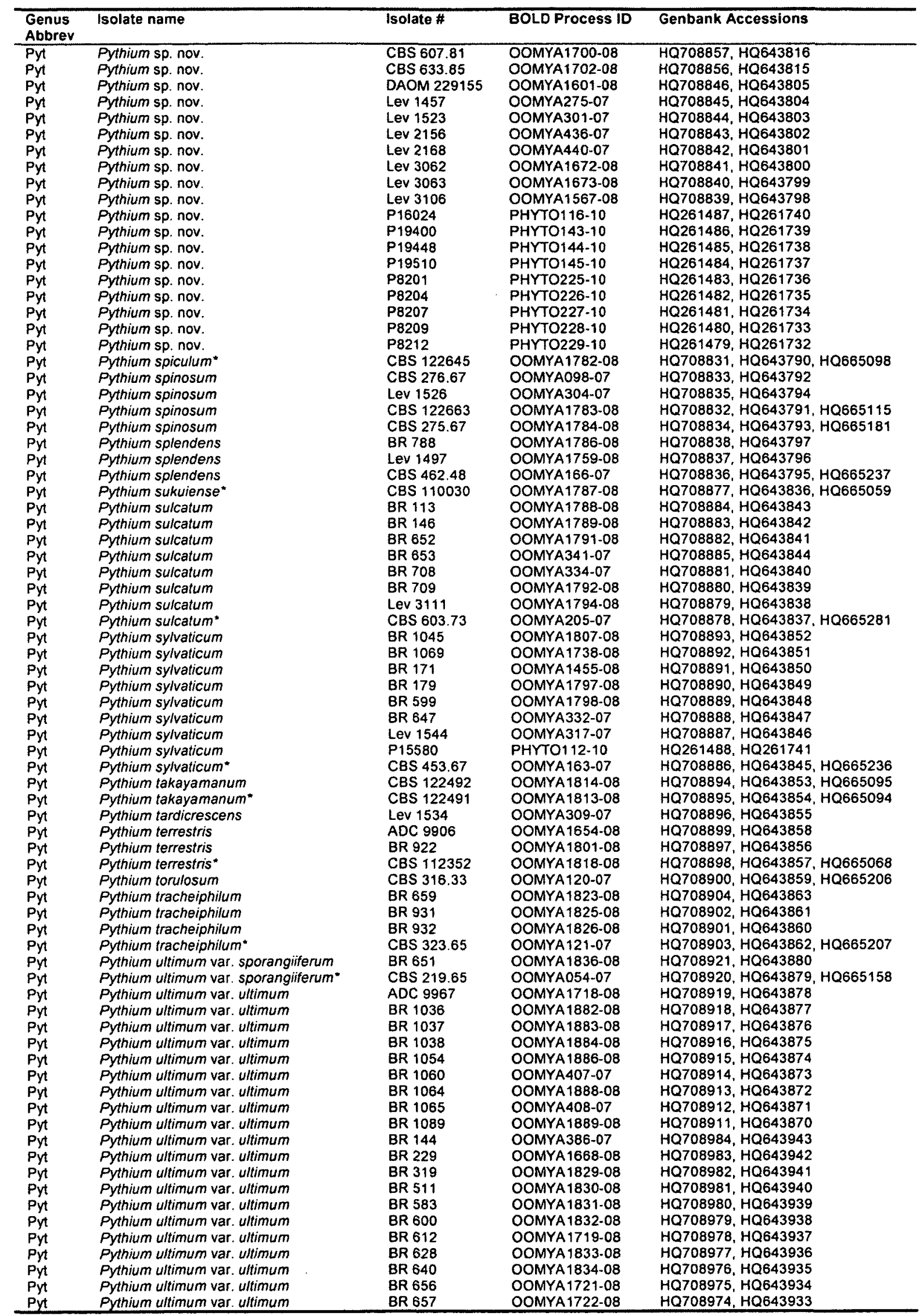




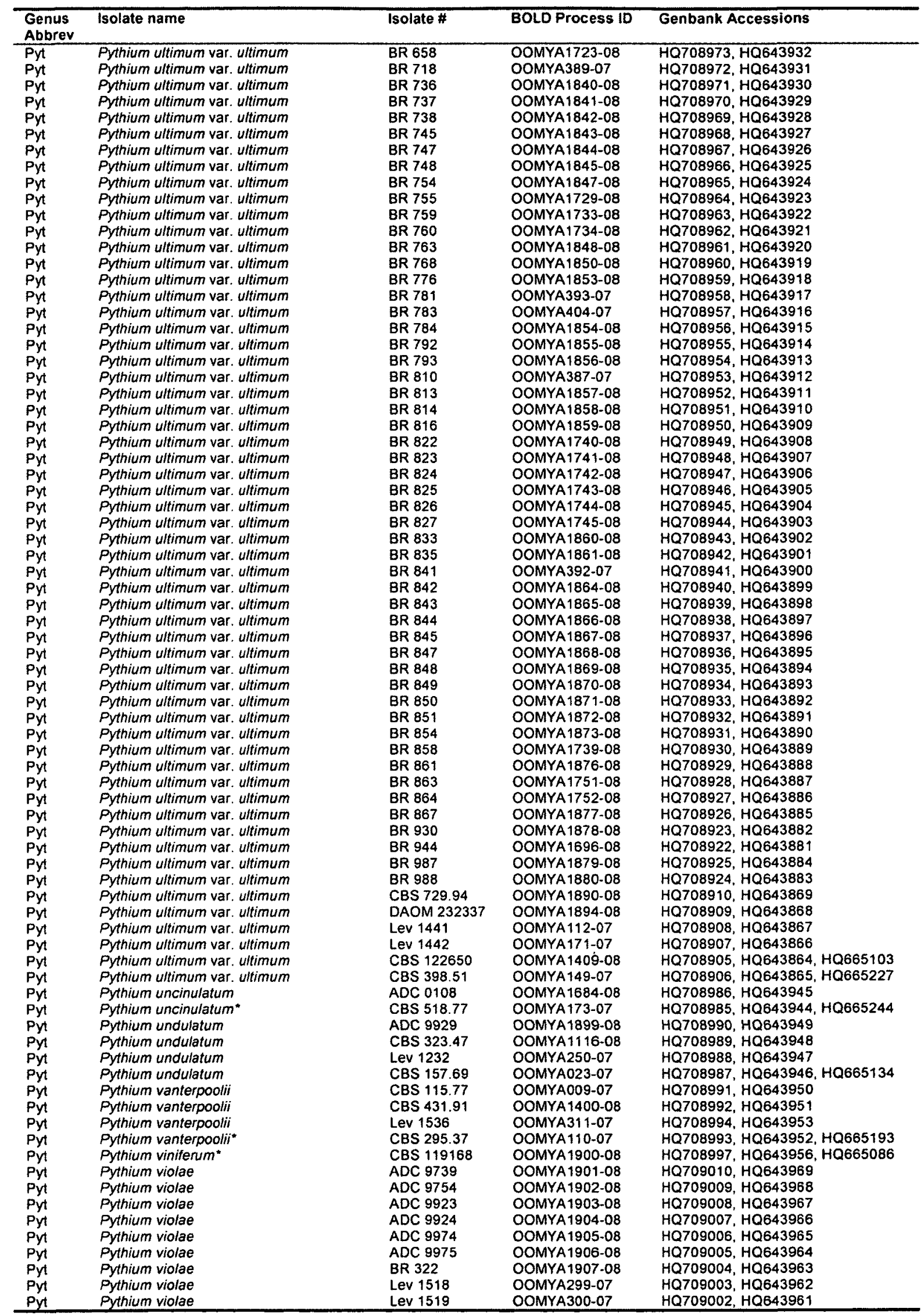




\begin{tabular}{|c|c|c|c|c|}
\hline $\begin{array}{l}\text { Genus } \\
\text { Abbrev }\end{array}$ & Isolate name & Isolate \# & BOLD Process ID & Genbank Accessions \\
\hline $\begin{array}{l}\text { Pyt } \\
\text { Pyt } \\
\text { Pyt } \\
\text { Pyt } \\
\text { Pyt } \\
\text { Pyt } \\
\text { Pyt } \\
\text { Sap } \\
\text { Sap } \\
\text { Sap } \\
\text { Sap } \\
\text { Sap } \\
\text { Sap } \\
\text { Sap } \\
\text { Sap } \\
\text { Sap } \\
\text { Sap } \\
\text { Sap } \\
\text { Sap } \\
\text { Sap } \\
\text { Sap } \\
\text { Sap } \\
\text { Sap } \\
\text { Sap } \\
\text { Sap } \\
\text { Sap } \\
\text { Sap } \\
\text { Sap } \\
\text { Sap } \\
\text { Sap } \\
\text { Sap } \\
\text { Sap } \\
\text { Sap } \\
\text { Sap } \\
\text { Sap } \\
\text { Sap } \\
\text { Sap } \\
\text { Sap } \\
\text { Sap } \\
\text { Sap } \\
\text { Sap } \\
\text { Sap } \\
\text { Sap } \\
\text { Sap } \\
\text { Sap } \\
\text { Sap } \\
\text { Sap } \\
\text { Sap } \\
\text { Sap } \\
\text { Tap } \\
\text { Thr }\end{array}$ & $\begin{array}{l}\text { Pythium violae } \\
\text { Pythium violae } \\
\text { Pythium violae } \\
\text { Pythium violae } \\
\text { Pythium volutum } \\
\text { Pythium zingiberis } \\
\text { Pythium zingiberis } \\
\text { Saprolegnia anisospora } \\
\text { Saprolegnia asterophora } \\
\text { Saprolegnia delica } \\
\text { Saprolegnia delica } \\
\text { Saprolegnia diclina } \\
\text { Saprolegnia diclina } \\
\text { Saprolegnia diclina } \\
\text { Saprolegnia eccentrica } \\
\text { Saprolegnia eccentrica } \\
\text { Saprolegnia eccentrica } \\
\text { Saprolegnia ferax } \\
\text { Saprolegnia ferax } \\
\text { Saprolegnia ferax } \\
\text { Saprolegnia ferax } \\
\text { Saprolegnia ferax } \\
\text { Saprolegnia hypogyna } \\
\text { Saprolegnia lapponica } \\
\text { Saprolegnia litoralis } \\
\text { Saprolegnia litoralis } \\
\text { Saprolegnia megasperma } \\
\text { Saprolegnia mixta } \\
\text { Saprolegnia mixta } \\
\text { Saprolegnia monilifera } \\
\text { Saprolegnia monilifera } \\
\text { Saprolegnia monoica } \\
\text { Saprolegnia monoica } \\
\text { Saprolegnia parasitica } \\
\text { Saprolegnia parasitica } \\
\text { Saprolegnia parasitica } \\
\text { Saprolegnia parasitica } \\
\text { Saprolegnia parasitica } \\
\text { Saprolegnia parasitica } \\
\text { Saprolegnia rodrigueziana } \\
\text { Saprolegnia sp. } \\
\text { Saprolegnia subterranea } \\
\text { Saprolegnia subterranea } \\
\text { Saprolegnia terrestris } \\
\text { Saprolegnia terrestris } \\
\text { Saprolegnia turfosa } \\
\text { Saprolegnia turfosa } \\
\text { Saprolegnia turfosa } \\
\text { Saprolegnia unispora } \\
\text { Saprolegnia unispora } \\
\text { Thraustotheca clavata } \\
\text { Thraustotheca clavata } \\
\text { Thraustotheca terrestris* }\end{array}$ & $\begin{array}{l}\text { LeV } 1604 \\
\text { LeV } 1605 \\
\text { CBS } 159.64 \\
\text { CBS } 178.86 \\
\text { CBS } 699.83 \\
\text { CBS } 217.82 \\
\text { CBS } 216.82 \\
\text { CBS } 110060 \\
\text { CBS } 531.67 \\
\text { CBS } 344.62 \\
\text { CBS } 345.62 \\
\text { CBS } 282.38 \\
\text { CBS } 326.35 \\
\text { CBS } 536.67 \\
\text { CBS } 199.38 \\
\text { CBS } 211.35 \\
\text { CBS } 551.67 \\
\text { BR } 114 \\
\text { CBS } 283.38 \\
\text { CBS } 534.67 \\
\text { CBS } 173.42 \\
\text { CBS } 305.37 \\
\text { CBS } 869.72 \\
\text { CBS } 284.38 \\
\text { CBS } 110062 \\
\text { CBS } 535.67 \\
\text { CBS } 532.67 \\
\text { CBS } 149.65 \\
\text { CBS } 307.37 \\
\text { CBS } 552.67 \\
\text { CBS } 558.67 \\
\text { CBS } 539.67 \\
\text { CBS } 599.67 \\
\text { CBS } 113187 \\
\text { CBS } 223.65 \\
\text { CBS } 300.32 \\
\text { CBS } 302.56 \\
\text { CBS } 397.34 \\
\text { CBS } 540.67 \\
\text { CBS } 119354 \\
\text { CBS } 632.85 \\
\text { CBS } 278.52 \\
\text { CBS } 113343 \\
\text { CBS } 533.67 \\
\text { CBS } 110063 \\
\text { CBS } 110065 \\
\text { CBS } 313.81 \\
\text { CBS } 327.35 \\
\text { CBS } 110066 \\
\text { CBS 213.35 } \\
\text { CBS } 343.33 \\
\text { CBS } 557.67 \\
\text { CBS } 109851 \\
\end{array}$ & $\begin{array}{l}\text { OOMYA336-07 } \\
\text { OOMYA337-07 } \\
\text { OOMYA026-07 } \\
\text { OOMYA033-07 } \\
\text { OOMYA220-07 } \\
\text { OOMYA1909-08 } \\
\text { OOMYA050-07 } \\
\text { OOMYA1910-08 } \\
\text { OOMYA1911-08 } \\
\text { OOMYA1912-08 } \\
\text { OOMYA1913-08 } \\
\text { OOMYA1915-08 } \\
\text { OOMYA1916-08 } \\
\text { OOMYA1917-08 } \\
\text { OOMYA1918-08 } \\
\text { OOMYA1919-08 } \\
\text { OOMYA1920-08 } \\
\text { OOMYA1921-08 } \\
\text { OOMYA1923-08 } \\
\text { OOMYA1925-08 } \\
\text { OOMYA1922-08 } \\
\text { OOMYA1924-08 } \\
\text { OOMYA1927-08 } \\
\text { OOMYA1928-08 } \\
\text { OOMYA1929-08 } \\
\text { OOMYA1930-08 } \\
\text { OOMYA1932-08 } \\
\text { OOMYA1933-08 } \\
\text { OOMYA1934-08 } \\
\text { OOMYA1935-08 } \\
\text { OOMYA1936-08 } \\
\text { OOMYA1939-08 } \\
\text { OOMYA1940-08 } \\
\text { OOMYA1941-08 } \\
\text { OOMYA1942-08 } \\
\text { OOMYA1943-08 } \\
\text { OOMYA1944-08 } \\
\text { OOMYA1945-08 } \\
\text { OOMYA1946-08 } \\
\text { OOMYA1948-08 } \\
\text { OOMYA1701-08 } \\
\text { OOMYA1950-08 } \\
\text { OOMYA1914-08 } \\
\text { OOMYA1952-08 } \\
\text { OOMYA1951-08 } \\
\text { OOMYA1953-08 } \\
\text { OOMYA1954-08 } \\
\text { OOMYA1938-08 } \\
\text { OOMYA1955-08 } \\
\text { OOMYA1956-08 } \\
\text { OOMYA1957-08 } \\
\text { OOMYA1958-08 }\end{array}$ & 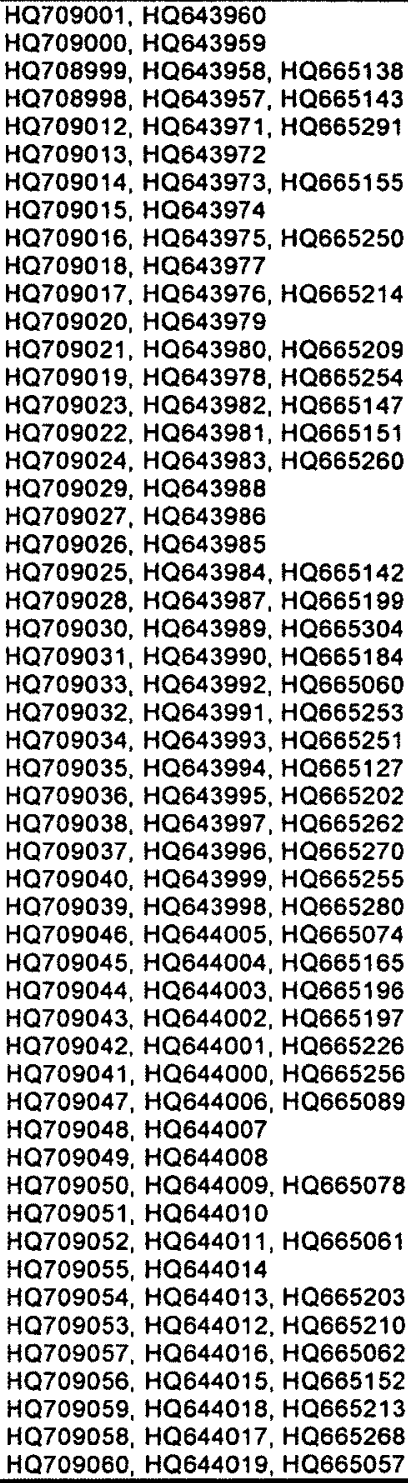 \\
\hline
\end{tabular}


Appendix B - Species resolved by COI that are indistinguishable by ITS.

\section{Phytophthora:}

- Phytophthora cambivora and Phytophthora alni

Pythium:

- Pythium catenulatum and Pythium rhizo-oryzae

- Pythium graminicola, Pythium periilum, and Pythium tardicrescens

- Pythium sylvaticum and Pythium terrestris

- Pythium mamillatum and Pythium spiculum

- Pythium attrantheridium and Pythium sp. "balticum"

- Pythium aquatile and Pythium sukuiense

- Pythium capillosum and Pythium flevoense

\section{Phytopythium:}

- Phytopythium boreale and Phytopythium megacarpum

- Phytopythium sp. "grandilobatum" and Phytopythium oedochilum

Appendix C - Species that are indistinguishable with either COI or ITS.

\section{Phytophthora:}

- Phytophthora capsici and Phytophthora mexicana (Mchau \& Coffey, 1995)

- Phytophthora melonis and Phytophthora sinensis (Erwin \& Ribeiro, 1996, Mirabolfathy, et al., 2001, Guharoy, et al., 2006)

- Phytophthora arecae and Phytophthora palmivora

- Phytophthora erythroseptica and Phytophthora himalayensis

- Phytophthora nicotianae and Phytophthora tabaci

- Phytophthora parsiana and Phytophthora sp. "thermophilum" or Phytophthora sp. "lagoariana"

In the last example, one isolate of $P$. parsiana shows conspecificity with $P$. sp.

"thermophilum", one shows conspecificity with $P$. sp. "lagoariana", and the third $P$. parsiana (P21281) seems separate from the rest.

Pythium:

- Pythium myriotylum and Pythium zingiberis

- Pythium aristosporum and Pythium arrhenomanes

- Pythium amasculinum, Pythium hydnosporum, Pythium lycopersicum, and Pythium ornamentatum.

- Pythium folliculosum and Pythium torulosum

- Pythium conidiophorum and Pythium salpingophorum

- Pythium debaryanum and Pythium viniferum

- Pythium irregulare, Pythium cryptoirregulare, and Pythium cylindrosporum

- Pythium acrogynum and Pythium hypogynum

- Pythium erinaceus and Pythium ornacarpum

- Pythium minus and Pythium pleroticum 
- Pythium dimorphum and Pythium undulatum

Saprolegnia:

- Saprolegnia subterranea and Saprolegnia rodrigueziana

Thraustotheca:

- Thraustotheca clavata and Thraustotheca terrestris

Appendix D - Apparent species complexes based on COI and ITS.

Achlya:

- Achlya ambisexualis, Achlya bisexualis, and Achlya heterosexualis

Phytophthora:

- Phytophthora citricola, Phytophthora inflata, Phytophthora pini, and Phytophthora plurivora.

- Phytophthora cryptogea, Phytophthora erythroseptica, Phytophthora sp. "kelmania", and Phytophthora cryptogea f. sp. begoniae

Other Phytophthora species that could be considered a complex on their own are:

- Phytophthora megasperma (Hansen \& Maxwell, 1991)

- Phytophthora cryptogea (Gallegly \& Hong, 2008)

\section{Pythium:}

- Pythium glomeratum and Pythium heterothallicum

- Pythium rhizosaccharum and Pythium takayamanum

- Pythium buismaniae, Pythium megalacanthum, Pythium polymastum, and Pythium uncinulatum.

Other Pythium species that could be considered a complex on their own are:

- Pythium irregulare (Barr, et al., 1997)

- Pythium ultimum var. ultimum (Barr, et al., 1996)

- Pythium acanthicum

- Pythium okanoganense

- Pythium violae (epithet is currently assigned to two distinct isolates from carrot and soil that occupy different clades in the genus Pythium).

\section{Phytopythium:}

- Phytopythium vexans and Phytopythium cucurbitacearum

\section{Saprolegnia}

- Saprolegnia ferax, Saprolegnia parasitica, Saprolegnia diclina, Saprolegnia lapponica, Saprolegnia mixta, Saprolegnia unispora, Saprolegnia hypogyna, and Saprolegnia delica 
Appendix E - Flagellar apparatus-related genes in Pythium and Phytophthora. Expression levels of Pythium ultimum genes are shown from hypoxia and Arabidopsis infection (Lévesque, et al., 2010).

\begin{tabular}{|c|c|c|c|c|c|c|c|c|c|}
\hline GenBank & Name & Function & $\begin{array}{c}\text { Pu } \\
\text { E-value }\end{array}$ & $\begin{array}{c}\text { Ps } \\
\text { E-value }\end{array}$ & $\begin{array}{c}\mathrm{Pr} \\
\text { E-value }\end{array}$ & $\begin{array}{c}\mathbf{P i} \\
\text { E-value }\end{array}$ & $\begin{array}{c}\text { Ha } \\
\text { E-value }\end{array}$ & $\begin{array}{l}\text { Hypoxia } \\
\text { RPKM }\end{array}$ & $\begin{array}{c}\text { Arabidopsis } \\
\text { RPKM }\end{array}$ \\
\hline gil 59485786 & ANK24 & $\begin{array}{l}\text { flagellar associated } \\
\text { protein }\end{array}$ & $e-152$ & $e-157$ & $e-156$ & $e-156$ & $9.0 \mathrm{E}-07$ & 4.975277 & 11.836567 \\
\hline gil59482892 & VFL2 & centrin & $5.0 \mathrm{E}-15$ & $9.0 \mathrm{E}-11$ & $9.0 \mathrm{E}-11$ & $7.0 \mathrm{E}-08$ & $2.0 \mathrm{E}-06$ & 26.481349 & 23.834006 \\
\hline gil 159474390 & VFL3 & $\begin{array}{l}\text { templated centriole } \\
\text { assembly }\end{array}$ & $2.0 \mathrm{E}-56$ & $4.0 \mathrm{E}-49$ & $7.0 \mathrm{E}-48$ & $4.0 \mathrm{E}-47$ & 3.9 & 0.898252 & 0.462289 \\
\hline gi 112734843 & SNF1 & $\begin{array}{l}\text { serine/threonine } \\
\text { protein kinase }\end{array}$ & $3.0 \mathrm{E}-35$ & $4.0 \mathrm{E}-41$ & $1.0 \mathrm{E}-40$ & $2.0 \mathrm{E}-41$ & $8.0 \mathrm{E}-38$ & 10.746487 & 12.950776 \\
\hline gi156766597 & IFTI44 & $\begin{array}{c}\text { intraflagellar } \\
\text { transport subunit } 144\end{array}$ & $e-166$ & $e-17 !$ & $e-170$ & $e-160$ & $2.0 \mathrm{E}-17$ & 0.242387 & 1.978383 \\
\hline gi159475992 & $\operatorname{IFr} 140$ & $\begin{array}{c}\text { intraflagellar } \\
\text { transport subunit } 140\end{array}$ & $1.0 \mathrm{E}-09$ & $8.0 \mathrm{E}-14$ & $5.0 \mathrm{E}-31$ & $2.0 \mathrm{E}-31$ & 0.71 & 0.084901 & 0.646769 \\
\hline gil 56630943 & KPL2 & $\begin{array}{l}\text { sperm flagellar } \\
\text { protein }\end{array}$ & $3.0 E-17$ & $5.0 \mathrm{E}-18$ & $7.0 \mathrm{E}-17$ & $7.0 \mathrm{E}-18$ & 0.015 & 0.95311 & 0.670222 \\
\hline gi 134084607 & An $18 \mathrm{c} 0170$ & $\begin{array}{l}\text { sperm tail associated } \\
\text { protein }\end{array}$ & 0.064 & 0.21 & 0.12 & 0.32 & 0.26 & 6.198063 & 4.538835 \\
\hline gi30580462 & DYHIB & $\begin{array}{l}\text { axonemal dynein } \\
\text { heavy chain l-beta }\end{array}$ & 0 & 0 & 0 & 0 & $e .179$ & 0.050607 & 0.041306 \\
\hline gil 72044682 & DYHIA & $\begin{array}{c}\text { flagellar inner arm } \\
\text { dynein heavy chain } \\
\text { l-alpha }\end{array}$ & 0 & 0 & 0 & 0 & 0 & 0.264108 & 0.479844 \\
\hline gi238231321 & OCM2 & $\begin{array}{l}\text { tubular mastigoneme } \\
\text { protein }\end{array}$ & $2.0 \mathrm{E}-53$ & $3.0 \mathrm{E}-53$ & $2.0 E-48$ & $5.0 \mathrm{E}-51$ & $1.0 \mathrm{E}-04$ & 10.328066 & 0.553628 \\
\hline gii 56632335 & IFT22 & $\begin{array}{c}\text { intraflagellar } \\
\text { transport subunit } 22\end{array}$ & 0.012 & $2.0 \mathrm{E}-06$ & 0.017 & $6.0 \mathrm{E}-04$ & 0.045 & 0.383921 & 0 \\
\hline gi46361984 & Hydin & $\begin{array}{c}\text { central pair flagellar } \\
\text { protein }\end{array}$ & 0 & 0 & 0 & 0 & no hits & 0.795243 & 0.979478 \\
\hline gil 72044538 & DYH2 & axonemal dynein & 0 & 0 & 0 & 0 & 0 & 0.745752 & 0.68105 \\
\hline gi2754612 & DNAL4 & $\begin{array}{l}\text { axonemal dynein } \\
\text { light chain } 4\end{array}$ & $1.0 \mathrm{E}-14$ & $2.0 E-16$ & $2.0 \mathrm{E}-16$ & $4.0 \mathrm{E}-17$ & $4.0 \mathrm{E}-07$ & 72.773384 & 34.516482 \\
\hline gil59469750 & OPEL & $\begin{array}{l}\text { thaumatin-like } \\
\text { secretory protein }\end{array}$ & 0.049 & 0.042 & 0.055 & 0.32 & 0.57 & 0.619814 & 0.973757 \\
\hline gi 75338601 & DNALI & $\begin{array}{l}\text { axonemal dynein } \\
\text { light chain ! }\end{array}$ & $4.0 \mathrm{E}-37$ & $6.0 \mathrm{E}-32$ & 4.0E-36 & $7.0 \mathrm{E}-37$ & $6.0 \mathrm{E}-11$ & 0.604104 & 0 \\
\hline gill 69693 & FLA 10 & $\begin{array}{l}\text { axonemal kinesin II } \\
\text { motor protein }\end{array}$ & $e-154$ & e-151 & e- 152 & $e-152$ & $3.0 \mathrm{E}-77$ & 0 & 0 \\
\hline gil 58280836 & KLPI & $\begin{array}{l}\text { axonemal kinesin- } \\
\text { like protein }\end{array}$ & $4.0 \mathrm{E}-81$ & $e-110$ & $1.0 \mathrm{E}-93$ & $e-109$ & $9.0 \mathrm{E}-55$ & 0.287059 & 2.342999 \\
\hline gi 159469111 & ANK 10 & $\begin{array}{c}\text { flagellar associated } \\
\text { protein }\end{array}$ & $1.0 \mathrm{E}-22$ & $9.0 \mathrm{E}-22$ & 5. $0 \mathrm{E}-23$ & $2.0 \mathrm{E}-17$ & $2.0 \mathrm{E}-16$ & 59.818471 & 126.131418 \\
\hline gi 71658800 & AKMI & $\begin{array}{c}\text { axonemal } \\
\text { kinesin/myosin-type } \\
\text { protein }\end{array}$ & $3.0 \mathrm{E}-05$ & $3.0 \mathrm{E}-06$ & $3.0 \mathrm{E}-04$ & $5.0 \mathrm{E}-04$ & 0.002 & 0.349882 & 0.324202 \\
\hline gi15193244 & AKM2 & $\begin{array}{c}\text { axonemal } \\
\text { kinesin/myosin-lype } \\
\text { protein }\end{array}$ & $2.0 \mathrm{E}-54$ & $2.0 \mathrm{E}-48$ & $6.0 \mathrm{E}-31$ & $4.0 \mathrm{E}-42$ & $3.0 \mathrm{E}-23$ & 16.747003 & 7.722479 \\
\hline gi61214500 & ANKPI & unknown & $2.0 E-06$ & 4.0E-07 & 4.0E-06 & $7.0 \mathrm{E}-05$ & 2.0E-06 & 108.64238 & 32.518791 \\
\hline gil 50371706 & OCM1 & $\begin{array}{l}\text { tubular mastigoneme } \\
\text { protein }\end{array}$ & $2.0 \mathrm{E}-61$ & $9.0 \mathrm{E}-60$ & $5.0 \mathrm{E}-55$ & $9.0 \mathrm{E}-56$ & 0.029 & 0.069511 & 3.177184 \\
\hline gi 74716342 & DYH7 & $\begin{array}{l}\text { axonemal dynein } \\
\text { heavy chain } 7\end{array}$ & 0 & 0 & 0 & 0 & 0 & 0.137818 & 0.385673 \\
\hline gil 59483419 & ANK19 & $\begin{array}{l}\text { flagellar associated } \\
\text { protein }\end{array}$ & $8.0 \mathrm{E}-49$ & 4.0E-49 & $3.0 \mathrm{E}-49$ & $4.0 \mathrm{E}-48$ & $5.0 \mathrm{E}-33$ & 2.839957 & 7.226302 \\
\hline gil 59478625 & FAP208 & $\begin{array}{l}\text { flagellar associated } \\
\text { protein }\end{array}$ & $2.0 \mathrm{E}-75$ & 4.0E-76 & $3.0 \mathrm{E}-76$ & $5.0 \mathrm{E}-77$ & $1.0 \mathrm{E}-07$ & 94.601084 & 81.255677 \\
\hline gi29825690 & IFT74 & $\begin{array}{c}\text { intraflagellar } \\
\text { transport subunit } 74\end{array}$ & $7.0 E-63$ & $4.0 \mathrm{E}-60$ & $2.0 \mathrm{E}-6 \mathrm{I}$ & $2.0 \mathrm{E}-60$ & $3.0 \mathrm{E}-08$ & 1.272272 & 3.503662 \\
\hline gil 59477026 & LRRI & unknown & $7.0 \mathrm{E}-17$ & 3.0E-09 & $5.0 \mathrm{E}-06$ & $5.0 \mathrm{E}-14$ & 0.022 & 2.170167 & 0.66489 \\
\hline gi2494209 & ODA2 & dynein gamma chain & 0 & 0 & 0 & 0 & 0 & 0.208189 & 0.733265 \\
\hline gi71384457 & LRR2 & unknown & 0.031 & 0.099 & 0.85 & 3.8 & 4 & 0.104301 & 0.148229 \\
\hline gi2317719 & AKM3 & $\begin{array}{c}\text { axonemal } \\
\text { kinesin/myosin-type } \\
\text { protein }\end{array}$ & $2.0 \mathrm{E}-14$ & $7.0 E-18$ & $2.0 \mathrm{E}-12$ & $3.0 \mathrm{E}-16$ & $1.0 \mathrm{E}-10$ & 0 & 0 \\
\hline
\end{tabular}




\begin{tabular}{|c|c|c|c|c|c|c|c|c|c|}
\hline GenBank & Name & Function & $\begin{array}{c}\text { Pu } \\
\text { E-value }\end{array}$ & $\begin{array}{c}\text { Ps } \\
\text { E-value }\end{array}$ & $\begin{array}{c}\mathrm{Pr} \\
\text { E-value }\end{array}$ & $\begin{array}{c}\text { Pi } \\
\text { E-value }\end{array}$ & $\begin{array}{c}\text { Ha } \\
\text { E-value }\end{array}$ & $\begin{array}{l}\text { Hypoxia } \\
\text { RPKM }\end{array}$ & $\begin{array}{c}\text { Arabidopsis } \\
\text { RPKM }\end{array}$ \\
\hline gi9716372 & CALK & $\begin{array}{l}\text { serine/threonine } \\
\text { protein kinase }\end{array}$ & $4.0 \mathrm{E}-41$ & $3.0 \mathrm{E}-31$ & $3.0 \mathrm{E}-39$ & $2.0 \mathrm{E}-42$ & $8.0 \mathrm{E}-43$ & 2.254314 & 2,823795 \\
\hline gil 58513400 & FAPI89 & $\begin{array}{c}\text { flagellar associated } \\
\text { protein }\end{array}$ & $9.0 \mathrm{E}-21$ & $2.0 \mathrm{E}-25$ & $6.0 \mathrm{E}-21$ & $5.0 \mathrm{E}-21$ & $3.0 \mathrm{E}-18$ & 1.668341 & 0.325047 \\
\hline gi83284725 & RSP7 & radial spoke protein 7 & $2.0 \mathrm{E}-42$ & $3.0 \mathrm{E}-13$ & $1.0 \mathrm{E}-37$ & $4.0 \mathrm{E}-14$ & 4.0E-09 & 0.182844 & 0.298478 \\
\hline gi61814636 & SPEF 1 & $\begin{array}{l}\text { flagellar associated } \\
\text { protein }\end{array}$ & $6.0 \mathrm{E}-24$ & $4.0 \mathrm{E}-27$ & $2.0 \mathrm{E}-28$ & $2.0 \mathrm{E}-27$ & 2.9 & 1.908435 & 0.298478 \\
\hline gi27805726 & SPAG4 & $\begin{array}{c}\text { flagellar associated } \\
\text { protein }\end{array}$ & 0.031 & $7.0 \mathrm{E}-05$ & 4.0E-06 & 0.069 & 0.007 & 4.752934 & 4.56398 \\
\hline gil 82637563 & DYHIO & $\begin{array}{l}\text { axonemal dynein } \\
\text { heavy chain } 10\end{array}$ & 0 & 0 & 0 & 0 & 0 & 0.192741 & 0.629266 \\
\hline gi75142763 & GAS8 & $\begin{array}{l}\text { dynein regulatory } \\
\text { complex protein }\end{array}$ & $e-102$ & e-117 & $e-106$ & $e-118$ & $4.0 \mathrm{E}-07$ & 0.080103 & 0.523047 \\
\hline gi 18277872 & DYHIIA & $\begin{array}{c}\text { axonemal dynein } \\
\text { heavy chain } 11 \text { aipha }\end{array}$ & 0 & 0 & 0 & 0 & 0 & 0.047278 & 0.308712 \\
\hline gi71384428 & $\mathrm{Cla}-18$ & $\begin{array}{c}\text { axoneme central } \\
\text { apparatus associated } \\
\text { protein }\end{array}$ & $1.0 \mathrm{E}-16$ & $2.0 \mathrm{E}-18$ & $5.0 \mathrm{E}-18$ & $5.0 \mathrm{E}-17$ & $9.0 \mathrm{E}-12$ & 22.466426 & 111.678633 \\
\hline gi33591148 & CAMK2D & $\begin{array}{c}\text { calcium/calmodulin } \\
\text { protein kinase II }\end{array}$ & $5.0 \mathrm{E}-47$ & $2.0 \mathrm{E}-51$ & $4.0 \mathrm{E}-47$ & $1.0 \mathrm{E}-49$ & $7.0 \mathrm{E}-48$ & 39.548012 & 78.251099 \\
\hline gil 56631028 & $|F T 12|$ & $\begin{array}{c}\text { intraflagellar } \\
\text { transport subunit } 121\end{array}$ & 0 & 0 & 0 & 0 & 0.25 & 2.519586 & 6.070168 \\
\hline gill7380778 & CCRK & $\begin{array}{c}\text { cell-cycle related } \\
\text { kinase }\end{array}$ & $1.0 \mathrm{E}-41$ & $2.0 \mathrm{E}-50$ & $8.0 \mathrm{E}-50$ & $9.0 \mathrm{E}-50$ & $2.0 \mathrm{E}-41$ & 4.241256 & 1.852766 \\
\hline gi75337416 & DYHIB & $\begin{array}{c}\text { axonemal dynein } 2 \\
\text { heavy chain lb }\end{array}$ & 0 & 0 & 0 & 0 & 0 & -0.222218 & 2.121905 \\
\hline gil 59488240 & RSPIO & $\begin{array}{c}\text { radial spoke protein } \\
10\end{array}$ & $6.0 \mathrm{E}-27$ & $6.0 \mathrm{E}-24$ & $6.0 \mathrm{E}-24$ & $4.0 \mathrm{E}-22$ & 2.0E-07 & 1.056154 & 4.388576 \\
\hline gi 122137042 & ODF3 & $\begin{array}{l}\text { flagellar outer dense } \\
\text { fiber } 3\end{array}$ & $7.0 \mathrm{E}-08$ & $7.0 \mathrm{E}-09$ & $9.0 \mathrm{E}-09$ & $8.0 \mathrm{E}-09$ & 2.4 & 0.90439 & 1.476341 \\
\hline gil 59466466 & ARL 3 & $\begin{array}{l}\text { ADP ribosylation } \\
\text { factor } 3\end{array}$ & $1.0 \mathrm{E}-26$ & $4.0 \mathrm{E}-2.5$ & $3.0 \mathrm{E}-25$ & $2.0 \mathrm{E}-24$ & $7.0 \mathrm{E}-18$ & 1.118461 & 3.605944 \\
\hline gi71063501 & AGG2 & $\begin{array}{c}\text { flagellar associated } \\
\text { protein }\end{array}$ & $6.0 E-04$ & 0.004 & 0.009 & $2,0 \mathrm{E}-06$ & 0.35 & 0 & 0 \\
\hline gil 59474288 & FAP21 & $\begin{array}{c}\text { flagellar associated } \\
\text { protein }\end{array}$ & $4.0 \mathrm{E}-12$ & $5.0 \mathrm{E}-12$ & $2.0 \mathrm{E}-11$ & $2.0 \mathrm{E}-11$ & $5.0 \mathrm{E}-11$ & 0.405764 & 0.316359 \\
\hline gil 48832347 & PKD2 & $\begin{array}{l}\text { polycistin cation } \\
\text { channel }\end{array}$ & $1.0 E-15$ & $6.0 \mathrm{E}-12$ & $7.0 \mathrm{E}-15$ & 8.0E-08 & $5.0 \mathrm{E}-08$ & 0 & 0 \\
\hline gi29648322 & DNAJBI & $\begin{array}{c}\text { Dna-J class } \\
\text { molecular chaperone }\end{array}$ & $1.0 \mathrm{E}-65$ & $5.0 \mathrm{E}-65$ & $4.0 \mathrm{E}-65$ & $4.0 \mathrm{E}-62$ & $8.0 \mathrm{E}-60$ & 2478.3068 & 172.608664 \\
\hline gi 14548081 & IDA4 & $\begin{array}{l}\text { axonemal dynein } \\
\text { light chain inner arm } \\
4\end{array}$ & $1.0 E-67$ & $8.0 E-66$ & $1.0 \mathrm{E}-66$ & $1.0 \mathrm{E}-64$ & 0.057 & 0 & 0 \\
\hline gi2226459514 & PPI-1 & $\begin{array}{l}\text { axonemal protein } \\
\text { phosphatase }\end{array}$ & $e-130$ & e-102 & $e-135$ & $e-135$ & $e-105$ & 220.74383 & 478.212376 \\
\hline gi158271520 ' & $\mathrm{PPI}-2$ & $\begin{array}{l}\text { axonemal protein } \\
\text { phosphatase }\end{array}$ & $e-123$ & e-110 & e- 127 & $e-145$ & $e-114$ & 210.63475 & 442.973938 \\
\hline gi 156632333 & FAP232 & $\begin{array}{c}\text { flagellar associated } \\
\text { protein }\end{array}$ & $5.0 \mathrm{E}-16$ & $3.0 \mathrm{E}-09$ & $2.0 \mathrm{E}-12$ & $2.0 \mathrm{E}-07$ & no hits & 1.98547 & 0 \\
\hline gi82082176 & AKM4 & $\begin{array}{c}\text { axonemal } \\
\text { kinesin/myosin-type } \\
\text { protein }\end{array}$ & $1.0 \mathrm{E}-22$ & $5,0 \mathrm{E}-22$ & $2.0 \mathrm{E}-18$ & $9.0 \mathrm{E}-20$ & $4.0 \mathrm{E}-18$ & 0.03129 & 0 \\
\hline gi81900317 & Rpgrip II & $\begin{array}{l}\text { retinitis pigmentosa } \\
\text { GTPase regulator } \\
\text { interacting protein }\end{array}$ & $2.0 \mathrm{E}-46$ & $6.0 \mathrm{E}-46$ & $7.0 \mathrm{E}-40$ & $3.0 \mathrm{E}-38$ & $5.0 \mathrm{E}-12$ & 0.870304 & 1.584423 \\
\hline gi212286121 & $\mathrm{PFI3}$ & $\begin{array}{l}\text { pre-assembly of } \\
\text { axonemal dyneins }\end{array}$ & $7.0 \mathrm{E}-29$ & $2.0 \mathrm{E}-16$ & $4.0 \mathrm{E}-26$ & $1.0 \mathrm{E}-27$ & $2.0 \mathrm{E}-06$ & 2.307763 & 1.777213 \\
\hline gi238231323 & OCM4 & $\begin{array}{c}\text { tubular mastigoneme } \\
\text { protein }\end{array}$ & $3.0 \mathrm{E}-66$ & $3.0 \mathrm{E}-63$ & $1.0 \mathrm{E}-62$ & $2.0 \mathrm{E}-64$ & $3.0 \mathrm{E}-04$ & 3.031403 & 2.440884 \\
\hline gil 59486159 & EBI & $\begin{array}{l}\text { microtubule plus-end } \\
\text { binding protein }\end{array}$ & $5.0 \mathrm{E}-85$ & $1.0 \mathrm{E}-71$ & $4.0 \mathrm{E}-84$ & $4.0 E-41$ & $3.0 \mathrm{E}-39$ & 58.489909 & 103.594999 \\
\hline gi| 59467981 & IFT52 & $\begin{array}{c}\text { intraflagellar } \\
\text { transport subunit } 52\end{array}$ & $3.0 \mathrm{E}-94$ & $2.0 \mathrm{E}-73$ & $3.0 \mathrm{E}-74$ & $3.0 \mathrm{E}-73$ & 9.4 & 0.166882 & 2.724201 \\
\hline gi61680380 & Tclexl & $\begin{array}{c}\text { axonemal dynein } \\
\text { light chain inner arm } \\
4\end{array}$ & $1.0 \mathrm{E}-23$ & $2.0 \mathrm{E}-23$ & $2.0 \mathrm{E}-23$ & $1.0 \mathrm{E}-23$ & $9.0 \mathrm{E}-09$ & 3.242392 & 7.913023 \\
\hline gi29839411 & ANXEI & annexin $E \mathbf{l}$ & $1.0 \mathrm{E}-13$ & $1.0 \mathrm{E}-10$ & $4.0 \mathrm{E}-10$ & $1.0 \mathrm{E}-11$ & $3.0 \mathrm{E}-09$ & 4195.8408 & 1425.681039 \\
\hline gi2811014 & DNAL6 & $\begin{array}{l}\text { axonemal dynein } \\
\text { light chain outer arm } \\
6\end{array}$ & $4.0 \mathrm{E}-46$ & $7.0 E-46$ & $6.0 \mathrm{E}-46$ & $2.0 \mathrm{E}-45$ & $1.0 \mathrm{E}-45$ & 306.5572 & 151.887844 \\
\hline
\end{tabular}




\begin{tabular}{|c|c|c|c|c|c|c|c|c|c|}
\hline GenBank & Name & Function & $\begin{array}{c}\text { Pu } \\
\text { E-value }\end{array}$ & $\begin{array}{c}\text { Ps } \\
\text { E-value }\end{array}$ & $\begin{array}{c}\text { Pr } \\
\text { E-value }\end{array}$ & $\begin{array}{c}\text { Pi } \\
\text { E-value }\end{array}$ & $\begin{array}{c}\text { Ha } \\
\text { E-value }\end{array}$ & $\begin{array}{c}\text { Hypoxia } \\
\text { RPKM }\end{array}$ & $\begin{array}{l}\text { Arabidopsis } \\
\text { RPKM }\end{array}$ \\
\hline gi 125302 & FCK & $\begin{array}{c}\text { flagellar creatine } \\
\text { kinase }\end{array}$ & 0 & 0 & 0 & 0 & 5.8 & 20.406949 & 77.028099 \\
\hline git22166113 & ODA7 & $\begin{array}{l}\text { outer row flagellar } \\
\text { dynein assembly } \\
\text { protein }\end{array}$ & $3.0 \mathrm{E}-43$ & $1.0 \mathrm{E}-48$ & $2.0 \mathrm{E}-47$ & $1.0 \mathrm{E}-48$ & $5.0 \mathrm{E}-09$ & 0 & 0.777902 \\
\hline gíl3157754 & DHC64C & $\begin{array}{l}\text { cytoplasmic dyne in } \\
\text { heavy chain }\end{array}$ & $8.0 \mathrm{E} \cdot 17$ & $6.0 \mathrm{E}-16$ & $5.0 \mathrm{E}-16$ & $2.0 E-15$ & $8.0 E-16$ & 5.139509 & 13.211344 \\
\hline gil 59467108 & IFTI 72 & $\begin{array}{c}\text { intraflagellar } \\
\text { transport subunit } 172\end{array}$ & 0 & 0 & 0 & 0 & $8.0 E-06$ & 0.140336 & 0.393744 \\
\hline gi159476286 & FAP279 & $\begin{array}{c}\text { flagellar associated } \\
\text { protein }\end{array}$ & 0 & 0 & 0 & 0 & 0.002 & 0.112806 & 0 \\
\hline gill 68796 & Caltractin & $\begin{array}{l}\text { basal body associated } \\
\text { calcium binding } \\
\text { protein }\end{array}$ & $7.0 \mathrm{E}-72$ & $3.0 \mathrm{E}-71$ & $2.0 \mathrm{E}-71$ & $6.0 \mathrm{E}-71$ & $5.0 \mathrm{E}-51$ & 16.715682 & 17.756905 \\
\hline gi61217633 & IFT 80 & $\begin{array}{c}\text { intraflagellar } \\
\text { transport subunit } 80\end{array}$ & 0 & 0 & 0 & 0 & $8.0 \mathrm{E}-06$ & 0.384307 & 0.896212 \\
\hline gill1145351 & IFT46 & $\begin{array}{l}\text { intraflagellar } \\
\text { transport subunit } 46\end{array}$ & $5.0 \mathrm{E}-65$ & $2.0 \mathrm{E}-65$ & $6.0 \mathrm{E}-65$ & $9.0 \mathrm{E}-63$ & 6.5 & 0.069742 & 1.138472 \\
\hline gi82400100 & IFTS7 & $\begin{array}{c}\text { intraflagellar } \\
\text { transport subunit } 57\end{array}$ & $9.0 \mathrm{E}-30$ & $2.0 \mathrm{E}-39$ & $3.0 \mathrm{E}-37$ & $4.0 \mathrm{E}-36$ & 0.016 & 1.867536 & 2.956215 \\
\hline gil 34041 & RSP3 & radial spoke protein 3 & $7.0 \mathrm{E}-39$ & $1.0 E-35$ & $8.0 \mathrm{E}-36$ & $1.0 \mathrm{E}-31$ & 8.5 & 0 & 0.43726 \\
\hline gil 59489466 & RSP2 & radial spoke protein 2 & $4.0 \mathrm{E}-05$ & 4.0E-05 & $1.0 \mathrm{E}-05$ & $2.0 \mathrm{E}-04$ & 0.31 & 0.084958 & 0.944803 \\
\hline gill17607157 & FBBS & $\begin{array}{l}\text { flagellar basal body } \\
\text { protein (predicted) }\end{array}$ & 0.42 & 2.7 & 1.7 & 1.2 & 2 & 3.804724 & 5.115736 \\
\hline gi221222440 & B9D2 & $\begin{array}{l}\text { B9 domain- } \\
\text { containing protein } 2\end{array}$ & $3.0 \mathrm{E}-44$ & $1.0 \mathrm{E}-36$ & $3.0 \mathrm{E}-37$ & $5.0 \mathrm{E}-37$ & 0.25 & 0.926525 & 0 \\
\hline gi74762434 & IFT 139 & $\begin{array}{c}\text { intraflagellar } \\
\text { transport subunit } 139\end{array}$ & e- 160 & 0 & 0 & 0 & 0.008 & 0.340205 & 0.749871 \\
\hline gil 59484104 & IFT88 & $\begin{array}{c}\text { intraflagellar } \\
\text { transport subunit } 88\end{array}$ & $9.0 \mathrm{E}-21$ & $6.0 \mathrm{E}-20$ & $2.0 \mathrm{E}-21$ & $1.0 \mathrm{E}-18$ & $2.0 \mathrm{E}-18$ & 0.199851 & 0.406212 \\
\hline gi4 2412387 & NDPK6 & $\begin{array}{c}\text { flagellar radial spoke } \\
\text { nucleoside } \\
\text { diphosphate kinase }\end{array}$ & $2.0 \mathrm{E}-32$ & $3.0 \mathrm{E}-33$ & $8.0 \mathrm{E}-35$ & $1.0 \mathrm{E}-28$ & $6.0 \mathrm{E}-16$ & 0.029326 & 0.191492 \\
\hline gil 59470411 & RSPl & radial spoke protein I & $1.0 \mathrm{E}-63$ & $3.0 \mathrm{E}-33$ & $2.0 \mathrm{E}-58$ & 8.0E-62 & $3.0 \mathrm{E}-07$ & 0.667526 & 0.476735 \\
\hline gil 59486617 & VFLI & $\begin{array}{c}\text { variable flagella } \\
\text { protein } 1\end{array}$ & 0 & 0 & 0 & 0 & 0 & 0.472518 & 0.530301 \\
\hline gil 22138665 & DC2LI & $\begin{array}{l}\text { axonemal dynein } 2 \\
\text { light intermediate } \\
\text { chain } 1\end{array}$ & $2.0 \mathrm{E}-36$ & $8.0 \mathrm{E}-38$ & $4.0 \mathrm{E}-37$ & $4.0 \mathrm{E}-34$ & 3.9 & 0 & 0.346717 \\
\hline gil 59468277 & ODA4 & $\begin{array}{l}\text { axonemal dynein } \\
\text { beta chain, flagellar } \\
\text { outer arm } \\
\text { importin }\end{array}$ & $3.0 \mathrm{E}-21$ & $2.0 \mathrm{E}-20$ & $4.0 \mathrm{E}-21$ & $4.0 \mathrm{E}-19$ & $3.0 \mathrm{E}-19$ & 133.28077 & 55.375525 \\
\hline gill 17923377 & $\begin{array}{l}\text { PRED- } \\
\text { UNKI }\end{array}$ & $\begin{array}{l}\text { predicted protein, } \\
\text { bacterial flagellin } \\
\text { domain }\end{array}$ & 0.036 & 0.2 & 0.089 & $9.0 \mathrm{E}-11$ & $7.0 E-44$ & 0.56433 & 54.17535 \\
\hline gil 58282063 & KAPI & $\begin{array}{l}\text { kinesin associated } \\
\text { protein } 1\end{array}$ & $5.0 \mathrm{E}-82$ & $1.0 \mathrm{E}-84$ & $1.0 \mathrm{E}-84$ & $3.0 E-84$ & 3.1 & 0.133505 & 0 \\
\hline gilo939!1S1 & ODA 16 & $\begin{array}{l}\text { axonemal dynein, } \\
\text { flagellar outer arm }\end{array}$ & $2.0 \mathrm{E}-36$ & $2.0 \mathrm{E}-38$ & 4.0E-38 & $9.0 \mathrm{E}-41$ & $2.0 \mathrm{E}-30$ & 0.968352 & 12.399678 \\
\hline gil 3157760 & DHC8 & $\begin{array}{l}\text { axonemal dynein } \\
\text { heavy chain } 8, \\
\text { flagellar inner arm }\end{array}$ & $2.0 \mathrm{E}=12$ & $4.0 \mathrm{E}-12$ & $3,0 E-12$ & $|.0 E-| \mid$ & $9.0 E-07$ & 0.382089 & 0.769707 \\
\hline gi401050 & RSP4 & radial spoke protein 4 & $3.0 \mathrm{E}-17$ & $9.0 \mathrm{E}-20$ & $9.0 \mathrm{E}-20$ & $4.0 \mathrm{E}-21$ & 0.88 & 1.172117 & 1.488187 \\
\hline gi32130553 & LF4 & $\begin{array}{l}\text { MAP kinase involved } \\
\text { in flagellar length } \\
\text { control }\end{array}$ & $e-128$ & $e-129$ & $e-129$ & e-126 & $2.0 E-46$ & 1.637978 & 0.852793 \\
\hline gi159465329 & RSP16 & $\begin{array}{c}\text { radial spoke protein } \\
16\end{array}$ & $2.0 \mathrm{E}-46$ & $1.0 \mathrm{E}-51$ & $5.0 \mathrm{E}-51$ & $6.0 \mathrm{E}-50$ & $2.0 \mathrm{E}-51$ & 0 & 0 \\
\hline gil 59469762 & FAP134 & $\begin{array}{c}\text { flagellar associated } \\
\text { protein }\end{array}$ & $2.0 \mathrm{E}-09$ & $6.0 \mathrm{E}-09$ & $9.0 E-10$ & $3.0 \mathrm{E}=08$ & $7.0 \mathrm{E}-09$ & 0.920912 & 0 \\
\hline gil 58280659 & BLDIO & $\begin{array}{c}\text { flagellar basal body } \\
\text { protein }\end{array}$ & $3.0 \mathrm{E}-12$ & $2.0 E-09$ & $2.0 \mathrm{E}-08$ & $5.0 \mathrm{E}-08$ & $3.0 \mathrm{E}-09$ & 28.940794 & 11.379463 \\
\hline gi50660932 & CPKGI & $\begin{array}{c}\text { flagellar cGMP- } \\
\text { dependent protein } \\
\text { kinase }\end{array}$ & $6.0 E-82$ & $7.0 E-85$ & $9.0 \mathrm{E}-85$ & $1.0 \mathrm{E}-78$ & $5.0 \mathrm{E}-66$ & 3.564768 & 13.0312 \\
\hline gi2494215 & ODA9 & $\begin{array}{l}\text { axonemal dynein } \\
\text { intermediate chain, } \\
\text { flagellar outer arm }\end{array}$ & $e-162$ & $e-161$ & $e-160$ & $e-161$ & 0.004 & 0 & 0.380859 \\
\hline
\end{tabular}




\begin{tabular}{|c|c|c|c|c|c|c|c|c|c|}
\hline GenBank & Name & Function & $\begin{array}{c}\mathbf{P u}_{\mathrm{u}} \\
\text { E-value }\end{array}$ & $\begin{array}{c}\text { Ps } \\
\text { E-value }\end{array}$ & $\begin{array}{c}\mathrm{Pr} \\
\text { E-value }\end{array}$ & $\begin{array}{c}\mathbf{P i} \\
\text { E-value }\end{array}$ & $\begin{array}{c}\text { Ha } \\
\text { E-value }\end{array}$ & $\begin{array}{c}\text { Hypoxia } \\
\text { RPKM }\end{array}$ & $\begin{array}{l}\text { Arabidopsis } \\
\text { RPKM }\end{array}$ \\
\hline gi159483683 & PPCTI & $\begin{array}{l}\text { peptidyl-prolyl cis- } \\
\text { trans isomerase }\end{array}$ & $6.0 \mathrm{E}-15$ & $9.0 \mathrm{E}-14$ & $7.0 \mathrm{E}-11$ & $5.0 \mathrm{E}-11$ & $4.0 \mathrm{E}-08$ & 141.80215 & 102.521256 \\
\hline gil 101777 & PF 16 & $\begin{array}{c}\text { axoneme central } \\
\text { apparatus }\end{array}$ & 0 & 0 & 0 & 0 & $1.0 \mathrm{E}-16$ & 1.180196 & 1.699421 \\
\hline gil 59486599 & HSP70A & heat shock protein 70 & $4.0 \mathrm{E}-36$ & $4.0 \mathrm{E}-36$ & $5.0 \mathrm{E}-35$ & $1.0 \mathrm{E}-35$ & $5.0 \mathrm{E}-37$ & 3749.1331 & 608.983783 \\
\hline gil 59487717 & RSP8 & radial spoke protein 8 & 0.004 & $3.0 \mathrm{E}-07$ & 1.0E-05 & $3.0 \mathrm{E}-06$ & 0.39 & 3.587389 & 0 \\
\hline gil 59478264 & IFT8I & $\begin{array}{c}\text { intraflagellar } \\
\text { transport subunit } 81\end{array}$ & 1.3 & 1.1 & 0.3 & 0.27 & 2.4 & 0.580911 & 0.198985 \\
\hline gi71384450 & $\mathrm{Cla}-34$ & $\begin{array}{c}\text { axoneme central } \\
\text { apparatus associated } \\
\text { protein }\end{array}$ & $3.0 \mathrm{E}-06$ & 0.021 & $5.0 E-05$ & 0.054 & 9.3 & 0.503642 & 3.956617 \\
\hline gi27922947 & FIBH & fibroin heavy chain & $2.0 \mathrm{E}-20$ & $1.0 \mathrm{E}-17$ & $9.0 \mathrm{E}-14$ & $3.0 \mathrm{E}-13$ & 0.001 & 91.796882 & 122.161487 \\
\hline gil 59487911 & IFT20 & $\begin{array}{c}\text { intraflagellar } \\
\text { Iransport subunit } 20\end{array}$ & 3.3 & 0.047 & 0.93 & 1.2 & 1.1 & 0 & 0 \\
\hline
\end{tabular}

$\mathrm{Pu}$ - Pythium ultimum, $\mathrm{Ps}$ - Phytophthora sojae, $\mathrm{Pr}$ - Phytophthora ramorum, $\mathrm{Pi}$ - Phytophthora infestans, $\mathrm{Ha}$ - Hyaloperonospora arabidopsidis, RPKM - Reads Per Kilobase per Million mapped reads. 
Appendix F - Isolates used in this study, their host/substrate, and GenBank accessions of DNA sequence data. Footnotes refer to sequences accessed directly from genome assemblies.

\begin{tabular}{|c|c|c|c|c|c|}
\hline Species & Isolate Number & Isolated From & $\begin{array}{l}\text { PF16 } \\
\text { Accession }\end{array}$ & $\begin{array}{l}\text { OCM1 } \\
\text { Accession }\end{array}$ & $\begin{array}{l}\text { LSU } \\
\text { Accession }\end{array}$ \\
\hline Achlya racemosa & CBS 103.38 & unknown & $\mathrm{JX} 115023$ & JXI15117 & $\mathrm{JXI15214}$ \\
\hline Achlya radiosa & CBS 547.67 & unknown & $J X 115024$ & $J X 115118$ & $\mathrm{JX} 115215$ \\
\hline Albugo candida & Ac2VRR & Brassica rapa & $\mathrm{JX} 556328$ & JX556329 & HQ665049 \\
\hline Albugo laibachii & $\mathrm{Ncl} 14$ & Arabidopsis thaliana & Footnote ${ }^{a}$ & Footnote $^{\mathrm{a}}$ & FR825184 \\
\hline Aphanomyces astaci & CBS 121537 & unknown & $\mathrm{JX} 115025$ & $J \times 115116$ & $J X 115216$ \\
\hline Aphanomyces cladogamus & CBS 108.29 & Lycopersicon esculentum & JX115026 & JX115119 & HQ665056 \\
\hline Aphanomyces cochlioides & CBS 477.71 & Beta vulgaris & $J \times 115027$ & $J \times 115120$ & HQ665241 \\
\hline Aphanomyces euteiches & CBS 156.73 & Pisum sativum & & $J X 115121$ & HQ665132 \\
\hline Apodachlya brachynema & CBS 557.69 & unknown & & $\mathrm{JX} 436345$ & $J \times 436350$ \\
\hline Dictyuchus monosporus & Lev 1848 & lake water & JX436354 & $\mathrm{JX} 436346$ & $J X 436351$ \\
\hline Ectocarpus siliculosus & $\mathrm{Ec} 32$ & sea water & Footnote ${ }^{b}$ & Footnote $^{b}$ & Footnote $^{b}$ \\
\hline $\begin{array}{l}\text { Halophytophthora } \\
\text { operculata }\end{array}$ & CBS 241.83 & Avicennia marina & $\mathrm{JX} 115028$ & $J X 115122$ & $J X 115217$ \\
\hline $\begin{array}{l}\text { Halophytophthora } \\
\text { polymorphica }\end{array}$ & CBS 680.84 & Eucalyptus sp. & $J X 115029$ & $J X 115123$ & HQ665288 \\
\hline Halophytophthora vesicula & CBS 393.81 & $\begin{array}{l}\text { Prunus laurocerasus leaf in } \\
\text { Pacific Ocean }\end{array}$ & $\mathrm{JX} 436355$ & $J \times 436347$ & $\mathrm{JX} 436352$ \\
\hline Lagenidium caudatum & CBS 584.85 & soil from cattle pen & JX115070 & $J \times 115165$ & HQ665277 \\
\hline Myzocytiopsis sp. & Lev 6103 & nematodes in rabbit dung & JX436357 & $\mathrm{JX} 436348$ & $J \times 436353$ \\
\hline Phytophthora capsici & LTI534 & Cucumis sp./Cucurbitasp. & Footnote $^{c}$ & Footnote $^{c}$ & \\
\hline Phytophthora capsici & CBS 128.23 & Capsicum annuum & & & HQ665120 \\
\hline Phytophthora cinnamomi & CBS 144.22 & Cinnamomum burmannii & $\mathrm{JX} 115032$ & $J \times 115126$ & HQ665126 \\
\hline Phytophthora cryptogea & CBS 113.19 & $\begin{array}{l}\text { Lycopersicon esculentum or } \\
\text { Petunia }\end{array}$ & $J \times 115033$ & $J \times 115127$ & HQ665075 \\
\hline Phytophthora drechsleri & CBS 291.35 & Beta vulgaris & $\mathrm{JX} 115034$ & $J \times 115128$ & EU079511 \\
\hline Phytophthora erythroseptica & CBS 380.61 & Tulipa sp. & $J X 115035$ & $J X 115129$ & HQ665121 \\
\hline Phytophthora fragariae & CBS 209.46 & Fragaria sp. & $\mathrm{JX} 115036$ & $J X 115130$ & HQ665150 \\
\hline Phytophthora gonapoctyides & CBS 554.67 & unknown & $\mathrm{JX} 115037$ & $J X 115131$ & HQ665265 \\
\hline Phytophthora heveae & CBS 296.29 & Hevea brasiliensis & JX115038 & $\mathrm{JX} 115132$ & HQ665194 \\
\hline Phytophthora hibernalis & CBS 522.77 & Aquilegia vulgaris & JXI15039 & $J X 115133$ & EU079518 \\
\hline Phytophthora humicola & CBS 200.81 & soil from citrus orchard & $J \times 115040$ & $J X 115134$ & HQ665148 \\
\hline Phytophthora ilicis & CBS 255.93 & unknown & JXI15041 & $J X 115135$ & EU079864 \\
\hline Phytophthora infestans & CBS 366.51 & Solanum tuberosum & $J X 115042$ & $J X 115136$ & HQ665217 \\
\hline Phytophthora infestans & Lev 1429 & Solanum tuberosum & $J X 115043$ & $J X 115137$ & \\
\hline Phytophthora infestans & $\mathrm{T} 30-4$ & Solanum tuberosum & Footnote ${ }^{d}$ & Footnote $^{d}$ & \\
\hline Phytophthora iranica & CBS 374.72 & Solanum melongena & JX115044 & $\mathrm{JX} 115138$ & HQ665219 \\
\hline Phytophthora katsurae & CBS 587.85 & soil & $J \times 115045$ & $\mathrm{JX} 115139$ & HQ665278 \\
\hline Phytophthora lateralis & CBS 168.42 & $\begin{array}{l}\text { Chamaecyparis } \\
\text { lawsoniana }\end{array}$ & $J \times 115046$ & $\mathrm{JX} 115140$ & EU080093 \\
\hline Phytophthora medicaginis & DAOM BR 331 & Medicago sativa & $\mathrm{JX} 115047$ & $J \times 115141$ & EU080695 \\
\hline Phytophthora megasperma & CBS 306.36 & Brassica sp. & $\mathrm{JX} 115048$ & $J \times 115142$ & HQ665201 \\
\hline Phytophthora mirabilis & CBS 678.85 & Mirabilis jalapa & JXI15049 & $J X 115143$ & HQ665285 \\
\hline $\begin{array}{l}\text { Phytophthora } \\
\text { multivesiculata }\end{array}$ & CBS 545.96 & Cymbidium $\mathrm{sp}$ & $\mathrm{JX} 115050$ & $J \times 115144$ & HQ665257 \\
\hline Phytophthora nicotianae & DAOM BR 235 & Euphorbia pulcherrima & $\mathrm{JX} 115051$ & $\mathrm{JX} 115145$ & EU079560 \\
\hline Phytophthora phaseoli & CBS 556.88 & Phaseolus lunatus & $\mathrm{JX} 115052$ & $J X 115146$ & HQ665267 \\
\hline Phytophthora psychrophila & CBS 803.95 & $\begin{array}{l}\text { rhizosphere of decaying } \\
\text { Quercus robur }\end{array}$ & $\mathrm{JX} 115053$ & $J X 115147$ & EU080521 \\
\hline Phytophthora ramorum & $\operatorname{Pr}-102$ & Quercus agrifolia & Footnote & Footnote $^{e}$ & \\
\hline Phytophihora ramorum & CBS 101553 & Rhododendron catawbiense & & & HQ665053 \\
\hline Phytophthora rubi & CBS 967.95 & Rubus idaeus & $\mathrm{JX} 115054$ & JX115148 & HQ665306 \\
\hline
\end{tabular}




\begin{tabular}{|c|c|c|c|c|c|}
\hline Species & Isolate Number & Isolated From & $\begin{array}{l}\text { PF16 } \\
\text { Accession }\end{array}$ & $\begin{array}{l}\text { OCM1 } \\
\text { Accession }\end{array}$ & $\begin{array}{l}\text { LSU } \\
\text { Accession }\end{array}$ \\
\hline Phytophthora sinensis & CBS 557.88 & Cucumis salivus & JX115055 & JX115149 & HQ665269 \\
\hline Phytophthora sojae & CBS 382.61 & Glycine $\max$ & $J X 115061$ & $J \times 115155$ & HQ665224 \\
\hline Phytophthora sojae & DAOM BR 1074 & Glycine $\max$ & JX115056 & $J X 115150$ & \\
\hline Phytophthora sojae & DAOM BR 1079 & Glycine $\max$ & $J \times 115057$ & $J X 115151$ & \\
\hline Phytophthora sojae & DAOM BR 1081 & Glycine $\max$ & $\mathrm{JX} 115058$ & $\mathrm{JX} 115152$ & \\
\hline Phytophthora sojae & DAOM BR 198 & Glycine $\max$ & $J \times 115059$ & $J \times 115153$ & \\
\hline Phytophthora sojae & DAOM BR 556 & Glycine $\max$ & $\mathrm{JX} 115060$ & JXI15154 & \\
\hline Phytophthora syringae & CBS 275.74 & Malus sylvestris & JX115062 & $J X 115156$ & HQ665123 \\
\hline Phylophthora vignae & CBS 241.73 & Vigna sinensis & $J \times 115063$ & $J \times 115157$ & EU079787 \\
\hline Phytopythium helicoides & CBS 286.31 & Phaseolus vulgaris & $J X 115030$ & $J X 115 ! 24$ & HQ665186 \\
\hline Phytopythium sindhum & DAOM 238986 & rhizosphere of Musa sp. & $J X 436356$ & $\mathrm{JX} 436349$ & HQ665309 \\
\hline Phytopythium vexans & CBS 119.80 & soil & JX115031 & $\mathrm{JX} 115125$ & HQ665090 \\
\hline Plasmopara halstedii & Lev 5881 & Helianthus annuus & & $J \times 115158$ & EF553469 \\
\hline Pythium acanthophoron & CBS 337.29 & Ananas sativus & JXI15064 & $J X 115159$ & HQ665212 \\
\hline Pythium anandrum & CBS 285.31 & Rheum rhaponticum & $J \times 115065$ & $J X 115160$ & HQ665185 \\
\hline Pythium angustatum & CBS 522.74 & soil & $\mathrm{JX} 115066$ & JXI15161 & HQ665246 \\
\hline Pythium aphanidermatum & CBS 118.80 & unknown & JXI15067 & JX115162 & HQ665084 \\
\hline Pythium aristosporum & CBS 263.38 & Triticum aestivum & $J X 115068$ & $J X 115163$ & HQ665179 \\
\hline Pythium arrhenomanes & DAOM BR 983 & Hordeum vulgare & $J \times 115069$ & $J X 115164$ & HQ665208 \\
\hline Pythium coloratum & CBS 154.64 & loamy nursery soil & JX115071 & $J X 115166$ & HQ665128 \\
\hline Pythium cryptoirregulare & CBS 118731 & Euphorbia pulcherima & $J \times 115072$ & $j \times 115167$ & HQ665083 \\
\hline Pythium cylindrosporum & CBS 218.94 & soil & $J X 115073$ & $J X 115168$ & HQ665157 \\
\hline Pythium cystogenes & CBS 675.85 & Vicia faba & $J X 115074$ & $J X 115169$ & HQ665284 \\
\hline Pythium dimorphum & CBS 406.72 & Pinus taeda & $J \times 115075$ & $\mathrm{JXI15170}$ & HQ665229 \\
\hline Pythium grandisporangium & CBS 286.79 & Distichilis spicata & & $J X 115171$ & HQ665187 \\
\hline Pythium hydnasporum & CBS 253.60 & unknown & $J X 115076$ & $J \times 115172$ & HQ665175 \\
\hline Pythium hypogynum & CBS 234.94 & soil & $\mathrm{JX} 115077$ & $\mathrm{JX} 115173$ & HQ665171 \\
\hline Pythium insidiosum & CBS 574.85 & Equus ferus & $J X 115078$ & $J X 115174$ & HQ665273 \\
\hline Pythium intermedium & CBS 266.38 & Agrastis stolonifera & $\mathrm{JX} 115079$ & $J \times 115175$ & HQ665180 \\
\hline Pythium irregulare & CBS 250.28 & Phaseolus vulgaris & $J X 115085$ & $J X 115181$ & HQ665172 \\
\hline Pythium irregulare & DAOM BR 724 & Apium graveolens & $\mathrm{JX} 115080$ & $J \times 115176$ & \\
\hline Pythium irregulare & DAOM BR 751 & unknown & JX115081 & $J X 115177$ & \\
\hline Pythium irregulare & DAOM BR 772 & Daucus carota & $\mathrm{JX} 115082$ & JX115178 & \\
\hline Pythium irregulare & DAOM BR 775 & Medicago sp. & $J X I 15083$ & JXI15179 & \\
\hline Pythium irregulare & DAOM BR 812 & Triticum sp. & $J X 115084$ & $J X 115180$ & \\
\hline Pythium iwayamai & CBS 156.64 & soil under Pinus sp. & $J X 115086$ & $J \times 115182$ & HQ665131 \\
\hline Pythium kunmingense & CBS 550.88 & soil under Vicia faba & $J X 115087$ & $J X 115183$ & HQ665259 \\
\hline Pythium lutarium & CBS 222.88 & soil & $J X 115088$ & JX115184 & HQ665163 \\
\hline Pythium mamillatum & CBS 251.28 & Beta vulgaris & $\mathrm{JX} 115089$ & $J X 115185$ & HQ665173 \\
\hline Pythium multisporum & CBS 470.50 & soil & $J X 115090$ & JX115186 & HQ665239 \\
\hline Pythium myriotylum & CBS 695.79 & Vigna sinensis & $\mathrm{JX} 115091$ & $J X 115187$ & HQ665176 \\
\hline Pythium nagaii & CBS 779.96 & soil & JX115092 & $J \times 115188$ & HQ665299 \\
\hline Pythium nodosum & CBS 102274 & soil & $J X 115093$ & $J \times 115189$ & HQ665055 \\
\hline Pythium nunn & CBS 808.96 & grassland soil & $J X 115094$ & $J X 115190$ & HQ665300 \\
\hline Pythium okanoganense & CBS 315.81 & Triticum sativum & $J X 115095$ & JX115191 & HQ665205 \\
\hline Pythium oligandrum & CBS 217.46 & Viola sp. & $J \times 115097$ & JX115193 & \\
\hline Pythium oligandrum & CBS 382.34 & Viola sp. & $J \times 115098$ & $J X 115194$ & HQ665223 \\
\hline Pythium oligandrum & DAOM BR 252 & Salureja hortensis & JX115096 & $\mathrm{JX} 115192$ & \\
\hline Pythium orthogonon & CBS 376.72 & Zea mays & $J \times 115099$ & $J \times 115195$ & HQ665221 \\
\hline Pythium paddicum & CBS 698.83 & $\begin{array}{l}\text { root of Triticum sp. and } \\
\text { Hordeum sp. }\end{array}$ & $J X 115100$ & JX115196 & HQ665290 \\
\hline Pythium periplocum & CBS 170.68 & $\begin{array}{l}\text { soil under Saccharum } \\
\text { officinarum }\end{array}$ & $\mathrm{JX} 115101$ & $J X 115197$ & HQ665189 \\
\hline
\end{tabular}




\begin{tabular}{|c|c|c|c|c|c|}
\hline Species & Isolate Number & Isolated From & $\begin{array}{l}\text { PF16 } \\
\text { Accession }\end{array}$ & $\begin{array}{l}\text { OCM1 } \\
\text { Accession }\end{array}$ & $\begin{array}{l}\text { LSU } \\
\text { Accession }\end{array}$ \\
\hline Pythium phragmitis & CBS 117104 & $\begin{array}{l}\text { rhizosphere soil of } \\
\text { Phragmites australis }\end{array}$ & $J \times 115102$ & JX115198 & HQ665081 \\
\hline Pythium pleroticum & CBS 776.81 & Nymphoides peltata & $\mathrm{JX} 115103$ & $J X 115199$ & HQ665298 \\
\hline Pythium porphyrae & CBS 369.79 & Porphyra yezoensis & JX115104 & $J X 115200$ & HQ665218 \\
\hline Pythium prolatum & CBS 845.68 & Rhododendron $\mathrm{sp}$. & $J \times 115105$ & $\mathrm{JX} 115201$ & HQ665303 \\
\hline Pythium pyrilobum & CBS 158.64 & Pinus radiata & $\mathrm{JX} 115106$ & $\mathrm{JX} 115202$ & HQ665136 \\
\hline Pythium rhizosaccharum & CBS 112356 & $\begin{array}{l}\text { rhizosphere soil of } \\
\text { Saccharum officinarum }\end{array}$ & $\mathrm{JX} 115107$ & $J X 115203$ & HQ665072 \\
\hline Pythium segnitium & CBS 112354 & soil & JX115108 & JX115204 & HQ665070 \\
\hline Pythium splendens & CBS 462.48 & unknown & $J \times 115109$ & $\mathrm{JX} 115205$ & HQ665237 \\
\hline Pythium sukuiense & CBS 110030 & soil & $J \times 115111$ & $J X 115207$ & HQ665059 \\
\hline Pythium sulcatum & CBS 603.73 & Daucus carota & $J \times 115112$ & $\mathrm{JX} 115208$ & HQ665281 \\
\hline Pythium ultimum & DAOM BR 144 & Nicotiana tabacum & Footnote ${ }^{t}$ & Footnote ${ }^{\mathrm{r}}$ & \\
\hline Pythium ultimum & CBS 398.51 & Lepidium sativum & & & HQ665227 \\
\hline $\begin{array}{l}\text { Pythium ultimum var. } \\
\text { sporangiiferum }\end{array}$ & CBS 219.65 & Chenopodium album & $\mathrm{JX} 115110$ & $J X 115206$ & HQ665158 \\
\hline Pythium undulatum & CBS 157.69 & soil under Pinus sp. & $\mathrm{JX} 115113$ & $J X 115209$ & HQ665134 \\
\hline Pythium violae & CBS 178.86 & Daucus carola & $J \times 115114$ & $\mathrm{JX} 115210$ & HQ665143 \\
\hline Pythium volutum & CBS 699.83 & $\begin{array}{l}\text { root of Triticum sp. and } \\
\text { Hordeum sp. }\end{array}$ & $J X 115115$ & $J X 115211$ & HQ665291 \\
\hline Saprolegnia eccentrica & CBS 551.67 & unknown & $J \times 1|502|$ & $J X 115212$ & HQ665260 \\
\hline Saprolegnia ferax & CBS 173.42 & unknown & $\mathrm{JX} 115022$ & $\mathrm{JX} 115213$ & HQ665142 \\
\hline Saprolegnia parasitica & CBS 223.65 & Esox lucius & Footnote $e^{B}$ & Footnotes & HQ665165 \\
\hline
\end{tabular}

${ }^{a}$ Nc14 PF16: GenBank FR824088: bp 20191 - 21717, OCM1: GenBank FR824315: bp 16898 - 18652.

${ }^{b}$ Ec32 PF16: Ectsi_PROT_LATEST: Esi0080_0014, OCM1: Ectsi_PROT_LATEST: Esi0101_0018, LSU: Ectsi genome 11x: sctg_595: bp 2939-4439.

${ }^{c}$ LT1534 PF 16: Phycal1: PHYCAscaffold_33: bp 104442 - 105967, OCM1: Phycall: PHYCAscaffold_109: bp 81981-83783.

d T30-4 PF16: P. infestans T30-4: Supercontig 2: bp 419667-421 193, OCM1: P. infestans T30-4: Supercontig 19: bp $180514-182223$.

e Pr-102 PF 16 : ramorum 1.allmasked: scaffold 43: bp 28702 - 30219, OCM1: ramorum 1.allmasked: scaffold 8: bp 188483 - 192711 .

'DAOM BR 144 PF16: Pythium ultimum DAOM BR144 Annotation: PYUI_T013715, OCM1: Pythium ultimum DAOM BR144 Annotation: PYU1_T003513.

${ }^{8}$ CBS 223.65 PF16: S. parasitica CBS 223.65: Supercontig 1: bp 1368869-1370535, OCM1: S. parasitica CBS 223.65: Supercontig 12: bp 219231-221253. 
Appendix G - Sequence alignments of PF16 and OCM1, respectively. Amino acid sequences have been converted to a Blosum 62 Score Matrix where a black column indicates $100 \%$ similarity, dark grey $80-100 \%$ similarity, light grey $60-80 \%$ similarity, and white indicates less than $60 \%$ similarity. Identity histogram displayed above alignment is based on mean pairwise identity over all pairs in a column. Green represents $100 \%$ identity, greeny-brown $30-100 \%$, and red indicates less than $30 \%$ identity.






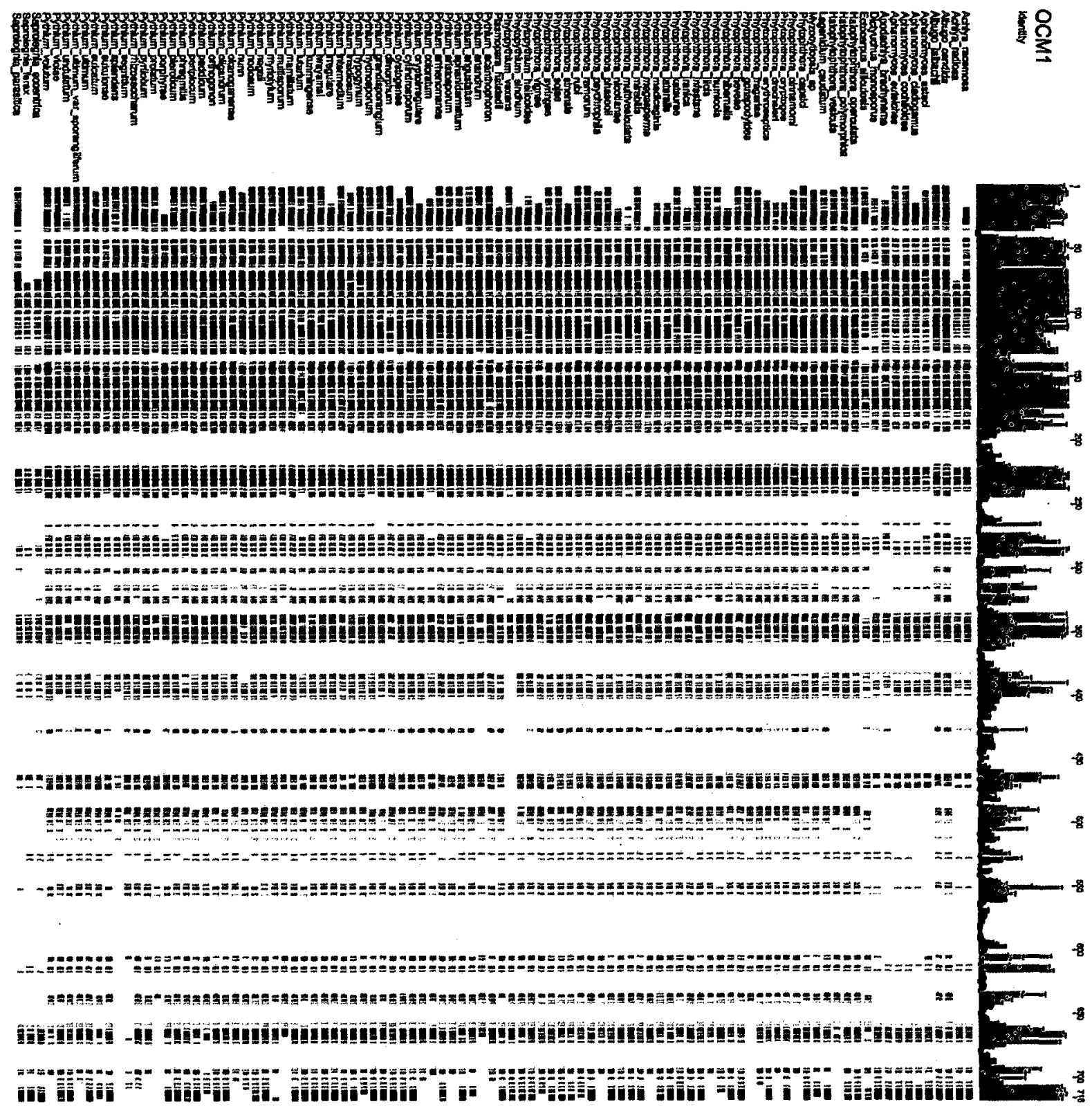


Appendix H - Recombinant flagellar protein and C-type lectin sequences. N-terminal polyhistidine tags and C-terminal c-myc epitopes are shown in bold.

$>$ OCM1_P. aphanidermatum_BR444_DNA

ATGTCGTACTACCATCACCATCACCATCACATGGAGTGCCCGAACGGATGCTCGGGTAAC GGCGATTGTATGGCCAAGGATATGTGCGAATGCTACAAAAACTACCAGGGGAACGACTGC GGTGACCGTACGTGTCTGTTCGGCCGTGCGCATGTCGACACGCCCAAGGGCGATATCAAC ATGGACAAGAACACGAAGACTACGGGATTGATCCTCACCAACTCGCAGCAGCACCCAGCG GGTACGTGGGAGTACTTCCCGGACAGTTCAGCCGCAGCGAACGAAGAGGCGCATTTCTAC ATGGAGTGCTCGAACAAGGGCATCTGTGACCGCGGTACGGGGCTATGTCAGTGCTTTGAC GGCTATGAAGGAAACGGATGCCAGCGCACGACGTGTCCTGGCAAGTGCAATGGCCACGGC ACGTGCGAGAGCATTCGCGAGCTCGGTCTGAAGGAGGCGGGAACATTGTTTGGGGGTGAG GGGCCGTCAGGCGCAGTGACGTATGACTTGTGGGACAGCAACAGCACTTACGGGTGCCGA TGCGACCCATGGTACTTTGGTCCGGACTGCAACCGACGCACATGCAAGGTTGGCGTGGAT CCGTTGTTCCTGTCGGCTGGATCTCCCAATTACGAAACGTTTGTTCTACATGCATACGTC GCATCCGGTGGCACTATCACCGACGGATGGGTCCGCCTTCGCTTGTTCGACTACTACGGG GAGTCTTATATCACCAAGAAGATAACAATCGTAGCTGATACTTCAACAGCTAACACAGAA GCAAATGCCAAGGCCGTGATGACTGCAATCAAAGGAGTGCCGAACCTCACATTCCGAAAT GTGAAGTGCGAGACACTCGGAGCAAATTTTTACGGCTCCGACTTACAAGGCTTCAAGTCG AAACGAGCAACTGGTACCGTAGGCACGTCCATTATTTGCCAATACGTCGACAACCCCGGG AAGATGCGAATCCCAGAAGTCGCTGGGTTTGGTGGTGTCACGTCAGCCTTTGTGGTGACG ACTTCGCAGCAGGGCATGAATGATGAATGGTTCACGGTGAAAACCACTAGTATTGTGGAC ACTGCCACTGACACTCCGACGAGCTTGCCACTCTTGGCTGCGCTTCCAGCGACTGTCACA TTTCCTGCGCTGGTGAAAATTGGTCAGAATATCGTGCTGGCCAAAACCGGATCTACATCG ACTTCTCTTACGCTCGAGTACGACCTCACACAGACGCTGGGCACTGCCCCACCTGTTTTC ATCCCAGAAACGGCGTCAGTTGTCACGGTCACCGCAGGAGTACCGACGAATGCTATCGCC GCAGTTGGTGACCAAACTCTCTCTTTCGATTCGACTGCTACGAACCCCGCACCAAGCATG TACTCCGTCGGCGATTTGATCTTCTTCCACAATCAGTTCTTCACGATTCAGAAAGTCGTG GATGACGGTACAAACTATGTGATCACACTCAACAAGCCGTTTGGAGGACAAGCGTCTGAC GGTGACGCCACTGGAGCTACGTCTCCTGTGTACGAAGTCACAATGGGGGCTGACAAGGCG AAAGTGTACAACTACGTCTCCGAGTGCTCAGGCCGTGGCATGTGCAACTACGAGACCGGC ATCTGCTCGTGCTTCAAGGGCTACACCAACGACAACTGTAACACACAGAACATCCTGGCG GTGGAACAAAAACTCATCTCAGAAGAGGATCTGTAA

$>$ OCM1_P. aphanidermatum_BR444_amino acid MSYYHHHHHHMECPNGCSGNGDCMAKDMCECYKNYQGNDCGDRTCLFGRAHVDTPKGDIN MDKNTKTTGLILTNSQQHPAGTWEYFPDSSAAANEEAHFYMECSNKGICDRGTGLCQCFD GYEGNGCQRTTCPGKCNGHGTCESIRELGLKEAGTLFGGEGPSGAVTYDLWDSNSTYGCR CDPWYFGPDCNRRTCKVGVDPLFLSAGSPNYETFVLHAYVASGGTITDGWVRLRLFDYYG ESYITKKITIVADTSTANTEANAKAVMTAIKGVPNLTFRNVKCETLGANFYGSDLQGFKS KRATGTVGTSIICQYVDNPGKMRIPEVAGFGGVTSAFVVTTSQQGMNDEWFTVKTTSIVD TATDTPTSLPLLAALPATVTFPALVKIGQNIVLAKTGSTSTSLTLEYDLTQTLGTAPPVF IPETASVVTVTAGVPTNAIAAVGDQTLSFDSTATNPAPSMYSVGDLIFFHNQFFTIQKVV DDGTNYVITLNKPFGGQASDGDATGATSPVYEVTMGADKAKVYNYVSECSGRGMCNYETG ICSCFKGYTNDNCNTQNILAVEQKLISEEDL*

>PF16_P. aphanidermatum_BR444_DNA

ATGTCGTACTACCAT $\bar{C} A C C A \overline{T C A C C A T C A C A T G G C G T C C A C C T C T G T G C T A C A G C A C T T C ~}$ GAAGTGTATCAGAAAGCACGCGTGACGTTCGTCCAGGCTGTGGCAGAGGCAGCGACGCGC CCACAGAACATTGAGGTCATGCAGAACGCTGGTGTGATGCAGCTGCTACGACCACTTTTA CTCGACAACGTCCCCAGCATCCAACAGTCGGCTGCTCTAGCGCTCGGTCGTCTCGCGAAC TATAGTGATGACCTCGCTGAGGCCGTAGTTGGAAATGAGATCCTGCCGCAACTCGTGTAC TCACTATCGGAGCAGAACCGGTTCTACAAGAAGGCGGCTGCGTTCGTGCTACGTGCTGTC GCCAAGCACTCACCCGAGTTGGCCCAAGCAGTAGTCGACTCGGGTGCACTGGAATCCCTT 
GTGCCATGTCTAGAAGAGTTCGATCCAACGGTTAAAGAAGCTGCTGCGTGGGCAATTGGT TACATCGCTCAGCACACTGGCGAGTTAGCACAGCATGTTGTCGACGCGGGTGCGGTGCCG TTACTTGTGTTGTGTATCCAAGAGCCTGAAGTCGCTCTGAAGCGAGTGGCTGCTTCTGCA TTAAGTGATATCGCCAAGCACTCGCCAGAGCTAGCTCAGGCTGTGGTTGACCCTGGCACA GTGGCATACCTTGCTCCTCTCATTCAGCACCCTGACTCTAAGCTGAAGCGTCAAGTATGC AGCTGTCTGGCACAGGTCGCCAAGCATTCGGTCGATCTTGCTGAGATCGTGGTCGAAGCC GAAATTTTCCCCAACATTCTATACAATTTGAAGGACATTGATCACACAGTTCGCAAAAAC GCAGCCACATGTGTACGAGAGATTGCCAAGCACACTCCAGAGCTCGCCAAGCTGATCGTG AATGCCGGCGGCGCGTCAGCGTTGGTTGACTACGTGGCGGAAGCGTCAGGAAACAACAAA CTGCCCGGCATCATGGCCATCGGCTACATCTCTGCATTTTCGGAGACACTCGCCCTCGCG GTTATTACATCCAAAGGAATACTACCGGTGAAAAGCGCACTCATCACAGAGCCAGAAGAC CACATCAAGGCCGCCAGTGCGTGGACACTTGGCCAAATTGGGCGTCACACGCCTGATCAC GCGCGGGCCATTGCCGAGGCAGATGTGCTTCGGCACCTTCTGGCGTGCATGGTGCATTCT AACAGCTCCGACGATCTCAGGACAAAATCGAAACGTGCACTTAAGAGCATCTTAGCGAAG TGCACGCATCTCCAGGCGCTGCAACCACTTCTACGCGAAGCCCCAATGAAGGTGCAGAAG TATATCCTAAAGCAGTTTGCACAGATGCTACCTCACGACCTGGAAGCCAGGCGATCATTT GTTCAGAATGGTGGTCTCGAATTTCTGCAGACACTAGGTGAGGCAGCTGGTGGCAAACTC ACGGAGTATATCATGGAGATCAACAATTGCTACCCGCCTGAGATTGTCGAGTACTACTCG CCTCACTACAGCAAGACATTACTCGACAAGCTCGACGAATACCAACCGCAAGTGAAGGAA CAAAAACTCATCTCAGAAGAGGATCTGTAA

>PF16 P. aphanidermatum BR444 amino acid MSYYHHHHHHMASTSVLQHFEVYQKARVTFVQAVAEAATRPQNIEVMQNAGVMQLLRPLL LDNVPSIQQSAALALGRLANYSDDLAEAVVGNEILPQLVYSLSEQNRFYKKAAAFVLRAV AKHSPELAQAVVDSGALESLVPCLEEFDPTVKEAAAWAIGYIAQHTGELAQHVVDAGAVP LLVLCIQEPEVALKRVAASALSDIAKHSPELAQAVVDPGTVAYLAPLIQHPDSKLKRQVC SCLAQVAKHSVDLAEIVVEAEIFPNILYNLKDIDHTVRKNAATCVREIAKHTPELAKLIV NAGGASALVDYVAEASGNNKLPGIMAIGYISAFSETLALAVITSKGILPVKSALITEPED HIKAASAWTLGQIGRHTPDHARAIAEADVLRHLLACMVHSNSSDDLRTKSKRALKSILAK CTHLQALQPLLREAPMKVQKYILKQFAQMLPHDLEARRSFVQNGGLEFLQTLGEAAGGKL TEYIMEINNCYPPEIVEYYSPHYSKTLLDKLDEYQPQVKEQKLISEEDL*

$>$ Cucumber_Cucumis_sativus_C-lectin_CuCsa134550_DNA

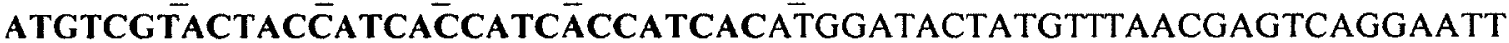
GGGTATTCGGTTGTTTCCAGAAAGGAAATTTCAAAAGGACGGTGCCCACATGGTTGGATT ATTAGCCCAAGCAAGACTAAGTGCTTTGGTTTCATGTCCAGCCCTAAATCATGGAATGAT TCAGAGACCCAATGTAATAGTTTTGGTGGGAACTTAGCAGCTCTGGTAACATATCAAGAG TTTAGCTATGCACAAAATCTGTGTAATGGAACTCTTGGTGGCTGTTGGGTTGGTGGCAGA GCGTTCAACTCTTTGAATGATTTCGTTTGGAAGTGGTCAGATAATGTTTCAAAATGGAAC GATTCCATTTTTCCCAGCGCAACTTTGCAATCGAACTGCAAAAATGCCTCTTGCCACCGG AATGATTCGGTTGAAACATGTACATTAATATTTGGTGGACCAGCAACACCATTCCTTAGG GACGAGAAATGCAACAGTTCTCACCCTTTTATATGCATGATAAACCTAGATGATAGATGC CACCGAATGCACTGTCACAAGGAGTAA

$>$ Cucumber_Cucumis_sativus_C-lectin_CuCsal34550_amino acid MSYYHH SETQCNSFGGNLAALVTYQEFSYAQNLCNGTLGGCWVGGRAFNSLNDFVWKWSDNVSKWN DSIFPSATLQSNCKNASCHRNDSVETCTLIFGGPATPFLRDEKCNSSHPFICMINLDDRC HRMHCHKE*

$>$ Wheat_Triticum_aestivum_PUT163b_1816165448_DNA ATGTC̈GTACTÄCCATCÄCCATCÄCCATCACATGCATACCCCGTCATGCCCCGACGGTTGG CAAATCAGTCCTGATCGGGCCAAATGCTTCATGCACATCTCAACATCCCTTTCCTGGGAC GGATCCGAAGCCCTCTGCCGCAACTTCAGCGGTCATCTGGCTGCATTATCATCAGTTCAG GAGCTGAATTTCGCGAGGTCTCTCTGTGGAGCTGCCTCCTCCGGGTGCTGGGTTGGAGGG CGTCGCCGCAACACCAGTAGTGGTGTTGTTGGCTGGAAATGGTCTGACAATTCGTCTTCT 
TGGAACGGGACCGCATTTCCCGGTGAGCCGTTGCGTCCCAATTGCACCGGTGCTCGCTGC GGTCTAGCCACCGGCGACGATATGTGCACTTTGGTGACCAGTAAGCACACTGCACTTACC GGAAAGAAGTGTGCCGAGTCACATGGGCTGATTTGCATGATGAATCACGAAGATAGGTGC TACCATGATCACTGCCACAAGGAGTAA

$>$ Wheat Triticum_aestivum_PUT163b_1816165448_amino acid

MSYYHНHНHНMHTPSCPDGWQISPDRAKCFMHISTSLSWDGSEALCRNFSGHLAALSSVQ

ELNFARSLCGAASSGCWVGGRRRNTSSGVVGWKWSDNSSSWNGTAFPGEPLRPNCTGARC GLATGDDMCTLVTSKHTALTGKKCAESHGLICMMNHEDRCYHDHCHKE* 


\section{References}

Abad ZG \& Coffey MD (2008) Development of a Morphological/Phylogenetic Lucid Key for the identification of Oomycetes: Phytophthora. p. 20.9th International Congress of Plant Pathology, Turin, Italy.

Abdelzaher HMA, Ichitani T, Elnaghy MA, Hassan SKM \& Fadl-Alla EM (1995) Materials for Pythium flora of Japan. X. Occurrence, identification and seasonality of Pythium spp. in three pond waters and mud soils in Osaka. Mycoscience 36: 71-85.

Adhikari BN, Savory EA, Vaillancourt B, Childs KL, Hamilton JP, Day B \& Buell CR (2012) Expression profiling of Cucumis sativus in response to infection by Pseudoperonospora cubensis. PLoS One 7: e34954.

Ali-Shtayeh MS, Len L-HL \& Dick MW (1986) The phenology of Pythium (Peronosporomycetidae) in soil. Journal of Ecology 74: 823-840.

Alvarez CP, Lasala F, Carrillo J, Muniz O, Corbi AL \& Delgado R (2002) C-type lectins DC-SIGN and L-SIGN mediate cellular entry by Ebola virus in cis and in trans. Journal of Virology 76: 6841-6844.

Armbrust EV \& Galindo HM (2001) Rapid evolution of a sexual reproduction gene in centric diatoms of the genus Thalassiosira. Applied and Environmental Microbiology 67: 3501-3513.

Ascencio-Ibanez JT, Sozzani R, Lee TJ, Chu TM, Wolfinger RD, Cella R \& HanleyBowdoin L (2008) Global analysis of Arabidopsis gene expression uncovers a complex array of changes impacting pathogen response and cell cycle during geminivirus infection. Plant Physiology 148: 436-454.

Aspberg A, Binkert C \& Ruoslahti E (1995) The versican C-type lectin domain recognizes the adhesion protein tenascin-R. Proceedings of the National Academy of Sciences of the United States of America 92: 10590-10594.

Aspberg A, Miura R, Bourdoulous S, et al. (1997) The C-type lectin domains of lecticans, a family of aggregating chondroitin sulfate proteoglycans, bind tenascin- $R$ by protein-protein interactions independent of carbohydrate moiety. Proceedings of the National Academy of Sciences of the United States of America 94: 10116-10121.

Bakkeren G, Kronstad JW \& Lévesque CA (2000) Comparison of AFLP fingerprints and ITS sequences as phylogenetic markers in Ustilaginomycetes. Mycologia 92: 510-521. 
Bala K, Robideau GP, Désaulniers N, de Cock AWAM \& Lévesque CA (2010) Taxonomy, DNA barcoding and phylogeny of three new species of Pythium from Canada. Persoonia 25: 22-31.

Bala K, Robideau GP, Levesque CA, et al. (2010) Phytopythium Abad, de Cock, Bala, Robideau, Lodhi \& Levesque, gen. nov. and Phytopythium sindhum Lodhi, Shahzad \& Levesque, sp. nov. Persoonia 24: 136-137.

Barr D \& Désaulniers N (1989) The flagellar apparatus of the oomycetes and hyphochytriomycetes. The Chromophyte Algae: Problems and Perspectives, (Green J, Leadbeater B \& Diver W, eds.), Oxford University Press, Oxford.

Barr DJS (1981) The phylogenetic and taxonomic implications of flagellar rootlet morphology among zoosporic fungi. BioSystems 14: 359-370.

Barr DJS \& Allan PME (1985) A comparison of the flagellar apparatus in Phytophthora, Saprolegnia, Thraustochytrium, and Rhizidiomyces. Canadian Journal of Botany 63: 138-154.

Barr DJS, Warwick SI \& Désaulniers NL (1996) Isozyme variation, morphology, and growth response to temperature in Pythium ultimum. Canadian Journal of Botany 74: 753-761.

Barr DJS, Warwick SI \& Desaulniers NL (1997) Isozyme variation, morphology, and growth response to temperature in Pythium irregulare. Can J Botany 75: 2073-2081.

Baxter L, Tripathy S, Ishaque N, et al. (2010) Signatures of adaptation to obligate biotrophy in the Hyaloperonospora arabidopsidis genome. Science 330: 1549-1551.

Beakes GW (1989) Oomycete fungi: their phylogeny and relationship to chromophyte algae. The Chromophyte Algae: Problems and Perspectives, (Green JC, Leadbeater BSC \& Diver WI, eds.), pp. 325-342. Clarendon Press, Oxford.

Beakes GW, Glockling SL \& Sekimoto S (2012) The evolutionary phylogeny of the oomycete "fungi". Protoplasma 249: 3-19.

Bimpong CE \& Clerk GC (1970) Motility and chemotaxis in zoospores of Phytophthora palmivora. Annals of Botany 34: 617-624.

Blackman LM, Arikawa M, Yamada S, Suzaki T \& Hardham AR (2011) Identification of a mastigoneme protein from Phytophthora nicotianae. Protist 162: 100-114. 
Blair JE, Coffey MD, Park SY, Geiser DM \& Kang S (2008) A multi-locus phylogeny for Phytophthora utilizing markers derived from complete genome sequences. Fungal Genetics and Biology 45: 266-277.

Blum M, Gamper HA, Waldner M, Sierotzki H \& Gisi U (2012) The cellulose synthase 3 (CesA3) gene of oomycetes: structure, phylogeny and influence on sensitivity to carboxylic acid amide (CAA) fungicides. Fungal Biology 116: 529-542.

Bouck GB (1971) The structure, origin, isolation, and composition of the tubular mastigonemes of the Ochromonas flagellum. The Journal of Cell Biology 50: 362-384.

Bouwmeester K \& Govers F (2009) Arabidopsis L-type lectin receptor kinases: phylogeny, classification, and expression profiles. Journal of Experimental Botany 60: 4383-4396.

Cahill DM, Cope M \& Hardham AR (1996) Thrust reversal by tubular mastigonemes: immunological evidence for a role of mastigonemes in forward motion of zoospores of Phytophthora cinnamomi. Protoplasma 194: 18-28.

Cambi A, Koopman M \& Figdor CG (2005) How C-type lectins detect pathogens. Cellular Microbiology 7: 481-488.

Campbell ID, Baron M, Cooke RM, Dudgeon TJ, Fallon A, Harvey TS \& Tappin MJ (1990) Structure-function relationships in epidermal growth factor (EGF) and transforming growth factor-alpha (TGF-alpha). Biochemical Pharmacology 40: 35-40.

Cantarel BL, Korf I, Robb SM, et al. (2008) MAKER: an easy-to-use annotation pipeline designed for emerging model organism genomes. Genome Research 18: 188-196.

Chang BSW, Du J, Weadick CJ, Muller J, Bickelmann C, Yu DD \& Morrow JM (2012) The future of codon models in studies of molecular function: ancestral reconstruction and clade models of functional divergence. Codon Evolution: Mechanisms and Models, (Cannarozzi GM \& Schneider A, eds.), pp. 145-163. Oxford University Press, New York.

Chen C, Belanger RR, Benhamou N \& Paulitz TC (1998) Induced systemic resistance (ISR) by Pseudomonas spp. impairs pre- and post-infection development of Pythium aphanidermatum on cucumber roots. European Journal of Plant Pathology 104: 877-886.

Chen J, Jacobson LM, Handelsman J \& Goodman RM (1996) Compatibility of systemic acquired resistance and microbial biocontrol for suppression of plant disease in a laboratory assay. Molecular Ecology 5: 73-80. 
Chen LL \& Haines TH (1976) The flagellar membrane of Ochromonas danica. Isolation and electrophoretic analysis of the flagellar membrane, axonemes, and mastigonemes. Journal of Biological Chemistry 251: 1828-1834.

Cock JM, Sterck L, Rouze P, et al. (2010) The Ectocarpus genome and the independent evolution of multicellularity in brown algae. Nature 465: 617-621.

Cooke DEL, Drenth A, Duncan JM, Wagels G \& Brasier CM (2000) A molecular phylogeny of Phytophthora and related oomycetes. Fungal Genetics and Biology 30: 1732.

de Bary A (1861) Die gegenwärtig herrschende Kartoffelkrankheit, ihre Ursache und ihre Verhütung. Eine pfl anzenphysiologische Untersuchung in allgemein verständlicher Form dargestellt. A. Förster'sche Buchhandlung (Arthur Felix), Leipzig.

De Bellis P \& Ercolani GL (2001) Growth interactions during bacterial colonization of seedling rootlets. Applied and Environmental Microbiology 67: 1945-1948.

de Cock AWAM, Neuvel A, Bahnweg G, de Cock JCJM \& Prell HH (1992) A comparison of morphology, pathogenicity and restriction fragment patterns of mitochondrial DNA among isolates of Phytophthora porri Foister. Netherlands Journal of Plant Pathology 98: 277-289.

de Witte L, Abt M, Schneider-Schaulies S, van Kooyk Y \& Geijtenbeek TB (2006) Measles virus targets DC-SIGN to enhance dendritic cell infection. Journal of Virology 80: $3477-3486$.

Deacon TW (2010) A role for relaxed selection in the evolution of the language capacity. Proceedings of the National Academy of Sciences of the United States of America 107 Suppl 2: 9000-9006.

Deitsch KW, Moxon ER \& Wellems TE (1997) Shared themes of antigenic variation and virulence in bacterial, protozoal, and fungal infections. Microbiology and Molecular Biology Reviews 61: 281-293.

Dick MW (2001) Straminipilous Fungi. Kluwer Academic Publishers, Dordrecht.

Dieguez-Uribeondo J, Garcia MA, Cerenius L, et al. (2009) Phylogenetic relationships among plant and animal parasites, and saprotrophs in Aphanomyces (Oomycetes). Fungal Genetics and Biology 46: 365-376. 
Donaldson SP \& Deacon JW (1993) Effects of amino acids and sugars on zoospore taxis, encystment and cyst germination in Pythium aphanidermatum (Edson) Fitzp., Pythium catenulatum Matthews and Pythium dissotocum Drechs. New Phytologist 123: 289-295.

Dreschler C (1946) Zoospore development from oospores of Pythium ultimum and Pythium debaryanum and its relation to rootlet-tip discoloration. Plant Disease Reporter 30: $226-227$.

Edgar RC (2004) MUSCLE: multiple sequence alignment with high accuracy and high throughput. Nucleic Acids Research 32: 1792-1797.

Eisen JA \& Fraser CM (2003) Phylogenomics: intersection of evolution and genomics. Science 300: 1706-1707.

Érsek T \& Nagy ZÁ (2008) Species hybrids in the genus Phytophthora with emphasis on the alder pathogen Phytophthora alni: a review. European Journal of Plant Pathology 122: 31-39.

Erwin DC \& Ribeiro OK (1996) Phytophthora diseases worldwide. American Phytopathological Society, St Paul.

Evan GI, Lewis GK, Ramsay G \& Bishop JM (1985) Isolation of monoclonal antibodies specific for human $c-m y c$ proto-oncogene product. Molecular and Cellular Biology 5: 3610-3616.

Folmer O, Black M, Hoeh W, Lutz R \& Vrijenhoek R (1994) DNA primers for amplification of mitochondrial cytochrome $\mathrm{c}$ oxidase subunit I from diverse metazoan invertebrates. Molecular Marine Biology and Biotechnology 3: 294-299.

Friedmann I (1961) Cinemicrography of spermatozoids and fertilization in Fucales. Bulletin of the Research Council of Israel 10 D: 73-79.

Gallegly ME \& Hong C (2008) Phytophthora: Identifying species by morphology and DNA fingerprints. American Phytopathological Society, St Paul.

Goldman N \& Yang Z (1994) A codon-based model of nucleotide substitution for protein-coding DNA sequences. Molecular Biology and Evolution 11: 725-736.

Gomez-Alpizar L, Hu CH, Oliva R, Forbes G \& Ristaino JB (2008) Phylogenetic relationships of Phytophthora andina, a new species from the highlands of Ecuador that is closely related to the Irish potato famine pathogen Phytophthora infestans. Mycologia 100: $590-602$. 
Graur D \& Li W-H (2000) Fundamentals of molecular evolution. Sinauer Associates, Sunderland.

Griffiths AJF (1996) Mitochondrial inheritance in filamentous fungi. Journal of Genetics 75: 403-414.

Gubler F, Jablonsky PP, Duniec J \& Hardham AR (1990) Localization of calmodulin in flagella of zoospores of Phytophthora cinnamomi. Protoplasma 155: 233-238.

Guharoy S, Bhattacharyya S, Mukherjee SK, Mandal N \& Khatua DC (2006) Phytophthora melonis associated with fruit and vine rot disease of pointed gourd in India as revealed by RFLP and sequencing of ITS region. Journal of Phytopathology 154: 612615.

Guindon S, Dufayard JF, Lefort V, Anisimova M, Hordijk W \& Gascuel O (2010) New algorithms and methods to estimate maximum-likelihood phylogenies: assessing the performance of PhyML 3.0. Systematic Biology 59: 307-321.

Gunn BM, Morrison TE, Whitmore AC, et al. (2012) Mannose binding lectin is required for alphavirus-induced arthritis/myositis. PLoS Pathogens 8: e1002586.

Habib F, Johnson AD, Bundschuh R \& Janies D (2007) Large scale genotype-phenotype correlation analysis based on phylogenetic trees. Bioinformatics 23: 785-788.

Hajibabaei M, Janzen DH, Burns JM, Hallwachs W \& Hebert PD (2006) DNA barcodes distinguish species of tropical Lepidoptera. Proceedings of the National Academy of Sciences of the United States of America 103: 968-971.

Hakariya M, Hirose D \& Tokumasu S (2007) A molecular phylogeny of Haptoglossa species, terrestrial peronosporomycetes (oomycetes) endoparasitic on nematodes. Mycoscience 48: 169-175.

Hall TA (1999) BioEdit: a user-friendly biological sequence alignment editor and analysis program for Windows 95/98/NT. Nucleic Acids Symposium Series 41: 95-98.

Hallett IC \& Dick MW (1981) Seasonal and diurnal fluctuations of oomycete propagule numbers in the free water of a freshwater lake. Journal of Ecology 69: 671-692.

Hansen EM \& Maxwell DP (1991) Species of the Phytophthora megasperma complex. Mycologia 83: 376-381. 
Hardham A \& Gubler F (1990) Polarity of attachment of zoospores of a root pathogen and pre-alignment of the emerging germ tube. Cell Biology International Reports 14: 947-956.

Hardham AR \& Suzaki E (1986) Encystment of zoospores of the fungus Phytophthora cinnamomi is induced by specific lectin and monoclonal antibody binding to the cell surface. Protoplasma 133: 165-173.

Hardison RC (2003) Comparative genomics. PLoS Biology 1: E58.

Hebert PD, Stoeckle MY, Zemlak TS \& Francis CM (2004) Identification of Birds through DNA Barcodes. PLoS Biology 2.

Hebert PDN, Cywinska A, Ball SL \& deWaard JR (2003) Biological identifications through DNA barcodes. Proceedings of the Royal Society of London, Series B: Biological Sciences 270: 313-321.

Hernandez-Mata G, Mellado-Rojas ME, Richards-Lewis A, Lopez-Bucio J, Beltran-Pena E \& Soriano-Bello EL (2010) Plant immunity induced by oligogalacturonides alters root growth in a process involving flavonoid accumulation in Arabidopsis thaliana. Journal of Plant Growth Regulation 29: 441-454.

Hill FG \& Outka DE (1974) The structure and origin of mastigonemes in Ochromonas minute and Monas sp. Journal of Protozoology 21: 299-312.

Hok S, Danchin EG, Allasia V, Panabieres F, Attard A \& Keller H (2011) An Arabidopsis (malectin-like) leucine-rich repeat receptor-like kinase contributes to downy mildew disease. Plant, Cell \& Environment 34: 1944-1957.

Hudspeth DSS, Nadler SA \& Hudspeth MES (2000) A COX2 molecular phylogeny of the Peronosporomycetes. Mycologia 92: 674-684.

Hulvey J, Telle S, Nigrelli L, Lamour K \& Thines M (2010) Salisapiliaceae - a new family of oomycetes from marsh grass litter of southeastern North America. Persoonia 25: $109-116$.

Hunt BG, Ometto L, Wurm Y, Shoemaker D, Yi SV, Keller L \& Goodisman MA (2011) Relaxed selection is a precursor to the evolution of phenotypic plasticity. Proceedings of the National Academy of Sciences of the United States of America 108: 15936-15941.

Huson DH, Richter DC, Rausch C, Dezulian T, Franz M \& Rupp R (2007) Dendroscope: An interactive viewer for large phylogenetic trees. BMC Bioinformatics 8: 460. 
Inaba K (2011) Sperm flagella: comparative and phylogenetic perspectives of protein components. Molecular Human Reproduction 17: 524-538.

Irving HR \& Grant BR (1984) The effect of calcium on zoospore differentiation in Phytophthora cinnamomi. Journal of General Microbiology 130: 1569-1576.

Iwabe N, Kuma K \& Miyata T (1996) Evolution of gene families and relationship with organismal evolution: rapid divergence of tissue-specific genes in the early evolution of chordates. Molecular Biology and Evolution 13: 483-493.

Jeger MJ \& Pautasso M (2008) Comparative epidemiology of zoosporic plant pathogens. European Journal of Plant Pathology 122: 111-126.

Jiang SY, Ma Z \& Ramachandran S (2010) Evolutionary history and stress regulation of the lectin superfamily in higher plants. BMC Evolutionary Biology 10: 79.

Johnson TW, Seymour RL \& Padgett DE (2002) Biology and Systematics of the Saprolegniaceae (online only).

Jones EE \& Deacon JW (1995) Comparative physiology and behaviour of the mycoparasites $P$ ythium acanthophoron, $P$. oligandrum and $P$. mycoparasiticum. Biocontrol Science and Technology 5: 27-39.

Jones SW, Donaldson SP \& Deacon JW (1991) Behaviour of zoospores and zoospore cysts in relation to root infection by Pythium aphanidermatum. New Phytologist 117: 289-301.

Kageyama K, Senda M, Asano T, Suga H \& Ishiguro K (2007) Intra-isolate heterogeneity of the ITS region of rDNA in Pythium helicoides. Mycological Research 111: 416-423.

Kang S, Mansfield MA, Park B, et al. (2010) The promise and pitfalls of sequence-based identification of plant-pathogenic fungi and oomycetes. Phytopathology 100: 732-737.

Katoh K, Kuma K, Toh H \& Miyata T (2005) MAFFT version 5: improvement in accuracy of multiple sequence alignment. Nucleic Acids Research 33: 511-518.

Kemen E, Gardiner A, Schultz-Larsen T, et al. (2011) Gene gain and loss during evolution of obligate parasitism in the white rust pathogen of Arabidopsis thaliana. PLoS Biology 9: e1001094.

Korves TM \& Bergelson J (2003) A developmental response to pathogen infection in Arabidopsis. Plant Physiology 133: 339-347. 
Kroon LP, Bakker FT, van den Bosch GB, Bonants PJ \& Flier WG (2004) Phylogenetic analysis of Phytophthora species based on mitochondrial and nuclear DNA sequences. Fungal Genetics and Biology 41: 766-782.

Lartillot N, Lepage T \& Blanquart S (2009) PhyloBayes 3: a Bayesian software package for phylogenetic reconstruction and molecular dating. Bioinformatics 25: 2286-2288.

Leadbeater BSC (1989) The phylogenetic significance of flagellar hairs in the Chromophyta. The Chromophyte Algae: Problems and Perspectives, (Green JC, Leadbeater BSC \& Diver WI, eds.), pp. 145-165. Clarendon Press, Oxford.

Leano EM, Vrijmoed LLP \& Jones EBG (1998) Zoospore chemotaxis of two mangrove strains of Halophytophthora vesicula from Mai Po, Hong Kong. Mycologia 90: 10011008 .

Lévesque CA \& de Cock AWAM (2004) Molecular phylogeny and taxonomy of the genus Pythium. Mycological Research 108: 1363-1383.

Lévesque CA, Brouwer H, Cano L, et al. (2010) Genome sequence of the necrotrophic plant pathogen Pythium ultimum reveals original pathogenicity mechanisms and effector repertoire. Genome Biology 11: R73.

Links MG, Holub E, Jiang RH, et al. (2011) De novo sequence assembly of Albugo candida reveals a small genome relative to other biotrophic oomycetes. BMC Genomics 12: 503 .

Lundell A, Olin AI, Morgelin M, Al-Karadaghi S, Aspberg A \& Logan DT (2004) Structural basis for interactions between tenascins and lectican C-type lectin domains: Evidence for a crosslinking role for tenascins. Structure 12: 1495-1506.

Man in 't Veld WA (2007) Gene flow analysis demonstrates that Phytophthora fragariae var. rubi constitutes a distinct species, Phytophthora rubi comb. nov. Mycologia 99: 222226.

Maric D, Epting CL \& Engman DM (2010) Composition and sensory function of the trypanosome flagellar membrane. Current Opinion in Microbiology 13: 466-472.

Markey DR \& Bouck GB (1977) Mastigoneme attachment in Ochromonas. Journal of Ultrastructure Research 59: 173-177.

Martin FN \& Tooley PW (2003) Phylogenetic relationships among Phytophthora species inferred from sequence analysis of mitochondrially encoded cytochrome oxidase I and II genes. Mycologia 95: 269-284. 
Mchau GRA \& Coffey MD (1995) Evidence for the existence of two subpopulations in Phytophthora capsici and a redescription of the species. Mycological Research 99: 89102.

Meusnier I, Singer GA, Landry JF, Hickey DA, Hebert PD \& Hajibabaei M (2008) A universal DNA mini-barcode for biodiversity analysis. BMC Genomics 9: 214.

Milikan JM, Carter TD, Horne JH, Tzortzopoulos A, Torok K \& Bolsover SR (2002) Integration of calcium signals by calmodulin in rat sensory neurons. European Journal of Neuroscience 15: 661-670.

Mirabolfathy M, Cooke DEL, Duncan JM, Williams NA, Ershad D \& Alizadeh A (2001) Phytophthora pistaciae sp. nov. and P. melonis: the principal causes of pistachio gummosis in Iran. Mycological Research 105: 1166-1175.

Mitchell DR (2007) The evolution of eukaryotic cilia and flagella as motile and sensory organelles. Advances in Experimental Medicine and Biology 607: 130-140.

Moestrup O (1982) Flagellar structure in algae: a review, with new observations particularly on the Chrysophyceae, Phaeophyceae (Fucophyceae), Euglenophyceae, and Reckertia. Phycologia 21: 427-528.

Möller EM, Bahnweg G, Sandermann H \& Geiger HH (1992) A simple and efficient protocol for isolation of high molecular weight DNA from filamentous fungi, fruit bodies and infected plant tissues. Nucleic Acids Research 20: 6115-6116.

Morris BM \& Gow NAR (1993) Mechanism of electrotaxis of zoospores of phytopathogenic fungi. Phytopathology 83: 877-882.

Mortazavi A, Williams BA, McCue K, Schaeffer L \& Wold B (2008) Mapping and quantifying mammalian transcriptomes by RNA-Seq. Nature Methods 5: 621-628.

Muse SV \& Gaut BS (1994) A likelihood approach for comparing synonymous and nonsynonymous nucleotide substitution rates, with application to the chloroplast genome. Molecular Biology and Evolution 11: 715-724.

Nechwatal J \& Mendgen K (2008) Evidence for the occurrence of natural hybridization in reed-associated Pythium species. Plant Pathology 58: 261-270.

Newman MA, Dow JM, Molinaro A \& Parrilli M (2007) Priming, induction and modulation of plant defence responses by bacterial lipopolysaccharides. Journal of Endotoxin Research 13: 69-84. 
O'Connor TD \& Mundy NI (2009) Genotype-phenotype associations: substitution models to detect evolutionary associations between phenotypic variables and genotypic evolutionary rate. Bioinformatics 25: i94-i100.

Osiewacz HD \& Esser K (1984) The mitochondrial plasmid of Podospora anserina: A mobile intron of a mitochondrial gene. Current Genetics 8: 299-305.

Palmer I \& Wingfield PT (2012) Preparation and extraction of insoluble (inclusion-body) proteins from Escherichia coli. Current Protocols in Protein Science 70: 6.3.1-6.3.20.

Parker J, Rambaut A \& Pybus OG (2008) Correlating viral phenotypes with phylogeny: accounting for phylogenetic uncertainty. Infection, Genetics and Evolution 8: 239-246.

Persson J, Beall B, Linse S \& Lindahl G (2006) Extreme sequence divergence but conserved ligand-binding specificity in Streptococcus pyogenes M protein. PLoS Pathogens 2: e47.

Petersen AB \& Rosendahl S (2000) Phylogeny of the Peronosporomycetes (Oomycota) based on partial sequences of the large ribosomal subunit (LSU rDNA). Mycological Research 104: 1295-1303.

Petersen TN, Brunak S, von Heijne G \& Nielsen H (2011) SignalP 4.0: discriminating signal peptides from transmembrane regions. Nature Methods 8: 785-786.

Picard K, Tirilly Y \& Benhamou N (2000) Cytological effects of cellulases in the parasitism of Phytophthora parasitica by Pythium oligandrum. Applied and Environmental Microbiology 66: 4305-4314.

R Development Core Team (2011) R: A Language and Environment for Statistical Computing. R Foundation for Statistical Computing, Vienna, Austria.

Ramos HC, Rumbo M \& Sirard JC (2004) Bacterial flagellins: mediators of pathogenicity and host immune responses in mucosa. Trends in Microbiology 12: 509517.

Rand TG \& Munden D (1993) Chemotaxis of zoospores of two fish-egg-pathogenic strains of Saprolegnia diclina (Oomycotina: Saprolegniaceae) toward salmonid egg chorion extracts and selected amino acids and sugars. Journal of Aquatic Animal Health 5: $240-245$.

Randall TA, Dwyer RA, Huitema E, et al. (2005) Large-scale gene discovery in the oomycete Phytophthora infestans reveals likely components of phytopathogenicity shared with true fungi. Molecular Plant-Microbe Interactions 18: 229-243. 
Rashid KY (1993) Incidence and virulence of Plasmopara halstedii on sunflower in western Canada during 1988-1991. Canadian Journal of Plant Pathology 15: 206-210.

Reichle RE (1969) Retraction of flagella by Phytophthora parasitica var. nicotiana zoospores. Archiv fuer Mikrobiologie 66: 340-347.

Ren F, Tanaka H \& Yang Z (2005) An empirical examination of the utility of codonsubstitution models in phylogeny reconstruction. Systematic Biology 54: 808-818.

Riethmüller A, Weiß M \& Oberwinkler F (1999) Phylogenetic studies of Saprolegniomycetidae and related groups based on nuclear large subunit ribosomal DNA sequences. Canadian Journal of Botany 77: 1790-1800.

Riethmüller A, Voglmayr H, Goker M, Weiß M \& Oberwinkler F (2002) Phylogenetic relationships of the downy mildews (Peronosporales) and related groups based on nuclear large subunit ribosomal DNA sequences. Mycologia 94: 834-849.

Ristaino JB, Haege MJ \& Hu CH (2008) Development of a Phytophthora Lucid Key. Vol. 90 (2, Supplement) p. S2.308. Journal of Plant Pathology, Turin, Italy.

Ristaino JB, Madritch M, Trout CL \& Parra G (1998) PCR amplification of ribosomal DNA for species identification in the plant pathogen genus Phytophthora. Applied and Environmental Microbiology 64: 948-954.

Robideau GP, de Cock AWAM, Coffey MD, et al. (2011) DNA barcoding of oomycetes with cytochrome $\mathrm{c}$ oxidase subunit I and internal transcribed spacer. Molecular ecology resources 11: 1002-1011.

Robold AV \& Hardham AR (2005) During attachment Phytophthora spores secrete proteins containing thrombospondin type 1 repeats. Current Genetics 47: 307-315.

Rodrigue N, Philippe H \& Lartillot N (2010) Mutation-selection models of coding sequence evolution with site-heterogeneous amino acid fitness profiles. Proceedings of the National Academy of Sciences of the United States of America 107: 4629-4634.

Rokas A \& Carroll SB (2005) More genes or more taxa? The relative contribution of gene number and taxon number to phylogenetic accuracy. Molecular Biology and Evolution 22: 1337-1344.

Royle DJ \& Thomas GG (1973) Factors affecting zoospore responses towards stomata in hop downy mildew (Pseudoperonospora humuli) including some comparisons with grapevine downy mildew (Plasmopara viticola). Physiological Plant Pathology 3: 405417. 
Sambrook J \& Russell DW (2001) Preparation of plasmid DNA by alkaline lysis with SDS: Minipreparation. Molecular Cloning: a laboratory manual, third edition, (Sambrook J \& Russell DW, eds.), pp. 1.32-31.34. Cold Spring Harbor Laboratory Press, Cold Spring Harbor, NY.

Saunders GW (2005) Applying DNA barcoding to red macroalgae: a preliminary appraisal holds promise for future applications. Philosophical Transactions of the Royal Society of London, Series B: Biological Sciences 360: 1879-1888.

Schoch CL, Seifert KA, Huhndorf S, Robert V, Spouge JL, Levesque CA \& Chen W (2012) Nuclear ribosomal internal transcribed spacer (ITS) region as a universal DNA barcode marker for Fungi. Proceedings of the National Academy of Sciences of the United States of America 109: 6241-6246.

Schurko AM, Mendoza L, Levesque CA, Desaulniers NL, de Cock AW \& Klassen GR (2003) A molecular phylogeny of Pythium insidiosum. Mycological Research 107: 537544.

Seifert KA, Samson RA, Dewaard JR, et al. (2007) Prospects for fungus identification using CO1 DNA barcodes, with Penicillium as a test case. Proceedings of the National Academy of Sciences of the United States of America 104: 3901-3906.

Seiler C \& Nicolson T (1999) Defective calmodulin-dependent rapid apical endocytosis in zebrafish sensory hair cell mutants. Journal of Neurobiology 41: 424-434.

Sekimoto S, Beakes GW, Gachon CM, Muller DG, Kupper FC \& Honda D (2008) The development, ultrastructural cytology, and molecular phylogeny of the basal oomycete Eurychasma dicksonii, infecting the filamentous phaeophyte algae Ectocarpus siliculosus and Pylaiella littoralis. Protist 159: 299-318.

Seo TK \& Kishino H (2009) Statistical comparison of nucleotide, amino acid, and codon substitution models for evolutionary analysis of protein-coding sequences. Systematic Biology 58: 199-210.

Sequeira L (1978) Lectins and their role in host-pathogen specificity. Annual Review of Phytopathology 16: 453-481.

Sing VO \& Bartnicki-Garcia S (1975) Adhesion of Phytophthora palmivora zoospores: electron microscopy of cell attachment and cyst wall fibril formation. Journal of Cell Science 18: 123-132.

Smith EF (2002) Regulation of flagellar dynein by the axonemal central apparatus. Cell Motility and the Cytoskeleton 52: 33-42. 
Smith EF \& Lefebvre PA (1996) PF16 encodes a protein with armadillo repeats and localizes to a single microtubule of the central apparatus in Chlamydomonas flagella. The Journal of Cell Biology 132: 359-370.

Smith EF \& Lefebvre PA (1997) The role of central apparatus components in flagellar motility and microtubule assembly. Cell Motility and the Cytoskeleton 38: 1-8.

Sparrow FK (1960) Aquatic Phycomycetes. University of Michigan Press, Ann Arbor.

Spehr J, Hagendorf S, Weiss J, Spehr M, Leinders-Zufall T \& Zufall F (2009) Ca2+ calmodulin feedback mediates sensory adaptation and inhibits pheromone-sensitive ion channels in the vomeronasal organ. Journal of Neuroscience 29: 2125-2135.

Stephenson LW, Erwin DC \& Leary JV (1974) Hyphal anastomosis in Phytophthora capsici. Phytopathology 64: 149-150.

Straschil U, Talman AM, Ferguson DJ, et al. (2010) The Armadillo repeat protein PF16 is essential for flagellar structure and function in Plasmodium male gametes. PLoS One 5: e12901.

Takada A, Fujioka K, Tsuiji M, et al. (2004) Human macrophage C-type lectin specific for galactose and $\mathrm{N}$-acetylgalactosamine promotes filovirus entry. Journal of Virology 78: 2943-2947.

Tautz D, Arctander P, Minelli A, Thomas RH \& Vogler AP (2002) DNA points the way ahead in taxonomy. Nature 418: 479.

Thines M (2007) Characterisation and phylogeny of repeated elements giving rise to exceptional length of ITS2 in several downy mildew genera (Peronosporaceae). Fungal Genetics and Biology 44: 199-207.

Thines M \& Spring O (2005) A revision of Albugo (Chromista, Peronosporomycetes). Mycotaxon 92: 443-458.

Toth $\mathrm{R}$ (1976) The release, settlement and germination of zoospores in Chorda tomentosa (Phaeophyceae, Laminariales). Journal of Phycology 12: 222-233.

Tyler BM, Wu M-H, Wang J-M, Cheung W \& Morris PF (1996) Chemotactic preferences and strain variation in the response of Phytophthora sojae zoospores to host isoflavones. Applied and Environmental Microbiology 62: 2811-2817.

Tyler BM, Tripathy S, Zhang X, et al. (2006) Phytophthora genome sequences uncover evolutionary origins and mechanisms of pathogenesis. Science 313: 1261-1266. 
Uzuhashi S, Tojo M \& Kakishima M (2010) Phylogeny of the genus Pythium and description of new genera. Mycoscience 51: 337-365.

van Damme M, Cano L, Oliva R, Schornack S, Segretin M, Kamoun S \& Raffaele S (2011) Evolutionary and functional dynamics of oomycete effector genes. Effectors in Plant-Microbe Interactions, (Martin F \& Kamoun S, eds.), Wiley-Blackwell, Oxford.

van der Plaats-Niterink AJ (1981) Monograph of the genus Pythium. Studies in Mycology 21: $1-242$.

van West $\mathrm{P}$, Morris BM, Reid B, et al. (2002) Oomycete plant pathogens use electric fields to target roots. Molecular Plant-Microbe Interactions 15: 790-798.

Verma A, Arora SK, Kuravi SK \& Ramphal R (2005) Roles of specific amino acids in the $\mathrm{N}$ terminus of Pseudomonas aeruginosa flagellin and of flagellin glycosylation in the innate immune response. Infection and Immunity 73: 8237-8246.

Voglmayr H (2003) Phylogenetic relationships of Peronospora and related genera based on nuclear ribosomal ITS sequences. Mycological Research 107: 1132-1142.

Voglmayr H \& Riethmüller A (2006) Phylogenetic relationships of Albugo species (white blister rusts) based on LSU rDNA sequence and oospore data. Mycological Research 110: $75-85$.

Ward RD, Zemlak TS, Innes BH, Last PR \& Hebert PD (2005) DNA barcoding Australia's fish species. Philosophical Transactions of the Royal Society of London, Series B: Biological Sciences 360: 1847-1857.

Weis WI, Taylor ME \& Drickamer K (1998) The C-type lectin superfamily in the immune system. Immunological Reviews 163: 19-34.

White TJ, Bruns T, Lee S \& Taylor J (1990) Amplification and direct sequencing of fungal ribosomal RNA genes for phylogenetics. PCR Protocols: a guide to methods and applications,(Innis MA, Gelfand DH, Sninsky JJ \& White TJ, eds.), pp. 315-322. Academic Press, San Diego.

Yamagishi T, Motomura T, Nagasato C \& Kawai H (2009) Novel proteins comprising the stramenopile tripartite mastigoneme in Ochromonas danica (Chrysophyceae). Journal of Phycology 45: 1100-1105.

Yamagishi T, Motomura T, Nagasato C, Kato A \& Kawai H (2007) A tubular mastigoneme-related protein, OCM1, isolated from the flagellum of a Chromophyte alga, Ochromonas danica. Journal of Phycology 43: 519-527. 
Yang Z \& Nielsen R (2008) Mutation-selection models of codon substitution and their use to estimate selective strengths on codon usage. Molecular Biology and Evolution 25: 568-579.

Yu IC, Parker J \& Bent AF (1998) Gene-for-gene disease resistance without the hypersensitive response in Arabidopsis dndl mutant. Proceedings of the National Academy of Sciences of the United States of America 95: 7819-7824.

Zelensky AN \& Gready JE (2005) The C-type lectin-like domain superfamily. FEBS Journal 272: 6179-6217.

Zipfel C (2009) Early molecular events in PAMP-triggered immunity. Current Opinion in Plant Biology 12: 414-420. 